Running head: WISE REASONING AND EMODIVERSITY

Wise Reasoning Benefits from Emodiversity, Irrespective of Emotional Intensity

\author{
Igor Grossmann ${ }^{1}$ \\ Harrison Oakes ${ }^{1}$ \\ Henri C. Santos ${ }^{2}$ \\ ${ }^{1}$ University of Waterloo, Canada \\ ${ }^{2}$ Geisinger Health System, U.S.A. \\ in press \\ in \\ Journal of Experimental Psychology: General
}

\begin{abstract}
Author Note
Igor Grossmann, Department of Psychology, University of Waterloo. Harrison Oakes, Department of Psychology, University of Waterloo. Henri C. Santos, Autism and Developmental Medicine Institute, Geisinger Health System.

Anonymized data, materials and code are available at Open Science Framework (osf.io/u4kx6) and pre-print is available on PsyarXiv (psyarxiv.com/jy5em).
\end{abstract}

\title{
Acknowledgements
}

We thank Ethan Kross, Ozlem Ayduk, Jordi Quoidbach, Kurt Gray and an anonymous reviewer for comments on a previous version of the manuscript. We further thank Judith Glück for providing raw data for re-analysis in Study 1, and Jörg Lehmann for help and advice with quantifying the Study 1 corpora using Affective Dictionary Ulm. This research was supported by the Insight Grant from the Social Sciences and Humanities Research Council of Canada, the Early Researcher Award from the Ontario Ministry of Research, Innovation and Science and the Pathways to Character Templeton Initiative Grant to the first author, and the Vanier Canada Graduate Scholarship to the second author.

Correspondence concerning this article should be addressed to Igor Grossmann, 200 University Avenue West, Waterloo, Ontario, Canada N2L 3G1, Phone: +1 347 850-4467. Fax: 519-746-8631 E-mail: igrossma@uwaterloo.ca

This paper is not the copy of record and may not exactly replicate the final, authoritative version of the article. The final article will be available, upon publication, via its DOI: 10.1037/xge0000543 


\begin{abstract}
The role of emotions in wise reasoning is not well understood. On the one hand, work on emotional regulation suggests downregulating intense emotions may lead to wiser reasoning. On the other hand, emerging work suggests recognizing and balancing emotions provides critical insights into life experiences, suggesting an alternative path to wiser reasoning. We present a series of observational, diary, and experimental studies $(N=3,678)$ addressing these possibilities, examining how wisdom-related characteristics of reasoning - epistemic humility, recognition of a world in flux/change, self-transcendence, recognition of diverse perspectives on an issue, search for integration of diverse perspectives/compromise - relate to emotional intensity and to emodiversity (i.e., emotional richness and evenness) in a given situation. Across five studiestesting wisdom nominees and examining individual differences and manipulated wise reasoning, it appeared in conjunction with emodiversity, independent of downregulated emotional intensity. The positive association between emodiversity and wisdom-related characteristics occurred consistently for daily challenges, unresolved interpersonal conflicts, as well as political conflicts. The relationship between emotional intensity and wisdom-related characteristics was less systematic, with some studies suggesting a positive (rather than negative) association between emotional intensity and wisdom. Together, these results demonstrate that wise reasoning does not necessarily require uniform emotional downregulation. Instead, wise reasoning can also benefit from a rich and balanced emotional life.

Keywords: wisdom, emotional complexity, emodiversity, emotion regulation, judgment, epistemic virtues
\end{abstract}




\section{Wise Reasoning Benefits from Emodiversity, Irrespective of Emotional Intensity}

Lay people ascribe wisdom to the effective management of emotionally charged experiences, including difficult situations and life challenges (Weststrate, Ferrari, \& Ardelt, 2016; Weststrate, Ferrari, Fournier, \& McLean, 2018). Religious scholars and philosophers tend to agree. Both in Abrahamic religions and in many streams of Buddhism (Low, 2014), the path to wisdom involves encountering and handling adversity effectively. A seemingly straightforward strategy to master such experiences concerns emotional down-regulation (Gross, 2015), which affords a rational way to navigate the issue at hand. For millennia, some philosophers advocated for this kind of strategy, including the Stoics in Ancient Greece and rationalists like Descartes and Spinoza (Dea, Walsh, \& Lennon, 2017).

However, the idea that wisdom requires emotional down-regulation does not always align with folk portrayals of wisdom. Analyses of the personal qualities of wisdom exemplars show a wide spectrum of emotionality, from empathy-oriented Jesus and Mother Theresa to rationalityoriented Confucius and Benjamin Franklin (Weststrate et al., 2016). Further, a large body of theoretical work in philosophy, within the sentimentalist tradition, suggests that emotions may communicate intrinsic criteria of appropriateness (e.g., Hume, 1978; bus also see Im, 1999, for earlier arguments by Mencius). Under certain circumstances such intrinsic criteria may be more meaningful than the conflicting formal rules (e.g., laws and norms in a society) one would rationally follow (D’Arms \& Jacobson, 2000; Gibbard, 1990). Consider Mark Twain's classic story, The Adventures of Huckleberry Finn (2003). Throughout much of the story, Huck struggles with his conscience for helping Jim escape slavery and wonders whether he should follow the moral dictates of White slave-owning society and return Jim to his owner, Miss 
Watson. Ultimately Huck listens to his emotions instead and resolves, "All right, then, I'll go to hell” (p. 271), and helps Jim escape slavery.

Despite a long-standing debate about the role of emotion for wisdom, many of the arguments overlook a critical component of life challenges. Instead of experiencing only one emotion when facing life challenges, people generally experience many emotions (e.g., Fitness \& Warburton, 2009). Accordingly, we propose the question of emotion and wisdom should be framed around how the presence and inter-relationship of many emotions influence one's wisdom. We explore this question by building on the functional perspective of affective processes, which suggests that emotions provide valuable information about the features of the situation and allow for a more informed prediction of future actions (L. F. Barrett, 2017; Keltner \& Gross, 1999). According to this perspective, feeling a wide range of emotions may in fact contribute to wiser reasoning about a given situation. We propose that wise reasoning benefits from recognizing and balancing a wide range of emotions (i.e., emodiversity, Quoidbach et al., 2014)_-irrespective of emotional down-regulation.

\section{Wise Reasoning}

Lay people, philosophers, and researchers have characterized wisdom in many ways (Staudinger \& Glück, 2011; Sternberg \& Jordan, 2005). For cognitive and behavioral scientists, wisdom goes beyond intelligence or general knowledge (Baltes \& Kunzmann, 2004; Baltes \& Smith, 2008; Baltes \& Staudinger, 2000; Jeste et al., 2010; Kekes, 1983; McKee \& Barber, 1999; Sternberg, 1998; Vervaeke \& Ferraro, 2013). At least since Aristotle, scholars have defined practical wisdom as the ability to discern how to act in a particular situation, with an aim to achieve a situation-appropriate balance between different moral virtues and personal preferences (Brienza, Kung, Santos, Bobocel, \& Grossmann, 2017). Elaborating on this idea, Sternberg 
suggested that "information processing in and of itself is not wise or unwise. Its degree of wisdom depends on the fit of a wise solution to its context" (1998, p. 353).

Building on this theoretical work, psychological scientists have specified several aspects of reasoning that may afford a flexible, context-sensitive processing of knowledge (Baltes \& Smith, 2008; Grossmann, 2017b, 2017a; Santos, Huynh, \& Grossmann, 2017; Vervaeke \& Ferraro, 2013): intellectual humility, acknowledgment of different points of view, appreciation of the context within which the issue unfolds, sensitivity to the possibility of change in social relations, acknowledgment of the likelihood of multiple outcomes of a conflict, a selftranscendent viewpoint on the issue, and preference for compromise in resolving opposing viewpoints. These aspects of wise reasoning appear across a wide range of definitions of wisdom in philosophy and the behavioral sciences (Bangen, Meeks, \& Jeste, 2013; Oakes, Brienza, Elnakouri, \& Grossmann, in press). Moreover, they converge on a single latent factor that is distinct from intelligence and established personality traits (Brienza \& Grossmann, 2017; Brienza et al., 2017; Grossmann, Na, Varnum, Kitayama, \& Nisbett, 2013) and that affords less biased and more balanced inferences about the social world (Brienza et al., 2017; Grossmann \& Brienza, 2018).

\section{Prior Insights on the Relationship of Emotion and Wisdom-Related Cognitions}

Besides reasoning, discerning how to act in a particular situation - the hallmark of practical wisdom - involves attention, memory and knowledge retrieval, interpretation of the situation, judging the likelihoods of various outcomes, and decision-making. Prior studies have revealed a complex relationship between these processes and emotions (De Houwer \& Hermans, 2010). For example, people recall emotional (vs. neutral) words better, but also reveal a bias toward recalling emotional features of the experience at the expense of neutral, less salient 
features (Levine \& Edelstein, 2009). Generally, emotions appear to impact cognitive processes through attentional bias to threatening information (Yiend, 2010), emotion-based activation of concepts and relevant semantic structures (affective priming, Fazio, 2001; mood-congruent effects, Forgas, 2006), working memory resources (e.g., Richards, French, Keogh, \& Carter, 2000) and deliberation-related processes (for review, see Blanchette \& Richards, 2010).

Whereas incidental affect (i.e., transient, target-independent) tends to contribute to biased information processing, judgment (Clore \& Huntsinger, 2007; Johnson \& Tversky, 1983; Mayer, Gaschke, Braverman, \& Evans, 1992) and decision-making (Blanchette \& Richards, 2004; Oaksford, Morris, Grainger, \& Williams, 1996), some work suggests that integral affect (i.e., elicited by the target situation) increases normative accuracy in decision-making (Bechara, Damasio, Tranel, \& Damasio, 1997) and reasoning (Johnson-Laird, Mancini, \& Gangemi, 2006). It is possible that incidental affect draws attention away from the task, whereas integral affect facilitates attention to the task (Blanchette \& Richards, 2010; Laney, Campbell, Heuer, \& Reisberg, 2004) and thus promotes greater accuracy and better decisions. However, some studies suggests that integral emotions can also distort judgments, including affective biases in evaluating one's past (Kahneman, 2000), assessing one's preferences (Dutton \& Aron, 1974; M. Wilson \& Daly, 2004), or forecasting one's future (T. D. Wilson, Wheatley, Meyers, Gilbert, \& Axsom, 2000). In short, the relationship of emotion to wiser judgment, reasoning and decisionmaking appears inconclusive.

Though some emerging work in the broad wisdom scholarship has started to test the role of reminiscence on past emotional experiences and emotion regulation for lifespan development of wisdom (Glück \& Bluck, 2013; Le, 2008; Weststrate \& Glück, 2017), only a handful of studies have examined the relationship between wise reasoning and emotions in a given situation 
(for a review, see Kunzmann \& Glück, 2018). These studies have yielded mixed results. Across most studies, wise reasoning has been associated with lower levels of negative affect (Grossmann et al., 2013; Kunzmann \& Baltes, 2003). The relationship to positive affect has been less conclusive: Studies suggest wise reasoning is associated with higher levels of positive affect (Grossmann, Gerlach, \& Denissen, 2016), whereas others show little or inverse relationship (Kunzmann \& Baltes, 2003; Mickler \& Staudinger, 2008), with the latter findings suggesting that wise reasoning may be associated with general emotional downregulation. To our knowledge, only a few studies have focused on the relationship of wise reasoning and specific emotions. Though Kunzmann and Baltes have observed no significant relationship between wise reasoning and general positive affect, they did observe a positive relationship between wise reasoning and specific positive feelings such as interest, curiosity and inspiration (Kunzmann \& Baltes, 2003). Further, one small study $(N=30)$ has examined the relationship between wise reasoning and discrete emotional responses (Hu, Ferrari, Wang, \& Woodruff, 2017), showing a positive relationship between wise reasoning and facial expressions of fear and surprise, but no relationship to expressions of other positive or negative emotions.

\section{From Isolated Emotions to Emodiversity}

Both the large body of scholarship on emotion and cognition and the smaller emerging body of research on emotion and wise reasoning have treated emotions in isolation, either considering the general intensity of positive vs. negative affect or separately examining specific emotions such as anger, guilt, happiness, or sadness. However, emotions rarely occur alone. When reflecting on an emotional experience, people usually report not just one, but multiple emotions (Izard, 1977). Moreover, emotional intensity is only one of many factors informing one's experience of, and guiding one's subsequent actions in difficult situations (Frijda \& 
Mesquita, 1994). Instead of downregulating negative emotions, people may spread their focus to other emotions, including those of the opposite valence. Indeed, reports of such seemingly contradictory emotions have emerged in past work, suggesting the diversification of emotion may be a viable alternative to emotional downregulation (Ersner-Hershfield, Mikels, Sullivan, \& Carstensen, 2008; Labouvie-Vief, Hakim-Larson, DeVoe, \& Schoeberlein, 1989). Additionally, emotions of similar intensity can vary in certainty, agency or novelty (Fontaine, Scherer, Roesch, \& Ellsworth, 2007; Roseman, 1991).

To provide a richer understanding of the relationship between wisdom and emotion, we propose to expand the focus beyond isolated emotions or general affect by considering how emodiversity - i.e., the breadth (i.e., number of emotions experienced) and evenness (i.e., relative dominance/intensity of each experienced emotion in relation to the other experienced emotions; Benson, Ram, Almeida, Zautra, \& Ong, 2018; Quoidbach et al., 2014) of different emotions - in a given situation may influence wise reasoning. For instance, in a challenging situation, a person with a narrow and less even emotional experience may report being uniformly "afraid," whereas a person with a broader and more even emotional experience may report being "upset, worried, and anxious," all to a similar extent, in response to the same situation (Grossmann, Huynh, \& Ellsworth, 2016; Lindquist \& Barrett, 2010). Past research indicates that emodiversity can reduce effects of affective psychopathology by preventing any one emotion from dominating a person's experience (Benson et al., 2018; Gruber \& Bekoff, 2017). For instance, in a clinical sample of agoraphobics, a more differentiated (i.e., fine-grained) categorization of emotions was shown to be more effective in attenuating physiological stimulusreactivity than the emotion regulation strategies of cognitive reappraisal and distraction (Kircanski, Lieberman, \& Craske, 2012). Moreover, emodiversity has been shown to promote 
mental and physical health (Quoidbach et al., 2014), including reduced biomarkers of systemic inflammation (Ong, Benson, Zautra, \& Ram, 2018). ${ }^{1}$

There are reasons to suspect that the ability to recognize the diversity in one's emotional experience may not only impact physical and mental health, but also afford wiser reasoning. Theoretically, emodiversity provides richer information about strategies to use for handling varied life situations than global affective states (Kashdan, Barrett, \& McKnight, 2015). For instance, greater precision in characterizations of emotional experiences may reduce misattributions about personal affective reactions (Schwarz, 1990; Schwarz \& Clore, 1983). Moreover, rich and differentiated emotional experiences may optimize an individual's adjustment to situational demands by prioritizing, organizing and regulating behavior (K. C. Barrett \& Campos, 1987; Keltner \& Gross, 1999). According to the functionalist perspective on emotions, emotions represent signals about social relationships. Through such signals, emotions can lead to behaviors that establish, maintain, change, or terminate the relationships between the person and their envirionment. Additionally, through feedback- loops, social signals can provide affective meaning to signal-related perceptions, thereby heightening the significance of the present person-environment transactions (Campos, Campos, \& Barrett, 1989; Jamieson, Mendes, \& Nock, 2013). A richer set of emotional signals can therefore establish a deeper relationship between the person and the environment, simultaneously providing a deeper meaning about the situation.

Within a situation, evenness in intensity of different emotions may also provide adaptive value. Consider an anger-provoking social conflict, in which two persons report experiencing the same number of emotions, but differ in evenness: Person A reports a great deal of anger, and just a bit of anxiety and sadness, whereas person B reports a moderate amount of anger, along with a 
decent amount of anxiety and some sadness. Per the functionalist account of emotions, the relative dominance of anger might crowd out other emotions, qualifying the weight of information provided by each emotion in the subjective evaluative space. Thus, in an angerprovoking, uncertain situation, the second person may be better prepared to react to it. Mostly driven by anger, person A may reflexively reject the other person and make foolish decisions, whereas person B may be more likely to consider different perspectives and even recognize that they may need more information about the situation. Together, these insights suggests that appraising the experience in an emotionally diverse (i.e., rich and even) way may afford greater attention to various situational contingencies, thereby facilitating wise reasoning.

\section{Research Overview}

To address the question of whether emodiversity promotes wiser reasoning, Study 1 examined emotion-focused reports of wisdom nominees and a control group from the same region. To compare the effects of emodiversity and emotional intensity, in Studies 2-5 we simultaneously entered them as predictors of wise reasoning. Study 2 extended the test of emodiversity and wise reasoning to a broader population, using daily diary reports on the most challenging event of a day. Study 3 explored the relationship between emodiversity and wise reasoning about personal relationship conflicts, by manipulating wise reasoning. Study 4 aimed to manipulate emodiversity to examine effects on wise reasoning about personal relationship conflicts. Beyond relationship conflicts, Study 5 explored how emodiversity relates to wise reasoning about an acute geopolitical event. The methods across these studies involved computerized content-analyses of affect in the narratives of wisdom-nominees and control

participants (Study 1), self-report measures (Studies 2-4), and human-coded content-analyses of wise reasoning in participants' narratives (Study 5). 


\section{Study 1: Emodiversity among People Nominated for their Wisdom}

In Study 1, we analyzed data from previous research that used a known-groups paradigm to compare emotional responses of people nominated by their peers for their wisdom with a similarly sized control group (Glück et al., 2013). Participants completed two sessions as part of the original study. Here, we focus on participants' interview about a difficult autobiographical experience from the second session. We performed a computerized sentiment analysis of the interview transcripts to examine emodiversity. We speculated that people nominated for their wisdom would demonstrate greater emodiversity in their interviews than people in the control group.

\section{Methods}

Glück and colleagues (2013) recruited wisdom nominees through newspaper and radio calls in the Austrian province of Carinthia, asking anyone who knew a particularly wise person to nominate that person to the project team. Self-nominations were not accepted. A total of 82 people were nominated and 47 of them agreed to participate. Researchers also recruited a group of 123 control participants through a commercially available random sample of about 1600 Carinthians, matched in age and gender to the wisdom nominees. Participants came to the laboratory for two interview sessions. The first session chiefly focused on measuring wisdom, whereas the second session included an interview about a difficult conflict they experienced. To reduce costs, the original authors transcribed interviews only for a subgroup of 47 control participants (23 women, 24 men; $M_{\text {age }}=60.0, S D_{\text {age }}=15.1$, Range: $26-84$ ) parallel in age and gender to the nominees (23 women, 24 men; $M_{\text {age }}=60.9, S D_{\text {age }}=16.3$, Range: $26-92$ ). Thus, both groups were matched in size and critical demographic characteristics. For further demographics, see original report (Glück et al., 2013). 
Sentiment analysis. As part of the second interview session, participants were interviewed about the emotions they experienced during a challenging conflict from their past. Specifically, they were asked, "What feelings did you have during the conflict?" We obtained 89 participant transcripts from the authors of the original study. Of these, 45 were from the control group and 44 from the wisdom nominees. Due to a technical error, the original authors were unable to provide us with the transcripts of two control group participants and 3 wisdom nominees. We performed a computerized sentiment analysis on all 89 transcripts.

In the first step, we removed any disfluencies from the transcripts and revised possible non-affect related homonyms of verbs, adverbs, and colloquialisms that could be misclassified in the affective dictionary (see procedure on Open Science Framework at osf.io/8p4rm). Subsequently, we created text corpora using the transcripts from the wisdom nominees and control group, respectively. To provide correct part-of-speech tags for each word, we used the TreeTagger program with a German dictionary (Schmid, 1995), converting each corpus into a list of words. Finally, we employed the German-language-based Affective Dictionary Ulm (ADU; Hölzer, Scheytt, \& Kächele, 1992) to count the frequency of words representing a set of 12 emotion categories. The ADU has been developed for computerized content-analysis to identify 12 affective categories following Dahl's (1978) classification of emotion: compassionate, interested, content, relieved, joyful, proud, guilty, ashamed, nervous, afraid, angry, and depressed. ${ }^{2}$ We counted the presence of the 12 categories in each text corpus. 


\section{Results and Discussion}

To examine the degree of emodiversity in each corpus, we first tested the distributions of affective themes in each for equality, followed up by a visual inspection of the richness and evenness components of emodiversity (Ong \& Bergeman, 2004; Quoidbach et al., 2014). For richness, we inspected the presence of different emotion themes in the narratives, controlling for word count. For evenness, we examined the relative dominance of one emotion theme over others.

A Chi-square test on the counts of affective themes in the text corpora indicated a significant difference between groups, $\chi^{2}(11, N=326)=37.88, p<.001$. As the left panel of Figure 1 shows, more affective themes were present in the narratives of the wisdom nominees than the control group. Further, the themes were also relatively more evenly distributed among the wisdom nominees than the control group. The right panel of Figure 1 indicates that the affective language of the control group consisted mainly of anger, anxiety and depression, whereas the wisdom nominees voiced relatively less anger and anxiety and relatively more nervousness, compassion and joy.

Supplementary analyses (see online supplement) indicated that the transcripts of the top $20 \%$ of performers on the content-analytic task measuring participants' wise reasoning about complex interpersonal dilemmas (based on interviews with the same participants on a prior interview day) also showed greater evenness than the transcripts of the bottom $20 \%$ (see Figure S3). These results suggest that the relationship between wisdom-related characteristics and emodiversity holds when using known groups and when examining patterns of affective language in participants' narratives. 
Panel A.

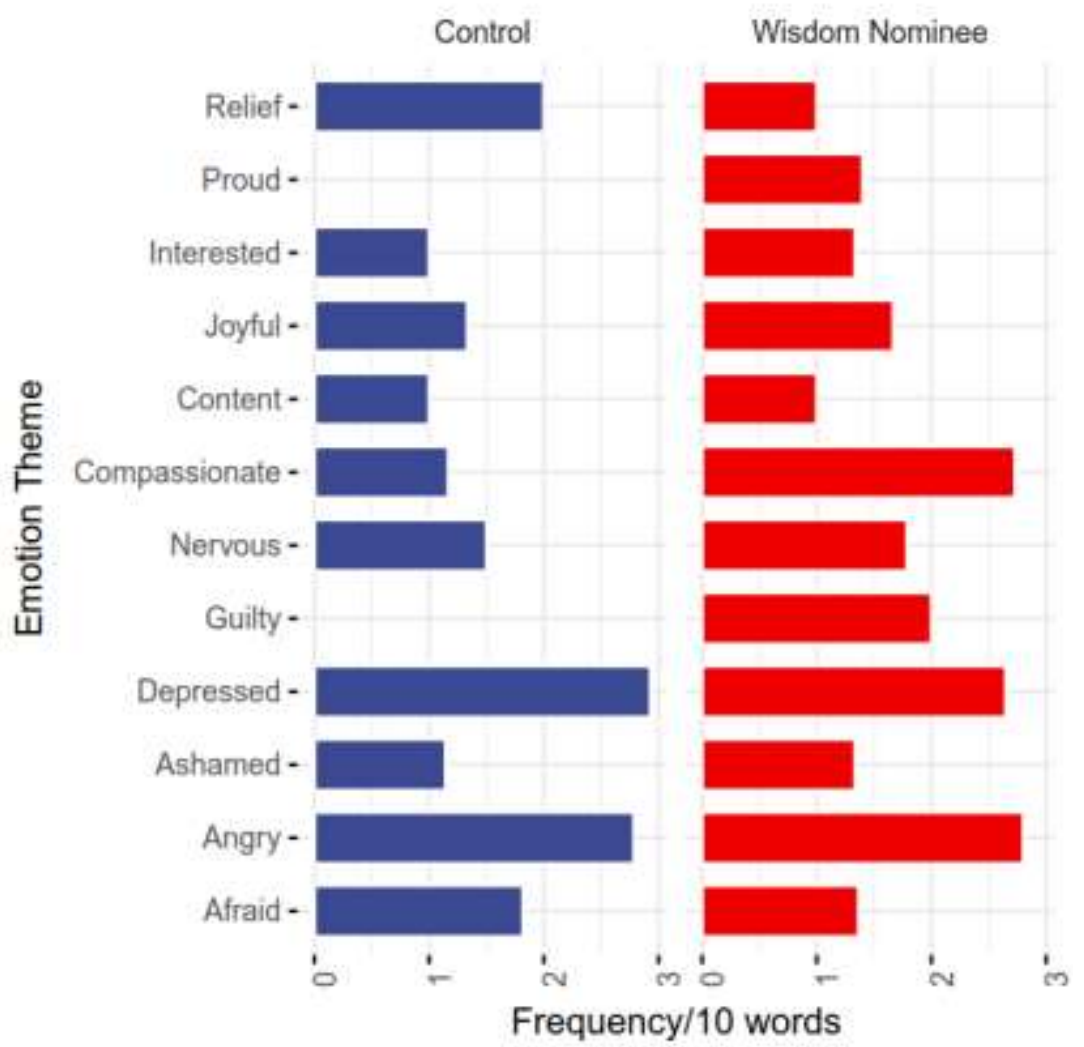

Panel B.

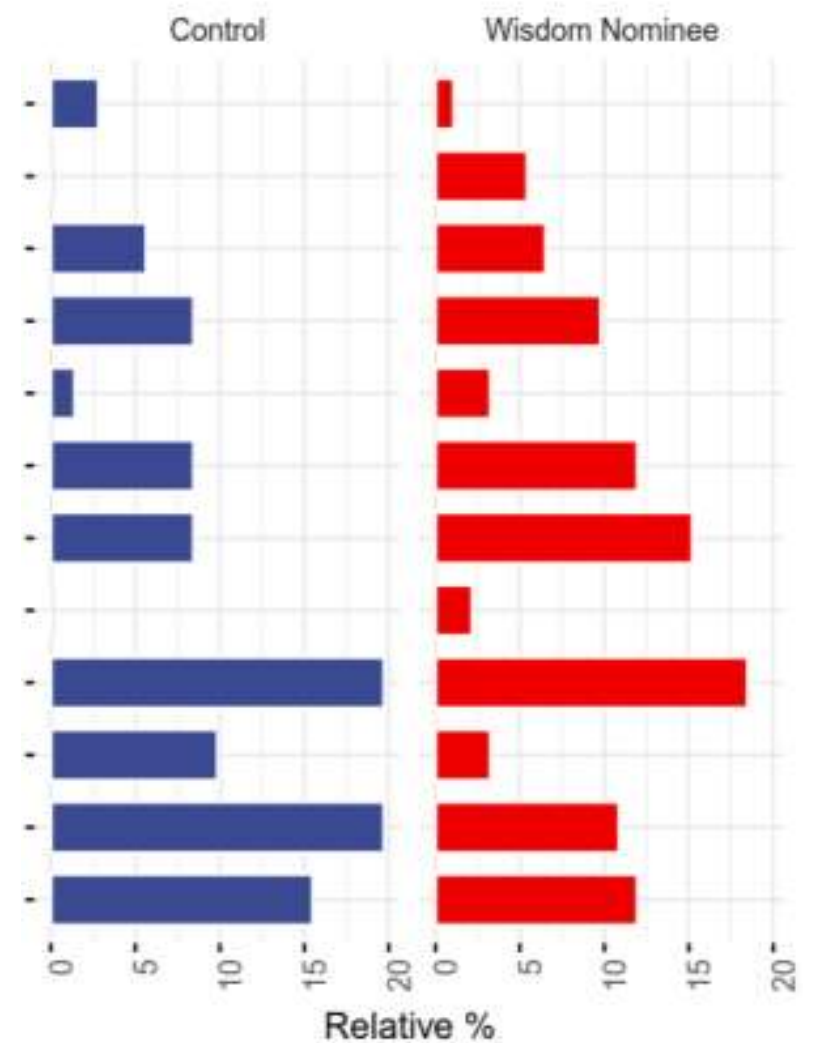

Figure 1. Distribution of emotion themes in narrative responses from the wisdom nominees and control group in Study 1. Panel A: Frequency count per 10 words. Panel B: Relative degree of dominance of one emotion theme over another.

\section{Study 2: Emodiversity and Wise Reasoning in Daily Life}

Study 1 focused on autobiographic reports of memorable, emotionally evocative situations. In Study 2, we sought to extend the pattern to reflections on daily challenges and hassles that people encounter in their lives. To this end, we reanalyzed the data from a 9-day diary study (Grossmann, Gerlach, et al., 2016) in which people reflected on the most challenging experience they encountered on the previous day. Using a day reconstruction protocol (Kahneman, Krueger, Schkade, Schwarz, \& Stone, 2004), participants reconstructed their experiences and subsequently reported on their emotions, reasoning, and event-processing strategies (thought suppression vs. insight \& closure). As reported in the original diary study, 
wise reasoning showed a substantial degree of intra-individual variability across diary days. Moreover, recent research suggests that emodiversity may function differently at the state- vs. trait-levels of analyses (Grossmann et al., 2016). Therefore, we explored the extent to which state- vs. trait-level emodiversity and emotional intensity contribute to wise reasoning.

\section{Methods}

\section{Participants}

The study was advertised through flyers and newspaper ads in the local communities around Berlin, Germany. Advertisements indicated that the study involved several research sessions and noted that people would be paid $50 €$ for their participation (see further recruitment details in Grossmann et al., 2016). Because participants were instructed to report on the most challenging/adverse experiences of the previous day, the researchers excluded episodes in which participants did not report any negative emotions. The final sample consisted of 152 adults reporting 1,177 diary episodes (74 women, 78 men; $M_{\text {age }}=24, S D_{\text {age }}=6.56$; see original report in Grossmann et al., 2016, for further demographic information).

\section{Procedure}

Every morning, participants received an e-mail link to their diary. To minimize recall bias, the researchers guided participants to select a specific negative experience from a previous day and to reconstruct the concrete circumstances of this experience, including the time, location, presence of other people, and activities they were involved in (Schwarz et al., 2009). Next, standardized instructions guided participants to reflect on their feelings and thoughts, taking as much time as they needed. Finally, participants completed questionnaires on the thoughts and feelings they had while reflecting on the incident, reporting on multiple aspects of wise reasoning, their subjective construal of the experience, and the emotions they experienced. 


\section{Measures}

Emotional intensity. To assess the emotional intensity of participants' difficult social events, participants indicated on a scale $(0=$ not at all, $4=$ very $m u c h)$ the extent to which they experienced six positive (happy, interested, convivial, relaxed, proud, and secure/intimate) and nine negative emotions (sad, blue/depressed, tense, angry, bored, insecure, unhappy, ashamed, and guilty). To separate emotional intensity from the mere presence of emotion, we operationalized emotional intensity through the mean score of experienced emotions (i.e., scores above 0$)$, creating respective indices of positive $(\alpha=.69)$ and negative emotional intensity $(\alpha=$ .68). Given that the focus was on negative events, for participants who reported experiencing only negative emotions, we set positive intensity to zero $(n=80)$.

Emodiversity. To calculate emodiversity, we followed the procedure outlined by Quoidbach and colleagues (2014), which quantifies the richness and evenness of participants' emotional experiences in their difficult social events based on Shannon's entropy formula:

$$
\text { Emodiversity }=\sum_{i=1}^{s}\left(p_{i} \times \ln p_{i}\right)
$$

In this formula, $s$ reflects the number of emotions, representing the richness (i.e., how many emotions are experienced), whereas $p_{i}$ reflects the proportion of $s$ made up of the $i$ th emotion, representing the evenness (i.e., the extent to which a specific emotion is experienced, relative to other experienced emotions). To reduce multicollinearity when using emodiversity and emotional intensity as simultaneous predictors, we regressed out the impact of positive and negative intensity from the index of global emodiversity across positive and negative emotions (also see Grossmann et al., 2016). See online supplement for analyses with valence-specific emodiversity scores, regressing out valence-specific intensity scores. 
Wise reasoning. Following the day reconstruction phase, participants reported the extent to which they utilized multiple aspects of wise reasoning (Grossmann et al., 2010, 2013; Grossmann \& Kross, 2014). Four aspects of wise reasoning were measured: (i) intellectual humility ("For better understanding of the incident, it is important for me to have more information and knowledge about the circumstances of the incident"); (ii) consideration of diverse perspectives ( 2 items; $r=.51$; "As I think about the incident, I understand the pros and cons of different positions;" "I am now better able to see the incident from the perspective of the other involved people and to understand their behavior;" $1=$ strongly disagree, $7=$ strongly agree, averaged into a single index); (iii) self-transcendence/observer viewpoint ( 3 items; $\alpha=$ .85; e.g., "As you thought about the incident, did you feel more like an involved participant or rather as a distanced observer;" 1 = immersed, 7 = distanced, averaged into a single index); and (iv) search for a compromise ("When I reason about incidents like this one, I am generally ready to put aside my interests for the benefit of my relationship with the involved person", $1=$ strongly disagree, $7=$ strongly agree). The recognition of dialecticism/uncertainty when predicting future change was operationalized through the degree of ambivalence $([\mathrm{P}+\mathrm{N}] / 2-\mid \mathrm{P}-$ $\mathrm{N} \mid$; M. M. Thompson, Zanna, \& Griffin, 1995) in predictions of negative $(\mathrm{N})$ versus positive (P) consequences of the event, measured via the agreement with the statements: "The consequences of the incident will be negative for me", and "The consequences of the incident will be positive for me"' $(1=$ very unlikely, 7 = very likely $)$. Notably, the perspective-taking and compromiserelated questions were only present if participants indicated that the incident involved a conflict with someone else (see Grossmann et al., 2016, for a more detailed scale description).

Event-processing strategies. To further zero-in on the down-regulation and wisdomrelated strategies, we examined two additional constructs assessed in the diary study. Participants 
reported their thought suppression strategies ("“I tried to suppress my thoughts about the incident") and their sense of insight and closure through reflection on the event ( 3 items; $\alpha=.77$;

"As I thought about the event, I realized something that helped me to gain a sense of closure," "As I thought about the event, I realized something that changed my way of thinking," "By reflecting on the event I now have a clearer and coherent understanding of the event;" $1=$ strongly disagree, 7 = strongly agree, averaged into a single index).

\section{Analytical procedure}

We normalized dependent variables that violated the normality assumption in general linear model analyses using the QuantPsyc package in $R$ (Fletcher, 2012), maintaining the original mean and standard deviation, but conforming to the requirement of a normal distribution. Preliminary analyses indicated that many components of wise reasoning in participants' diaries were statistically independent, $.01 \leq r s<.24$ (see online supplement for more details). For this reason (and due to design-driven differences in observation points for social and non-social aspects of wise reasoning), in Study 2 we performed separate, parallel sets of analyses for each aspect of wise reasoning.

We used lme4 (Bates, Maechler, Bolker, \& Walker, 2015) in $R$ to perform multilevel analyses with diary responses nested within individuals, and trait- and state-level emodiversity and intensity as predictors (i.e., person's mean scores across the diary and person's scores representing situation-specific deviation from the mean, respectively; Bolger, Davis, \& Rafaeli, 2003). Based on insights in personality research (e.g., Fleeson \& Jayawickreme, 2015; Fleeson \& Noftle, 2008), states may reflect individual behavior in a given moment rather than in general. Accumulating over time and across situations, a person's distribution of states (i.e., trait) indicates the typical frequency with which the individual is at each level of the state. 


\section{Results and Discussion}

As Table 1 indicates, emodiversity was associated with each aspect of wise reasoning.

For intellectual humility, recognition of diverse perspectives, and search for compromise,

emodiversity showed state-specific effects. Additionally, for intellectual humility and

dialecticism, emodiversity showed significant trait-level effects. Simultaneously, higher intensity

of negative emotions was associated with significantly lower dialecticism in predictions of future

changes, lower self-transcendence, and lower search for compromise, but unrelated to other

aspects of wise reasoning. Additionally, state-level intensity of positive emotions was associated

with greater self-transcendence.

\section{Table 1}

Results of State- and Trait-level Emodiversity and Emotional Intensity on Wise Reasoning in a 9Day Diary.

\begin{tabular}{|c|c|c|c|c|c|c|c|c|c|c|c|c|c|c|c|}
\hline & \multicolumn{3}{|c|}{ Int. Humility } & \multicolumn{3}{|c|}{ Change/Dialecticism } & \multicolumn{3}{|c|}{ Self-transcendence } & \multicolumn{3}{|c|}{ Diverse Perspectives } & \multicolumn{3}{|c|}{ Compromise } \\
\hline & $B$ & $S E$ & $p$ & $B$ & $S E$ & $p$ & $B$ & $S E$ & $p$ & $B$ & $S E$ & $p$ & $B$ & $S E$ & $p$ \\
\hline $\begin{array}{l}\text { Fixed Parts } \\
\text { (Intercept) }\end{array}$ & 2.68 & 0.58 & $<.001$ & 1.80 & 0.48 & $<.001$ & 4.11 & 0.65 & $<.001$ & 4.16 & 0.93 & $<.001$ & 3.90 & 0.86 & $<.001$ \\
\hline State Emodiversity & 0.42 & 0.20 & .036 & 0.13 & 0.23 & .569 & 0.10 & 0.17 & .538 & 1.00 & 0.39 & .011 & 2.24 & 0.44 & $<.001$ \\
\hline Trait Emodiversity & 1.01 & 0.31 & .002 & 0.82 & 0.26 & .002 & -0.01 & 0.35 & .980 & 0.14 & 0.54 & .802 & 0.69 & 0.50 & .174 \\
\hline State Neg. Intensity & 0.05 & 0.08 & .576 & -0.40 & 0.10 & $<.001$ & -0.22 & 0.07 & .002 & -0.32 & 0.17 & .070 & -0.38 & 0.19 & .048 \\
\hline Trait Neg. Intensity & -0.14 & 0.22 & .540 & -0.41 & 0.18 & .027 & -0.60 & 0.25 & .017 & -0.12 & 0.35 & .731 & -0.46 & 0.32 & .156 \\
\hline State Pos. Intensity & -0.02 & 0.07 & .759 & -0.09 & 0.08 & .269 & 0.13 & 0.06 & .027 & 0.08 & 0.14 & .558 & 0.02 & 0.15 & .870 \\
\hline Trait Pos. Intensity & 0.24 & 0.18 & .187 & 0.03 & 0.15 & .850 & 0.13 & 0.20 & .500 & -0.09 & 0.29 & .758 & 0.30 & 0.27 & .271 \\
\hline \multicolumn{16}{|l|}{ Random Parts } \\
\hline$\sigma^{2}$ & & 2.201 & & & 3.029 & & & 1.544 & & & 1.69 & & & 2.214 & \\
\hline$\tau_{00, \text { id }}$ & & 0.581 & & & 0.194 & & & 0.890 & & & 0.985 & & & 0.472 & \\
\hline$N_{\text {id }}$ & & 152 & & & 152 & & & 152 & & & 118 & & & 118 & \\
\hline $\mathrm{ICC}_{\mathrm{id}}$ & & 0.209 & & & 0.060 & & & 0.366 & & & 0.368 & & & 0.176 & \\
\hline Observations & & 1177 & & & 1177 & & & 1177 & & & 242 & & & 242 & \\
\hline$R^{2} / \Omega_{0}^{2}$ & & $321 / .297$ & & & $155 / .129$ & & & $450 / .437$ & & & $634 / .529$ & & & $432 / .374$ & \\
\hline
\end{tabular}

Notes. Int. Humility = Intellectual humility/Recognition of limits of knowledge, Dialecticism $=$ Recognition of uncertainty/dialecticism in predictions of event-related consequences, Self-transcendence $=$ Adopting a self-transcendent, observer viewpoint on the issue, Diverse perspectives $=$ Recognition of diverse perspectives, Compromise $=$ Search for a way to integrate different viewpoints/compromise. To compute $p$-values we followed the procedure outlined in the sjPlot package (Lüdecke, 2018), using conditional $F$-tests with Kenward-Roger approximation for the $d f$, which provides relatively more conservative estimates as compared to Satterthwaite's method (Kuznetsova, Brockhoff, \& Christensen, 2017).

Further supplementary analyses indicated that emodiversity contributed to wise reasoning when controlling for the demographic characteristics of the sample (see Table $\mathrm{S} 2$ in the online supplement). Also, state-level thought suppression was negatively related to dialecticism, self- 
transcendence and appreciation of diverse perspectives (but positively related to intellectual humility), whereas sense of insight/closure was positively related to most aspects of wise reasoning (see Table S3 in the online supplement). Finally, the relationship between emodiversity and wise reasoning was particularly pronounced for the diversity of positive emotions (Table S4).

The observation of additive state- and trait-level effects of emodiversity on wise reasoning is consistent with the situated account of wisdom (Grossmann, 2017b), and the broad constructionist and functional frameworks of affective processes (e.g., L. F. Barrett, 2017; Ellsworth \& Scherer, 2003). It suggests that emodiversity may afford greater insight into a given situation, thereby facilitating wiser reasoning about the situation. Indeed, supplementary analyses indicated greater emodiversity among participants reporting a greater sense of insight into the situation (Table S5). Moreover, state-specific effects of emodiversity for wise reasoning suggest that situation-specific shifts in emodiversity may produce changes in wise reasoning. We sought to address this possibility in subsequent experiments.

\section{Study 3: Emodiversity and Boosts in Wise Reasoning about Autobiographic Events}

Study 3 explored the state-specific relationship between emodiversity and wisdomrelated characteristics. Made up of four sub-samples, Study 3 was designed to test whether manipulating ego-decentering-i.e., taking a self-distanced or observer perspective on the issue (Kross \& Ayduk, 2017)—enhances wise reasoning about autobiographic experiences, similarly to how ego-decentering enhances wise reasoning about hypothetical issues (Grossmann \& Kross, 2014; Kross et al., 2014). In each sub-sample, we tested how people reasoned about interpersonal conflicts they had recently experienced. We simultaneously examined whether one's ability to reason wisely manifests itself in conjunction with down-regulated emotional reactions or with 
one's view of emotions in a differentiated and balanced—rather than black-or-white—manner (Grossmann, Huynh, et al., 2016; Kashdan et al., 2015).

\section{Methods}

\section{Participants}

The study was approved by the University of Waterloo Office of Research Ethics (ORE\#: 22985). Participants were recruited from Amazon’s Mechanical Turk (MTurk). We initially aimed to recruit 50 participants per cell, similar to the initial in-lab studies employing egodecentering manipulations (Grossmann \& Kross, 2014; Kross \& Grossmann, 2012). Because we sought to counterbalance the presentation order of the reasoning and emotions tasks, we employed a 2 (Condition: Egocentric vs. Ego-decentered) x 2 (Measure Order: Wise Reasoning/Emotions vs. Emotions/Wise Reasoning) design. G*power analyses after our first sample collection (i.e., Study 3a) revealed that the sample was too small to detect the effect observed in prior studies (i.e., $\eta_{\mathrm{p}}^{2}=.024$ ), suggesting that with four cells, $\alpha=.05$ and power $=$ .95, we should have recruited 518 participants. Therefore, we ran a second sub-sample (Study 3b), aiming to ensure adequate power. We conducted preliminary analyses on this data (i.e., Studies $3 \mathrm{a} \& \mathrm{~b}$ ) and subsequently pre-registered our hypotheses and analyses (osf.io/kvua7). Subsequently, we collected two more sub-samples (Studies $3 \mathrm{c}$ and d) to evaluate our preregistration plan, following the $\mathrm{G}^{*}$ power estimate for each of the subsequent samples. Because the main results across the exploratory (Studies 3a and b) and pre-registered (Studies 3c and d) samples were similar, we report our results collapsed across samples in the main text (with sample as a dummy-coded covariate). See Table 2 for demographics (sample-specific demographics and analyses are presented in the Table S6 in the online supplement). 
As specified in the pre-registration protocol, prior to analyses we excluded participants who repeated the survey (based on IP-addresses; 1.8\%); resided in non-English speaking countries (2.2\%); did not answer open-ended probes and wisdom-related measures (1.4\%); indicated that they did not experience any negative emotion $(0.1 \%)$; and indicated that their responses were of poor quality and did not want us to use their data $(5.1 \%)$. This attrition rate $(10.7 \%)$ is comparable to those typically observed in MTurk studies (Chandler, Paolacci, Peer, Mueller, \& Ratliff, 2015). Our final sample consisted of 1,567 participants.

\section{Table 2}

Demographics across Experimental Studies.

\begin{tabular}{|c|c|c|c|c|c|}
\hline & Study 3 & Study 4a & Study 4b & Study 4c & Study $5^{+}$ \\
\hline$N_{\text {Recruited }}$ & 1755 & 343 & 1037 & 615 & 525 \\
\hline$N_{\text {Valid }}$ & 1567 & 271 & 767 & 503 & 329 \\
\hline $\operatorname{Age}_{M d n}(S D)$ & $31(11.50)$ & $32(11.11)$ & $33(11.32)$ & $31(11.91)$ & $29(6.88)$ \\
\hline Sex $\%$ (f/m/other) & $66.9 / 32.6 / 0.5$ & $55.0 / 43.5 / 1.5$ & $46.5 / 52.2 / 0.7$ & $62.8 / 36.2 / 1.0$ & $59.7 / 40.3$ \\
\hline \multicolumn{6}{|l|}{ Ethnicity (\%) } \\
\hline Asian-Am. & 5.1 & 5.2 & 5.1 & 6.0 & 6.7 \\
\hline African-Am. & 7.3 & 7.0 & 9. & 7.8 & 5.5 \\
\hline White & 78.3 & 77.4 & 73.7 & 74.6 & 75.5 \\
\hline Latino & 5.4 & 4.1 & .2 & 4.2 & 5.5 \\
\hline Mixed/“'Other” & 3.9 & 6.3 & 7.2 & 7.4 & 6.8 \\
\hline Income $_{M d n}$ & $35 \mathrm{k}-50 \mathrm{k}$ & $35 k-50 k$ & $35 \mathrm{k}-50 \mathrm{k}$ & $35 \mathrm{k}-50 \mathrm{k}$ & \\
\hline \multicolumn{6}{|l|}{ Education (\%) } \\
\hline High school & 9.5 & 14.4 & 12.8 & 10.6 & 6.5 \\
\hline Some college & 32.9 & 31.0 & 30.3 & 32.2 & 66.2 \\
\hline College & 42.2 & 39.5 & 44.2 & 40.2 & 3.7 \\
\hline Masters + & 15.4 & 15.1 & 12.7 & 17.0 & 23.7 \\
\hline
\end{tabular}

Note $. N_{\text {Valid }}=$ sample size after screening procedures. ${ }^{+}$Income was not measured due to a technical error.

Procedure

We employed the Event Reconstruction Method (ERM; Schwarz, Kahneman, \& Xu, 2009), which has been adopted to assess state-level wise reasoning in reflection on autobiographic experiences (Brienza et al., 2017). Participants first read a definition of a difficult social event as "conflicts or arguments with other people [or] social interactions with other people involving annoyances or other things that irritate [you]" and were then asked to recall the most recent conflict/argument they had experienced with another person. 
During the recall phase, we manipulated ego-decentering by randomly assigning participants to visualize the event from a $3^{\text {rd }}$ - (ego-decentered) vs. $1^{\text {st }}$-person (egocentric) perspective (Grossmann \& Kross, 2014; Kross et al., 2014). We told participants to adopt their randomly assigned perspective to facilitate their recall. Specifically, participants were instructed to picture themselves in the event and ask themselves, "Why am I feeling or behaving this way" (egocentric condition) or "Why is s/he [referring to yourself] feeling or behaving this way" (egodecentered condition).

Following the Event Reconstruction Method (Schwarz et al., 2009), participants reinstated the specifics of the event, including the first name of the person involved and the day/time/location/duration of the event, and were instructed to provide a brief description of the event from their assigned perspective. This method of reinstating the autobiographic experience attenuates social desirability and memory recall biases in participants' responses to their events (Brienza et al., 2017).

Next, participants reflected on the event from their randomly assigned perspective for a minimum of 30 seconds, using the pronouns I/me (egocentric condition) or their name (egodecentered condition) as much as possible while trying to understand their thoughts, feelings and behaviors during the event. Following the reflection task, participants wrote a description of their stream of thought during their reflections on the difficult social event (for verbatim wording, see open-access materials at osf.io/u4kx6).

Next, participants answered questions about the reasoning strategies they engaged in while reflecting on and writing about the difficult social event, and the emotions they experienced during the event as it took place. The order of these two measures was randomized. 
Lastly, participants completed a demographics questionnaire, were debriefed, thanked for their participation, and paid USD \$0.75.

\section{Materials and Measures}

Emotions. Participants were instructed to indicate how they felt during the difficult event they wrote about. They were presented with eight negative (annoyed, blue, angry, worried, anxious, guilty, afraid, criticized) and eight positive emotions (happy, competent, calm, friendly, relaxed, proud, joyful, inspired $)$, and were instructed to rate their emotions on a 7 -point scale (0 $=$ Not at all, $6=$ Very much). We clarified the end-points of the scale: "A rating of 0 means that you did not experience that feeling at all. A rating of 6 means that this feeling was a very important part of the experience.” Emotions were selected from the PANAS-X (Watson \& Clark, 1999) based on their applicability to the interpersonal context and supplemented with additional items to balance both high and low arousal aspects of the potential emotional experience. Preliminary analyses indicated that participants selected subjectively unpleasant events (see supplementary materials online).

Emotional intensity. As in Study 2, we operationalized emotional intensity through the mean score of experienced (i.e., scores above 0) emotions, creating respective indices of positive $(\alpha=.87)$ and negative emotional intensity $(\alpha=.76)$. Given that the focus was on negative events, for participants who reported experiencing only negative emotions, we set positive intensity to zero $(n=129)$.

Emodiversity. We followed the procedure from Study 2, quantifying participants' emotional experiences of difficult events based on Shannon's entropy formula. Also following Study 2, to reduce multicollinearity when using emodiversity and emotional intensity as simultaneous predictors, we regressed out the impact of positive and negative intensity on global 
emodiversity scores, using the unstandardized residuals for subsequent analyses. See online supplement for valence-specific emodiversity scores, regressing out valence-specific intensity scores.

Wise reasoning. Participants reported the extent to which they engaged in various aspects of reasoning while reflecting on their reinstated experience via the Situated Wise Reasoning Scale (SWiS; Brienza et al., 2017). The SWIS is comprised of the following five wisdom-related themes: (i) intellectual humility—i.e., recognizing the limits of one's knowledge (4 items, $\alpha=.80$; e.g., "Looked for any extraordinary circumstances before forming my opinion"), (ii) recognition of multiple ways a situation may unfold and change (4 items, $\alpha=.84$, e.g., "Believed the situation could lead to a number of different outcomes"), (iii) selftranscendence-i.e., adopting an outsider viewpoint (4 items, $\alpha=.89$; e.g., "Tried to see the conflict from the point of view of an uninvolved person"), (iv) recognition of others' perspectives (4 items, $\alpha=.88$; e.g., "Made an effort to take the [name of the other person's] perspective"), and (v) consideration of conflict resolution and search for compromise ( 5 items, $\alpha=.83$; e.g., "Tried my best to find a way to accommodate both of us"). All items were rated on a 5-point scale $(0=$ Not at all, $1=$ Very little, $2=$ Somewhat, $3=$ A lot, $4=$ Very $m u c h)$. We computed a weighted averages composite of the five sub-scales and used these scores in our analyses $(\alpha=$ $.83)$.

Analytical procedure. In the main text we report analyses across all samples, treating dummy-coded sample as a covariate (see online supplement for separate analyses of the exploratory [Studies 3a and b] and pre-registered [Studies 3c and d] confirmatory samples). Preliminary analyses indicated that the effect of our manipulation was qualified by task order (emotion vs. reasoning; see supplement). The manipulation effect was substantially weaker for 
participants who reported on their emotions before the reasoning task. Because of this observation and research showing that introduction of measures prior to the key dependent variable can augment the psychological reality of the study (Ellsworth, 2010; Ellsworth \& Gonzalez, 2003; Hauser, Ellsworth, \& Gonzalez, 2018), we chose to deviate from the preregistered analytic plan, presenting manipulation-related analyses separately by task order. To correct for violations of normality, relevant dependent variables in general linear model analyses were normalized using the QuantPsyc package in $R$. We followed up significant interactions with simple slopes tests. Here and throughout the rest of the paper, we present $95 \%$ confidence intervals, unless otherwise stated.

\section{Results}

The manipulation did not significantly influence emotional intensity, all $F$ s $<0.76, p \mathrm{~s}>$ .385 , or emodiversity, all $F \mathrm{~s}<1.92, p \mathrm{~s}>.166$. Following the pre-registered plan, we examined the effects of condition, global emodiversity, and positive and negative emotional intensity as simultaneous predictors of wise reasoning. As seen in Table 3, when the reasoning task immediately followed the manipulation, participants in the ego-decentered condition reported greater wise reasoning $(M=2.17[2.10,2.25])$ than participants in the egocentric condition $(M=$ $1.99[1.91,2.06])$. In contrast, there was no significant effect of condition on wise reasoning when the emotion task came first (ego-decentered condition: $M=2.03[1.96,2.11]$ vs. egocentric condition: $M=1.97[1.90,2.04])$. Irrespective of task order, global emodiversity and positive emotional intensity were simultaneously and positively associated with wise reasoning. However, negative emotional intensity had only a weak effect on wise reasoning, and only when the reasoning task came first. Supplementary analyses indicated that the effect of emodiversity was pronounced both for positive and negative emodiversity, and when separately examining the 
richness and evenness components of emodiversity. Moreover, the effect held when controlling for demographic factors (i.e., age, sex, education; see online supplement).

Table 3

Effects of Manipulated Ego-Decentering, Emodiversity and Emotional Intensity on Wise Reasoning in Study 3

\begin{tabular}{llrrrrr}
\hline Task Order & Variable & $B$ & $95 \% C I$ & $t$ & $p$-value & partial $\eta^{2}$ \\
\hline Reason first & Condition & 0.19 & {$[0.08,0.30]$} & 3.36 & $<.001$ & .010 \\
$(d f=795)$, & Positive Intensity & 0.05 & {$[0.01,0.10]$} & 2.76 & .006 & .009 \\
$R^{2}=.105$ & Negative Intensity & 0.05 & {$[-0.01,0.10]$} & 1.99 & .047 & .005 \\
& Emodiversity & 0.69 & {$[0.52,0.85]$} & 8.24 & $<.001$ & .077 \\
\hline \multirow{2}{*}{ Emotions first } & Condition & 0.06 & {$[-0.05,0.16]$} & 1.15 & .252 & .001 \\
$(d f=755)$, & Positive Intensity & 0.08 & {$[0.04,0.12]$} & 3.90 & .001 & .017 \\
$R^{2}=.101$ & Negative Intensity & 0.02 & {$[-0.03,0.07]$} & 0.76 & .450 & $<.001$ \\
& Emodiversity & 0.74 & {$[0.57,0.90]$} & 8.69 & $<.001$ & .089 \\
\hline
\end{tabular}

Note. Analyses include Sample, decomposed into 3 dummy-covariates. Condition dummy: $1=$ ego-decentered vs. $0=$ egocentric.

\section{Discussion}

Consistent with Studies 1-2, Study 3 revealed that greater attunement to one's emotions in an emotionally challenging situation is aligned with wiser reasoning about it. Specifically, wise reasoning was associated with greater intensity of positive emotions and greater emodiversity-i.e., recognition of a diverse set of emotions experienced during the conflict and evenness in intensity across those emotions. This latter observation is consistent with recent work suggesting that wiser individuals approach past emotional experiences in a way that enables them to see greater meaning in adversity, rather than uniformly attempt to engage in emotional down-regulation (Weststrate \& Glück, 2017).

Study 3 also provided the first empirical evidence for the causal role of an experimentally induced ego-decentered viewpoint for wise reasoning in the context of real-life experiences, extending prior work employing hypothetical scenarios (Grossmann \& Kross, 2014; Kross \& Grossmann, 2012). This effect was modest in magnitude, comparable to a wide range of other 
effects in social psychology (Richard, Bond Jr., \& Stokes-Zoota, 2003). Notably, it was absent when asking participants to consider their emotional experiences before proceeding to the reasoning task. This finding suggests that ego-decentering may be affected by a time-delay between the stimulus and reasoning variable, and the possible shift toward emotional recounting when asked to recall episode-specific emotions.

In contrast to some prior work (Kross et al., 2014; Kross, Ayduk, \& Mischel, 2005), we found only limited support for the direct effect of ego-decentering on down-regulation of negative affect, with an exception of ego-decentering reducing the intensity of anxiety (see supplement). We return to this observation in the general discussion.

\section{Studies 4a-c: Attempts to Manipulate Emodiversity}

In Studies 4a-c, we aimed to introduce heightened vs. reduced emodiversity and test downstream effects for wise reasoning. Based on prior work suggesting that a more differentiated view of emotions is central to emodiversity (Grossmann, Huynh, et al., 2016; Quoidbach et al., 2014), Study 4a aimed to induce shifts in emodiversity through instructions to appraise emotions in a good/bad (diminished emodiversity) or differentiated (enhanced emodiversity) fashion. Focusing more directly on the richness aspect of emodiversity, Study $4 \mathrm{~b}$ instructed participants to focus on the feeling they experienced most strongly (diminished emodiversity) or the different feelings they experienced (enhanced emodiversity). Similarly, Study $4 \mathrm{c}$ instructed participants to reflect on whether they experienced one of five broad emotions (diminished emodiversity) or 23 specific emotions (enhanced emodiversity). Across experiments, we also varied the number and specificity of emotion terms to probe the robustness of the emodiversity-wise reasoning link. 


\section{Methods}

\section{Participants}

The studies were approved by the University of Waterloo Office of Research Ethics (ORE\#: 22985). We recruited MTurk participants for all three studies. For Study 4a, we aimed for at least 150 participants per condition. We doubled the sample for Studies $4 b$ and $4 c$ to increase power. Demographics and final sample sizes are presented in Table 2. As in Study 3, we excluded participants who did not answer open-ended ERM probes and wisdom-related measures $(4 \mathrm{a}=17 \% ; 4 \mathrm{~b}=0 \% ; 4 \mathrm{c}=15.93 \%)$, indicated that they did not experience any negative emotion $(4 a=17.50 \% ; 4 b=21.79 \% ; 4 c=15.77 \%)$, and indicated their responses were of poor quality $(4 \mathrm{a}=1.73 \% ; 4 \mathrm{~b}=1.24 \% ; 4 \mathrm{c}=1.53 \%)$. See Table 2 for total exclusions.

\section{Procedure}

In each study, participants took part in a study on "what people feel and do in negative social experiences." We employed the ERM protocol (see Study 3 methods for details; Schwarz et al., 2009), asking people to recall the most recent anger-provoking (Study 4a) or serious, negative (Studies $4 \mathrm{~b} \& \mathrm{c}$ ) event they had experienced with another person, to learn what they did and how they felt during the event. Following the ERM protocol, participants were assigned to one of two conditions, aiming to create a less vs. more differentiated/emodiverse reflection on their experiences.

In Study 4a, participants were randomly assigned to spend 10 seconds reflecting on the event they thought about, either focusing on how good or bad they felt (diminished emodiversity) or the nuances and subtleties of what they felt (enhanced emodiversity). The manipulation was adopted from Cameron, Payne, and Doris (2013) and adapted to the context of reflecting on experience-specific emotions (see supplement for verbatim instructions). 
In Study 4b, participants were randomly assigned to spend 30 seconds reflecting on either the (one) feeling they experienced most strongly (diminished emodiversity) or the various different feelings they experienced (enhanced emodiversity) during this negative event, followed by a report on their feelings while reflecting on the negative event and subsequent reports of their reasoning about the event.

In Study 4c, participants spent 30 seconds reflecting on the emotions they experienced during their recent serious negative experience, and then chose the emotions they experienced during the event from a list of emotions. Participants were randomly assigned to be presented with either a list of five broad, negative emotion terms from the international positive and negative affect schedule short-form (I-PANAS-SF; E. R. Thompson, 2007; diminished emodiversity), or a list of 23 more specific negative emotions from the PANAS-X (enhanced emodiversity). Subsequently, participants wrote down their thoughts and feelings during the reflection, and reported on their reasoning and emotions during the reflection task.

Finally, participants completed the quality check and demographics questionnaire at the end of each study, were debriefed and paid USD \$1.75.

\section{Materials and Measures}

Wise reasoning. Studies 4a-b participants completed the same 21-item SWiS measure of state-level wise reasoning (Brienza et al., 2017) as in Study 3. Study 4c used an abridged 16-item version dropping items measuring search for compromise/conflict resolution, to zero-in on aspects of wise reasoning dealing with more epistemic rather than moral virtues. SWiS subscores were reliable (see online supplement), so we created a weighted-average composite of sub-scores as in Study 3 (Study 4a: $\alpha=.89$; Study 4b: $\alpha=.88$; Study 4c: $\alpha=.87$ ). 
Emotions. Study 4a participants filled out a 10-item emotion questionnaire on a 7-point scale $(0=$ not at all, $6=$ very strongly), aiming to include items of relevance to the context of a social conflict varying in valence and arousal (positive: happy, calm, excited, joyful; negative: annoyed, sad, angry, anxious, blue, afraid). Study 4b participants filled out the 16-item emotion questionnaire from Study 3. Study 4c participants filled out the 20-item PANAS questionnaire(10 positive and 10 negative emotion terms; Watson, Clark, \& Tellegen, 1988) using a 5-point scale $(0=$ very slightly or not at all, $1=$ a little, $2=$ moderately, $3=$ quite a bit, 4 $=$ extremely).

Emotional intensity. Following Studies 2 and 3, we operationalized emotional intensity through the mean score of experienced positive (Study 4a: $\alpha=.91$; Study 4b: $\alpha=.93$; Study 4c: $\alpha$ $=.88$ ) and negative emotions (Study 4a: $\alpha=.77$; Study 4b: $\alpha=.78$; Study 4c: $\alpha=.84$ ). Given that the focus was on negative events, for participants who reported experiencing only negative emotions, we set positive intensity to zero (Study 4a: $n=108$; Study 4b: $n=220$; Study 4c: $n=$ 41).

Emodiversity. We followed the procedure from Studies 2 and 3, quantifying participants' emotional experiences of difficult events based on Shannon's entropy formula and regressing out the impact of positive and negative intensity on global emodiversity, and using the unstandardized residuals for our subsequent analyses. In addition to assessing emodiversity during the reflection task, Study $4 \mathrm{c}$ also included a manipulation check: counting the number of negative emotions participants reported experiencing during the event-i.e., a richness-focused aspect of negative emodiversity (Benson et al., 2018).

Analytical procedure. To correct for violations of normality, relevant dependent variables in general linear model analyses were normalized using the QuantPsyc package in $R$. 


\section{Results and Discussion}

In Study 4a, the manipulation did not significantly affect or interact with any of the dependent variables, all $F \mathrm{~s}<1$, $n s$. In Study $4 \mathrm{~b}$, the enhanced emodiversity prompt suggested greater intellectual humility $(M=1.83[1.73,1.94])$ and greater intensity of positive emotions $(M$ $=1.99[1.84,2.14])$ compared to the diminished emodiversity prompt (intellectual humility: $M=$ $1.69[1.59,1.80]$, positive intensity: $M=1.79[1.64,1.94]): F_{\text {int. humility }}(1,765)=3.38, p=.067$, $\eta_{\mathrm{p}}^{2}=.004, F_{\text {pos intensity }}(1,765)=3.31, p=.069, \eta_{\mathrm{p}}^{2}=.004$, respectively. In Study 4c, participants considering 23 emotions (enhanced emodiversity) reported lower intensity of negative emotions during the reflection task $(M=2.15[2.06,2.25])$ than participants considering 5 broad emotions (diminished emodiversity; $M=2.31[2.22,2.40]$ ), $F(1,501)=5.39, p=.021, \eta_{\mathrm{p}}^{2}=.011$. Other condition effects in Studies 4b-c were not significant, $F_{\mathrm{s}}<1.44, n s$.

In all three studies, greater emodiversity was positively associated with wiser reasoning (see Table 4), replicating Studies 2 and 3. Further replicating Study 2, positive emotional intensity was also positively associated with wiser reasoning (see Table 4). Moreover, supplementary analyses indicated that the effect of emodiversity on wise reasoning held when controlling for critical demographic covariates (age, sex, and education). Additional supplementary analyses showed that the emodiversity-wise reasoning association held for positive and negative emodiversity, and for each component of wise reasoning.

Overall, three different manipulations failed to produce significant changes in emodiversity. ${ }^{3}$ Nevertheless, we successfully replicated all of the prior studies' main effects. Furthermore, we again observed that greater positive emotional intensity was consistently associated with wiser reasoning. The relationship of negative emotional intensity and wise 
reasoning was less systematic, with Studies 4a and 4c indicating no significant relationship, whereas Study $4 \mathrm{~b}$ indicating a positive relationship between the two constructs.

Table 2

Effects of Condition, Emodiversity and Emotional Intensity on Wise Reasoning in Studies 4a-c.

\begin{tabular}{llrrrrr}
\hline Study & Variable & \multicolumn{1}{c}{$B$} & \multicolumn{1}{c}{$95 \% C I$} & \multicolumn{1}{c}{$t$} & \multicolumn{1}{c}{$p$-value } & partial $\eta^{2}$ \\
\hline \multirow{2}{*}{ 4a } & Condition & -0.04 & {$[-0.25,0.17]$} & -0.35 & .726 & $<.001$ \\
$(d f=266)$, & Positive Intensity & 0.11 & {$[0.04 .0 .17]$} & 3.26 & .001 & .033 \\
$R^{2}=.117$ & Negative Intensity & 0.04 & {$[-0.04,0.12]$} & 0.92 & .359 & .001 \\
& Emodiversity & 0.69 & {$[0.41,0.96]$} & 4.94 & $<.001$ & .082 \\
\hline \multirow{2}{*}{$4 \mathrm{~b}$} & Condition & 0.04 & {$[-0.08 .0 .15]$} & 0.65 & .518 & .001 \\
$(d f=762)$, & Positive Intensity & 0.14 & {$[0.10,0.17]$} & 7.65 & $<.001$ & .075 \\
$R^{2}=.165$ & Negative Intensity & 0.10 & {$[0.05,0.16]$} & 3.98 & $<.001$ & .020 \\
& Emodiversity & 0.43 & {$[0.33,0.53]$} & 8.49 & $<.001$ & .086 \\
\hline \multirow{2}{*}{$4 \mathrm{c}$} & Condition & 0.11 & {$[-0.04,0.26]$} & 1.23 & .219 & .002 \\
$(d f=498)$, & Positive Intensity & 0.16 & {$[0.07,0.24]$} & 3.64 & $<.001$ & .032 \\
$R^{2}=.091$ & Negative Intensity & 0.05 & {$[-0.05,0.15]$} & 0.90 & .370 & .002 \\
& Emodiversity & 0.53 & {$[0.35,0.70]$} & 6.10 & $<.001$ & .066 \\
\hline
\end{tabular}

Note. Condition dummy: 1 = enhanced emodiversity, $0=$ diminished emodiversity.

\section{Study 5: Emodiversity and Wise Reasoning about Intergroup Conflict}

Studies 1-4c consistently showed that when participants reported greater emodiversity in a given situation, they were also more likely to reason wisely-i.e., recognize the limits of their knowledge and change in the flow of events, consider a wide range of viewpoints and perspectives, and consider ways to integrate multiple perspectives through compromise and conflict resolution. Notably, with the exception of Study 1, these studies utilized questionnairebased methods to assess wise reasoning concerning significant experiences in people's lives, raising the question whether the link between emodiversity and wise reasoning is reliable when examining spontaneous reflections rather than self-report questionnaires. We addressed this question with the final study.

Study 5 had three goals. First, we aimed to test the relationship between emodiversity and reasoning about politics. To this end, we focused on the geopolitically uncertain and internationally disputed Crimean referendum in Ukraine, which followed the occupation of the 
Crimean Peninsula by Russian soldiers. Second, by focusing on a situation marked by uncertainty, we also aimed to test whether the relationship between emodiversity and wise reasoning extends from uniformly negative situations with concrete conflict-related outcomes to ambivalent/uncertain situations where outcomes are unclear. Third, we aimed to examine whether the relationship between emodiversity and wise reasoning extends beyond self-reports, content-analyzing wisdom-related themes in participants' open-ended reflections (see Grossmann et al., 2010; 2013) on the unfolding of the conflict.

\section{Methods}

\section{Participants}

The study was approved by the University of Waterloo Office of Research Ethics (ORE\#: 19168). We recruited 525 U.S. Americans and Canadians from MTurk to take part in a study on people's thoughts about proverbs and current events. We excluded participants who did not complete the open-ended $(n=79)$ and emotion-related questions $(n=100)$, and participants who spent less than 30s reflecting and answering the three open-ended questions $(n=97)$. Our final sample consisted of 329 participants. See Table 2 for further demographics.

\section{Procedure}

We conducted the study from March 21 to March 28, 2014, which was immediately after the controversial referendum in Crimea deciding on the annexation of Crimea into Russia on March 18, 2014. Participants read a statement that summarized the conflict in Ukraine (see supplemental materials) and then answered open-ended questions about their thoughts on the issue. Afterwards, they answered additional questions about their current emotions, wisdomrelated characteristics, their access to news, prior knowledge about this particular issue, and demographics. Finally, participants were debriefed and paid USD \$1.00. 
To investigate a separate research question, before reading the statement about Ukraine, participants read eight proverbs and rated them for familiarity, understanding, liking and frequency of use. To address a separate research question, participants read proverbs that either included or did not include a contradiction. Preliminary analyses indicated that type of proverbs presented did not significantly influence wise reasoning, emotional intensity, or emodiversity, $|t| \mathrm{s}$ $<1.04, n s$, nor did including proverb type as a covariate alter the size of the effects reported in the main text. Therefore, we did not consider this factor in our main analyses.

\section{Materials}

Content-analyses of wise reasoning. Participants' responses to the open-ended questions were content-analyzed by two independent and hypothesis-blind raters for partial or full presence of previously used dimensions of wise reasoning (Grossmann et al., 2010): recognition of uncertainty and limits of knowledge, recognition of change, acknowledgement of diverse perspectives, search for a compromise, and consideration of conflict resolution. Reliability across raters was good (Cohen's $\kappa s \geq .71$ ), with disagreement resolved via discussion between raters and the hypothesis-blind independent rater. Because participants' responses were relatively short ( 1.5 sentences per question; $M d n$ word count across all questions $=249$ ), we quantified the general presence of each aspect of reasoning across the three open-ended responses combined $(0=$ no presence, $1=$ partial or full presence $)$.

Preliminary analyses indicated that most dimensions of wise reasoning were significantly and positively related to each other, $.124 \leq$ Spearman's $\rho \leq .296, .00001 \leq p s \leq .025$. An exception to this trend concerned the change and resolution dimensions. Change was significantly related to recognition of limits of knowledge, and resolution to search for compromise, but neither was related to the other dimensions. We created a wise reasoning index 
by counting the total number of dimensions present in the narratives. Results were very similar when using average scores across the five dimensions.

Emotional intensity. To assess the emotional intensity of participants' difficult social events, participants indicated on a 6 -point scale $(1=$ not at all, $6=$ very strongly $)$ the extent to which they "felt the following emotions right now, at this moment:" worried, ashamed, sad, angry, afraid, proud, happy, joyful, inspired, calm, afraid. As in prior studies, we selected these emotion items from the PANAS scale (Watson et al., 1988) (Watson, Clark, \& Tellegen, 1988), supplemented with low arousal items ( $\mathrm{sad} / \mathrm{calm})$ to ensure balance across valence and arousal dimensions. Following Studies 1-4c, we operationalized emotional intensity through the mean score of experienced positive $(\alpha=.84)$ and negative emotions $(\alpha=.79)$. Because not all participants may have viewed the geopolitical scenario in a negative light, when participants did not report experiencing any emotions of a particular valence, we set the intensity index to zero (positive: $n=29$, negative: $n=55$ ).

Emodiversity. We followed the procedure used in the preceding studies, quantifying emodiversity of participants' emotional experiences based on Shannon's entropy formula. Also following the preceding studies, we regressed out the impact of positive and negative intensity on global emodiversity to reduce multicollinearity when using emodiversity and emotional intensity as simultaneous predictors. We used the unstandardized residuals for our subsequent analyses.

\section{Analytical Procedure}

To correct for violations of normality, relevant dependent variables in general linear model analyses were normalized using the QuantPsyc package in $R$. Because the wisdom-related scores represented ordinal counts and were left-skewed, we used ordinal logistic regression 
analyses within the MASS package in $R$ (Venables \& Ripley, 2002), with emodiversity and emotional intensity as predictors. Supplementary analyses indicated very similar results when using OLS analyses with a transformed wisdom index and when using Poisson regression.

\section{Results and Discussion}

As Table 5 indicates, reports of greater emodiversity were associated with a significantly greater likelihood of wise reasoning in participants' reflections on an acute geopolitical event. Specifically, a one-unit increase in emodiversity produced 1.67 greater odds of considering an additional aspect of wise reasoning when reflecting on the event. In contrast, neither positive nor negative emotional intensity were significantly related to wise reasoning. Supplementary results indicated that the effects of emodiversity on wise reasoning held when controlling for demographic characteristics of the sample (age, sex, level of education, degree of urbanization), lengths of narratives, and political orientation.

Overall, the results from Study 5 indicate that the effects of emodiversity on wise reasoning extend to ambiguous situations involving acute political events. Study 5 employed a content-analytic method to assess wise reasoning, providing evidence that the relationship between emodiversity and wise reasoning extends beyond the self-report questionnaires employed in Studies 2-4.

Table 5

Effects of Emodiversity and Emotional Intensity on Wise Reasoning in Study 5.

\begin{tabular}{lcllc}
\hline Estimate & $B[95 \% C I]$ & $t$ & $p$ & $O R[95 \% C I]$ \\
\hline Emodiversity & $0.51[0.07,0.95]$ & 2.29 & .022 & $1.66[1.08,2.58]$ \\
Positive Intensity & $-0.10[-0.28,0.07]$ & 1.14 & .256 & $0.90[0.76,1.08]$ \\
Negative Intensity & $-0.004[-0.19,0.18]$ & 0.05 & .961 & $1.00[0.83,1.19]$ \\
Estimate & $B[95 \% C I]$ & $t$ & $p$ & $O R[95 \% C I]$ \\
\hline Goodness of Fit $(d f=8)$ & & & \\
\hline Residual Deviance & & & & \\
$A I C$ & & & & \\
\hline
\end{tabular}

Note $. A I C=$ Akaike Information Criterion, $d f=$ degree of freedom. 


\section{General discussion}

Spock: We disposed of emotion, Doctor. Where there is no emotion, there is no motive for violence (McEveety \& Bar-David, 1966).

Yoda: Use your feelings, Obi-Wan, and find him you will (McCallum \& Lucas, 2005).

In popular culture, wisdom is often attributed to fictional characters such as Star Wars'

Yoda or Star Trek's Mr. Spock. What unites both the grand master of the Jedi order and the first officer of the starship Enterprise are their critical acumen, their ability to reason through complex situations, and their selfless willingness to forego personal interests for the common good. At the same time, these two icons differ fundamentally in their attitudes toward emotions. Spock shows little emotional response in the face of adversity, having learned to down-regulate his emotions in line with his people's historical decision to eschew emotions in favor of logic and rationality. In contrast, Yoda embraces his emotions and aims to achieve a balance between them. Yoda is known to be emotionally expressive, to share a good joke with others, but also to recognize sorrow and his past mistakes. Inspired by these pop-cultural icons, we explored whether wise reasoning aligns with uniform emotional down-regulation (as portrayed by Star Treck's Mr. Spock) and/or one's ability to recognize and balance a wide range of emotions (as portrayed by Star Wars' Yoda).

We proposed that reporting a wide range of emotions can contribute to wise reasoning about a given situation, because emodiversity (Benson et al., 2018; Quoidbach et al., 2014)—i.e., the breadth and relative abundance of different emotions - can provide valuable information about the features of the situation and allow for more informed predictions of future actions (Campos et al., 1989). Across studies employing a wide range of methods, the results from the narrative analyses of emotion-focused reflections by individuals nominated for their wisdom, 
diaries on daily challenges in a broader population, autobiographic reflections on interpersonal conflicts, and content analyses of open-ended responses to geopolitical challenges were consistent with this proposition.

First, in Study 1, greater emodiversity in reflections was more common among wisdom nominees than a gender- and age-matched control group from the same region. Daily diary results from Study 2 indicated both trait- and state-specific effects of emodiversity on a range of wisdom-related characteristics. The latter observation suggested that it might be beneficial to examine state-specific effects of emodiversity and wise reasoning, which we followed up on in Studies 3 and 4, demonstrating an association between emodiversity and greater self-reported wise reasoning about recent, unresolved interpersonal conflicts. Study 5 showed that greater emodiversity was associated with a greater likelihood of mentioning wisdom-related themes in open-ended reflections on geopolitical challenges. Overall, the positive association between emodiversity and wise reasoning was robust across different measures of emotion and different methods of assessing wise reasoning.

\section{Theoretical Implications}

Wisdom. The present results have some implications for a broader conceptualization of wisdom in psychology. Numerous theoretical frameworks of wisdom in psychology view emotion regulation as central to the notion of wisdom (e.g., Bangen et al., 2013; Brugman, 2000; Webster, 2003). For some wisdom scholars, the connection between wisdom and emotion appears to take the path of down-regulating affective responses to a situation (for a review, see Ardelt \& Ferrari, 2014; but see Walsh, 2015). Our paper focused on a complementary approach to emotional down-regulation, showing how a differentiated and balanced focus on multiple emotions is associated with wiser reasoning. Our data suggest that focusing on multiple emotions 
and their relationship to each other is more effective for predicting wise reasoning than a uniform focus on down-regulating emotional intensity.

The latter insight is consistent with recent theorizing about the positive role of emotional homeostasis for wisdom (Bangen et al., 2013), which is conceptually related to the evenness component of the emodiversity construct (Benson et al., 2018) ${ }^{4}$. Notably, our supplementary analyses indicated that the relationship between emodiversity and wise reasoning is not solely a product of emotional evenness, but also richness - i.e., the recognition of a wide range of emotions in a given situation—suggesting that beyond balancing the intensity of different emotions, wise reasoning can benefit from a more differentiated focus on multiple emotions (Kashdan \& Barrett, 2015).

Emotion and cognition. Insights from the present research extend beyond wisdom scholarship to the broad discourse on the relationship between emotion and cognition. Because wisdom involves a wide range of cognitive processes beyond reasoning, it remains an open question whether the focus on multiple emotions can help to resolve some of the inconsistent findings concerning the role of emotion in memory retrieval, interpretation of situations, and judgment and decision-making. The immediate implication of the current work is that the study of broad cognitive processes may benefit from considering the degree of emodiversity in affectladen judgments and decisions, rather than focusing on broad emotional intensity or singular emotions. Moreover, while the present research focused on emotional reactions integral to the situation people reasoned about, much of the research on emotion and cognition concerns incidental emotions, raising the question whether diversity in incidental emotions may facilitate wise reasoning and attenuate bias in judgment and decision-making. Some preliminary work 
appears to suggest that this may be the case, with instructions to differentiate one's emotional experience attenuating the affective bias in moral judgments (Cameron et al., 2013).

Emotions, moral psychology and philosophy. The present insights also contribute to the theoretical discourse on the role of emotions for moral psychology and philosophy. Sidestepping the classic debate between rationalists and sentimentalists about the role of emotion for virtuous reasoning and action, we suggest expanding the focus beyond singular emotions to provide a more ecologically realistic picture of emotional experiences and their role for ethics in everyday life. This perspective dovetails with recent theorizing in moral psychology about the balance between multiple systems involved in moral judgments in a way that integrates deliberative, analytical processes on the one hand, and a more implicit, experiential processes on the other hand (Narvaez, 2010). According to this perspective, the interaction of experiential and deliberative processes can happen in myriad ways. Similar concerns have been raised within the constructionist view of the relationship between morality and emotion, which states that there is no unique one-to-one mapping between discrete emotions and moral content, and instead suggests a flexible combination of various aspects of emotional and moral experiences (Cameron, Lindquist, \& Gray, 2015). The constructionist view of the emotion and morality emphasizes the critical role of variability in emotional experiences, consistent with the present research. Expanding the focus beyond singular emotions can provide a fruitful way to have a more refined understanding of processes at the intersection of experience and deliberation.

\section{Additional Thoughts and Future Directions}

Before concluding, we would like to draw the reader's attention to several final noteworthy observations. First, Studies 2 and 3 provided evidence about the cross-situational malleability of wise reasoning. In Study 2, we extended some of the earlier work by our group 
(Grossmann, Gerlach, et al., 2016), showing that in situations where people demonstrate greater emodiversity, they also report greater likelihoods of engaging in aspects of wise reasoning such as intellectual humility, willingness to consider diverse viewpoints and search for compromise. Moreover, Study 3 demonstrated initial evidence of how experimentally enhancing egodecentering can boost wise reasoning about a recent interpersonal conflict. Together, these insights dovetail with emerging theorizing on the malleability of wisdom (Staudinger \& Glück, 2011), extending prior observations employing hypothetical scenarios (Böhmig-Krumhaar, Staudinger, \& Baltes, 2002; Grossmann \& Kross, 2014; Kross \& Grossmann, 2012; Staudinger \& Baltes, 1996).

Second, the effects of emodiversity on wise reasoning in the present work cannot be accounted for by ego-decentering. In Study 3, the ego-decentering manipulation (which instigates psychological distance from the self; Kross \& Ayduk, 2017; Trope \& Liberman, 2010)did not influence emodiversity. Additionally, supplementary analyses of Study 3 indicated that ego-decentering manipulation did not moderate the effect of emodiversity on wise reasoning. Moreover, supplementary analyses in Studies 2-4c indicated that the effect of emodiversity on such aspects of wise reasoning as intellectual humility, acknowledgement of change, consideration of diverse viewpoints and search for a compromise held when controlling for the self-transcendence component of wise reasoning, the latter of which conceptually aligns with the idea of ego-decentering. Together, these observations suggest that the effect of emodiversity on wise reasoning is unique, rather than a by-product of an association between wise reasoning and ego-decentering (Grossmann, 2017b). Given that ego-decentering is central to emotional downregulation strategies such as cognitive reappraisal (Finkel, Slotter, Luchies, Walton, \& Gross, 2013; Grossmann \& Kross, 2010; Kross, Gard, Deldin, Clifton, \& Ayduk, 
2012; Verduyn, Van Mechelen, Kross, Chezzi, \& Van Bever, 2012), this observation provides further evidence for dissociation between effects of emodiversity and emotional downregulation for wise reasoning.

Third, the present work did not provide empirical evidence of the mechanisms connecting emodiversity and wise reasoning. One viable possibility is that greater diversity of emotional experience promotes greater conceptual knowledge (e.g., Barrett, 2017; Lindquist \& Barrett, 2008), which in turn facilitates wise reasoning. This idea would imply that the central element linking emodiversity to wise reasoning concerns contextually sensitive knowledge. Some prior research has examined the relationship between wise reasoning and general knowledge (Grossmann et al., 2013), suggesting only a modest positive relationship between these constructs. But to our knowledge no work has yet tested the relationship between contextspecific knowledge (e.g., knowledge of how a specific strategy fits a given situation; Haines et al., 2016) and wise reasoning. Testing this possible mechanism presents an exciting avenue for future research.

Fourth, in contrast to some prior work (e.g., Kross et al., 2014, 2005), we found only limited support in Study 3 for the direct effect of ego-decentering on down-regulation of negative affect. Specifically, we observed an effect of ego-decentering reducing the intensity of personcentered emotions (anxious and afraid), but not other more complex or other-focused emotions (criticized, guilty). This observation supports recent theorizing on psychological distance, which suggests that the effects of psychological distance on reduced emotional intensity are more likely to be pronounced for concrete emotions concerning the self than abstract emotions concerning the experience in general or involving social considerations (Liberman, Trope, \& Stephan, 2007). Moreover, the results in Study 3 are consistent with evidence from prior experiments that 
successfully manipulated wise reasoning, yet failed to observe a significant relationship between wise reasoning and emotional intensity (Kross \& Grossmann, 2012; Grossmann \& Kross, 2014). ${ }^{5}$

Fifth, supplementary analyses of our data do not provide a conclusive picture of whether positive or negative emodiversity enhances wise reasoning more than the other. Most of our studies suggested that both components statistically accounted for unique variance in wise reasoning. As such, it seems likely that the balance between emotions of different valence and arousal contributes to the effects of emodiversity on wise reasoning, similar to how balancing positive and negative affect can improve judgment accuracy (Rees, Rothman, Lehavy, \& Sanchez-Burks, 2013; also see additional evidence to this point in supplementary analyses about the role of emotional dialecticism for emodiversity and wise reasoning). Along similar lines, supplementary analyses of Study 3 indicated that richness and evenness components of emodiversity independently contributed to wise reasoning, when reasoning preceded emotional assessment (also see Figure 1 for convergent Study 1 results), but only the richness subcomponent significantly contributed to wise reasoning when emotional assessment preceded reasoning. Future work is needed to explore how frequency- and intensity-based components of emodiversity impact wise reasoning when emotions systematically vary in valence, arousal, and other appraisal dimensions, such as controllability.

Finally, so far we failed to manipulate emodiversity through explicit instructions in Studies $4 \mathrm{a}-\mathrm{c}$. It is possible that the three web-based, rather short manipulations of emodiversity may not have been sufficiently powerful for altering participants' emotional representations. Future research may address this question by bringing participants to the laboratory for a longer time-period. A trained interviewer could then guide them to reflect on the wide range of [more emodiverse] or most potent [least emodiverse] emotion they experience. Another avenue may 
involve using situation-focused manipulations, in which situations participants will find themselves in will either promote more [e.g., emotionally ambivalent situation] or less emotional complexity [e.g., emotionally non-ambivalent situation]. Both possibilities open exciting avenues for future research.

\section{Constrains of Generality}

The present research focused on adults from North America and German-speaking Western Europe, raising the question whether the effects of emodiversity generalize to nonWestern cultures. The present samples chiefly included samples of convenience varying in level of education and social class. Notably, recent work suggests emodiversity varies across cultures (Grossmann, Huynh, et al., 2016), such that non-Western countries like India, Russia or Japan tend to report greater emodiversity than their Western counterparts. With an exception of Study 1, the present samples mostly focused on young and middle-aged adults, raising the question how the relationship between wise reasoning and emodiversity changes across the lifespan (e.g., Ersner-Hershfield et al., 2008; for a review, see Grossmann \& Ellsworth, 2017). Therefore, future research is necessary to explore whether the effects of emodiversity on wise reasoning found in our samples would similarly affect samples from non-Western cultural contexts and whether the effects of emodiversity and wise reasoning change across lifespan.

\section{Context of the Research}

In a recent review of the growing field of psychological wisdom research, Staudinger and Glück (2011) concluded with the following suggestion: "Wisdom research would likely profit from studying the 'processes' of dealing wisely with life problems" (p. 236). Heeding this call, the present project provides a fine-grained analysis of emotional processes for wise reasoning, showcasing the central role of global emodiversity for wise reasoning about daily hassles, 
interpersonal challenges, geopolitical conflicts, and ambivalent situations people encounter in their lives. We became interested in this relationship due to a surprising observation in the first set of experimental studies on wise reasoning (Grossmann \& Kross, 2014; Kross \& Grossmann, 2012): Despite effective boosts in wise reasoning, participants did not report shifts in their emotional intensity. This observation, together with frequent questions about the role of emotions for wise reasoning put the first author on the path of uncovering the complex relationship between wisdom and emotion. In future work, we plan to further unpack situational factors facilitating emodiversity and its effects for wise reasoning, as well as explore possible underlying mechanisms. 


\section{Footnotes}

${ }^{1}$ Emodiversity here refers to a local evaluation of an experience, which includes considerations of relative dominance of several emotions in the representation of this experience. The experience can reflect a month, a week, or a particular episode. Whether the effects of emodiversity work similarly across these different scopes is unknown yet. Consistent with most recent work on this topic (Benson et al., 2018; Grossmann et al., 2016), our chief argument here concerns the episodic level of analysis, focusing on the relationship between emotion and cognition in a concrete situation.

${ }^{2}$ Though the ADU classification system has limitations, including the somewhat outdated theoretical model and a restriction of emotion terms, it is the only validated system available to date for the German language that allows for a fine-grained and linguistically-informed classification.

${ }^{3}$ One exception to this pattern is the effect of condition on the manipulation check index of the richness of emotions participants reported experiencing during the conflict in Study 4c.

Participants in the enhanced emodiversity condition reported experiencing more emotions during the event $(M=7.21,95 \% C I[6.88,7.54])$ than participants in the diminished emodiversity condition $(M=2.53,95 \% C I[2.20,2.86]), F(1,501)=388.37, p<.001, R^{2}=.44$. Further, participants who recalled more emotions during their past conflict experience were more likely to view their emotions during the reflection-task in an emodiverse fashion, $r=.17, p<.001$. Moreover, a serial mediation model of condition $\rightarrow$ rich emotional recall $\rightarrow$ emodiversity $\rightarrow$ wise reasoning was significant, $B=0.09,95 \% C I[0.05,0.14], z=3.88, p<.001$, indicating an indirect effect of condition on wise reasoning via rich recall of emotions and greater emodiversity during the reflection task.

${ }^{4}$ The concept of emotional homeostasis is also intimately linked to the other related form of emotional complexity - emotional dialecticism, which concerns the degree to which positive and negative emotions are reported not in a bipolar fashion but rather co-occur (Grossmann et al., 2016). Relevant supplementary analyses for Studies 2-5 examined how emotional dialecticism markers are related to emodiversity and wise reasoning. As Table S7-S12 in the supplement indicate, emotional dialecticism markers were consistently positively related to emodiversity, but only one of the markers of emotional dialecticism was reliably, though less strongly, related to wise reasoning.

${ }^{5}$ Notably, the intensity of recalled emotional experiences in prior work (Kross et al., 2005) was low across conditions $(M=1.76,1-5$ scale), whereas the intensity of emotional experiences in the present work was at or above the mid-point of the scale, suggesting that ego-decentering may lead to lower emotional intensity when the overall intensity is already fairly low. Indeed, prior research shows that the effect of ego-decentering on emotional intensity is more pronounced among depressive (vs. non-depressive) individuals (Kross \& Ayduk, 2009), whose emotional experience tends to be less intense than that of non-depressive individuals (American Psychiatric Association, 2013). 


\section{References}

American Psychiatric Association. (2013). Diagnostic and Statistical Manual of Mental Disorders (DSM-5®). Arlington, VA: American Psychiatric Association.

Ardelt, M., \& Ferrari, M. (2014). Wisdom and emotions. In P. Verhaeghen \& C. Hertzog (Eds.), The Oxford Handbook of Emotion, Social Cognition, and Problem Solving in Adulthood (pp. 256-272). Oxford, UK: Oxford University Press.

Baltes, P. B., \& Kunzmann, U. (2004). The two faces of wisdom: Wisdom as a general theory of knowledge and judgment about excellence in mind and virtue vs. Wisdom as everyday realization in people and products. Human Development, 47, 290-299. https://doi.org/10.1159/000079156

Baltes, P. B., \& Smith, J. (2008). The fascination of wisdom: Its nature, ontogeny, and function. Perspectives on Psychological Science, 3(1), 56-64. https://doi.org/10.1111/j.17456916.2008.00062.x

Baltes, P. B., \& Staudinger, U. M. (2000). Wisdom: A metaheuristic (pragmatic) to orchestrate mind and virtue toward excellence. The American Psychologist, 55(1), 122-136. https://doi.org/10.1037//0003-066X.55.1.122

Bangen, K. J., Meeks, T. W., \& Jeste, D. V. (2013). Defining and assessing Wisdom: A review of the literature. The American Journal of Geriatric Psychiatry, 21(12), 1254-1266.

Barrett, K. C., \& Campos, J. J. (1987). Perspectives on emotional development II: A functionalist approach to emotions. In J. D. Osofsky (Ed.), Wiley series on personality processes. Handbook of infant development (pp. 555-578). Oxford, England: John Wiley \& Sons.

Barrett, L. F. (2017). How emotions are made. The secret life of the brain. New York, N.Y.: 


\section{Houghton Mifflin Harcourt.}

Bates, D., Maechler, M., Bolker, B., \& Walker, S. (2015). Fitting Linear Mixed-Effects Models Using lme4. Journal of Statistical Software, 67(1), 1-48. https://doi.org/10.18637/jss.v067.i01

Bechara, A., Damasio, H., Tranel, D., \& Damasio, A. R. (1997). Deciding Advantageously Before Knowing the Advantageous Strategy. Science, 275(5304), 1293-1295. https://doi.org/10.1126/science.275.5304.1293

Benson, L., Ram, N., Almeida, D. M., Zautra, A. J., \& Ong, A. D. (2018). Fusing Biodiversity Metrics into Investigations of Daily Life: Illustrations and Recommendations With Emodiversity. The Journals of Gerontology, Series B: : Psychological Sciences and Social Sciences, 73(1), 75-86. https://doi.org/10.1093/geronb/gbx025

Blanchette, I., \& Richards, A. (2004). Reasoning About Emotional and Neutral Materials: Is Logic Affected by Emotion? Psychological Science, 15(11), 745-752. https://doi.org/10.1111/j.0956-7976.2004.00751.x

Blanchette, I., \& Richards, A. (2010). The influence of affect on higher level cognition: A review of research on interpretation, judgement, decision making and reasoning. Cognition \& Emotion, 24(4), 561-595. https://doi.org/10.1080/02699930903132496

Böhmig-Krumhaar, S. A., Staudinger, U. M., \& Baltes, P. B. (2002). Mehr Toleranz tut Not: Lässt sich wert-relativierendes Wissen und Urteilen mit Hilfe einer wissensaktivierenden Gedächtnisstrategie verbessern? Zeitschrift für Entwicklungspsychologie und Pädagogische Psychologie, 34(1), 30-43. https://doi.org/10.1026//0049-8637.34.1.30

Bolger, N., Davis, A., \& Rafaeli, E. (2003). Diary methods: Capturing life as it is lived. Annual 
Review of Psychology, 54(1), 579-616.

Brienza, J. P., \& Grossmann, I. (2017). Social class and wise reasoning about interpersonal conflicts across regions, persons and situations. Proceedings of the Royal Society B: Biological Sciences, 284(1869), 20171870. https://doi.org/10.1098/rspb.2017.1870

Brienza, J. P., Kung, F. Y. H., Santos, H. C., Bobocel, D. R. R., \& Grossmann, I. (2017). Wisdom, bias, and balance: Toward a process-sensitive measurement of wisdom-related cognition. Journal of Personality and Social Psychology. https://doi.org/10.1037/pspp0000171

Brugman, G. M. (2000). Wisdom: Source of narrative coherence and eudaimonia. Delft, The Netherlands: Eburon.

Cameron, C. D., Lindquist, K. A., \& Gray, K. (2015). A Constructionist Review of Morality and Emotions. Personality and Social Psychology Review, 19(4), 371-394. https://doi.org/10.1177/1088868314566683

Cameron, C. D., Payne, B. K., \& Doris, J. M. (2013). Morality in high definition: Emotion differentiation calibrates the influence of incidental disgust on moral judgments. Journal of Experimental Social Psychology, 49(4), 719-725. https://doi.org/10.1016/j.jesp.2013.02.014

Campos, J. J., Campos, R. G., \& Barrett, K. C. (1989). Emergent themes in the study of emotional development and emotion regulation. Developmental Psychology, 25(3), 394402. https://doi.org/10.1037/0012-1649.25.3.394

Chandler, J., Paolacci, G., Peer, E., Mueller, P., \& Ratliff, K. A. (2015). Using nonnaive participants can reduce effect sizes. Psychological Science, 26(7), 1131-1139. https://doi.org/10.1177/0956797615585115 
Clore, G. L., \& Huntsinger, J. R. (2007). How emotions inform judgment and regulate thought. Trends in Cognitive Sciences, 11(9), 393-399. https://doi.org/10.1016/j.tics.2007.08.005

D’Arms, J., \& Jacobson, D. (2000). Sentiment and Value. Ethics, 110(4), 722-748. Retrieved from https://www.journals.uchicago.edu/doi/10.1086/233371

Dahl, H. (1978). A new psychoanalytic model of motivation: Emotions as appetites and messages. Psychoanalysis and Contemporary Thought, 1(3), 373-408.

De Houwer, J., \& Hermans, D. (2010). Cognition and emotion: Reviews of current research and theories. New York, New York: Psychology Press.

Dea, S., Walsh, J., \& Lennon, T. M. (2017). Continental Rationalism. In Edward N. Zalta (Ed.), The Stanford Encyclopedia of Philosophy. Retrieved from https://plato.stanford.edu/entries/continental-rationalism/

Dutton, D. G., \& Aron, A. P. (1974). Some evidence for heightened sexual attraction under conditions of high anxiety. Journal of Personality and Social Psychology, 30(4), 510-517. https://doi.org/10.1037/h0037031

Ellsworth, P. C. (2010). The rise and fall of the high impact experiment. In M. Gonzalez, C. Tavris, \& J. Aronson (Eds.), The Scientist and the Humanist: A Festschrift in Honor of Elliot Aronson (pp. 79-106). New York, New York: Taylor and Francis.

Ellsworth, P. C., \& Gonzalez, R. (2003). Questions, comparisons, and preparation: methods of research in social psychology. In M. A. Hogg \& J. Cooper (Eds.), The Sage Handbook of Social Psychology (pp. 24-42). Thousand Oaks, CA: Sage.

Ellsworth, P. C., \& Scherer, K. (2003). Appraisal processes in emotion. In R. J. Davidson, K. 
Scherer, \& H. H. Goldsmith (Eds.), Handbook of Affective Science (pp. 572-595). New York: Oxford University Press.

Ersner-Hershfield, H., Mikels, J. A., Sullivan, S. J., \& Carstensen, L. L. (2008). Poignancy: mixed emotional experience in the face of meaningful endings. Journal of Personality and Social Psychology, 94(1), 158.

Fazio, R. H. (2001). On the automatic activation of associated evaluations: An overview. Cognition \& Emotion, 15(2), 115-141. https://doi.org/10.1080/02699930125908

Finkel, E. J., Slotter, E. B., Luchies, L. B., Walton, G. M., \& Gross, J. J. (2013). A Brief Intervention to Promote Conflict Reappraisal Preserves Marital Quality Over Time. Psychological Science, 24(8), 1595-1601. https://doi.org/10.1177/0956797612474938

Fitness, J., \& Warburton, W. (2009). Thinking the Unthinkable: Cognitive Appraisals and Hurt Feelings. In A. L. Vangelisti (Ed.), Feeling Hurt in Close Relationships (pp. 34-49). Cambridge: Cambridge University Press. https://doi.org/10.1017/CBO9780511770548.004

Fleeson, W., \& Jayawickreme, E. (2015). Whole trait theory. Journal of Research in Personality, 56, 82-92. https://doi.org/10.1016/j.jrp.2014.10.009

Fleeson, W., \& Noftle, E. (2008). The end of the Person-Situation debate: An emerging synthesis in the answer to the consistency question. Social and Personality Psychology Compass, 2(4), 1667-1684. https://doi.org/10.1111/j.1751-9004.2008.00122.x

Fletcher, T. D. (2012). QuantPsyc: Quantitative Psychology Tools. R package version 1.5. Retrieved from https://cran.r-project.org/package=QuantPsyc

Fontaine, J. R. J., Scherer, K. R., Roesch, E. B., \& Ellsworth, P. C. (2007). The world of 
emotions is not two-dimensional. Psychological Science, 18(12), 1050-1057.

https://doi.org/10.1111/j.1467-9280.2007.02024.x

Forgas, J. P. (2006). Affect in social thinking and behavior. New York: Psychology Press.

Frijda, N. H., \& Mesquita, B. (1994). The social roles and functions of emotions. In S. Kitayama \& H. R. Markus (Eds.), Emotion and culture: Empirical studies of mutual influence (pp. 51-87). Washington, DC: American Psychological Association.

Gibbard, A. (1990). Wise Choices, Apt Feelings. Cambridge: Harvard University Press.

Glück, J., \& Bluck, S. (2013). The MORE Life Experience Model: A Theory of the Development of Personal Wisdom. In M. Ferrari \& N. M. Weststrate (Eds.), The Scientific Study of Personal Wisdom (pp. 75-97). Dordrecht: Springer Netherlands.

Glück, J., König, S., Naschenweng, K., Redzanowski, U., Dorner, L., Straßer, I., \& Wiedermann, W. (2013). How to measure wisdom: content, reliability, and validity of five measures. Frontiers in Psychology, 4(JUL), 1-13. https://doi.org/10.3389/fpsyg.2013.00405

Gross, J. J. (2015). Emotion regulation: Current status and future prospects. Psychological Inquiry, 26(1), 1-26. https://doi.org/10.1080/1047840X.2014.940781

Grossmann, I. (2017a). Wisdom and How to Cultivate It. European Psychologist, 22(4), 233246. https://doi.org/10.1027/1016-9040/a000302

Grossmann, I. (2017b). Wisdom in Context. Perspectives on Psychological Science, 12(2), 233257. https://doi.org/10.1177/1745691616672066

Grossmann, I., \& Brienza, J. (2018). The Strengths of Wisdom Provide Unique Contributions to Improved Leadership, Sustainability, Inequality, Gross National Happiness, and Civic 
Discourse in the Face of Contemporary World Problems. Journal of Intelligence, 6(2), 22. https://doi.org/10.3390/jintelligence6020022

Grossmann, I., \& Ellsworth, P. C. (2017). What are mixed emotions and what conditions foster them? Life-span experiences, culture and social awareness. Current Opinion in Behavioral Sciences, 15, 1-5. https://doi.org/10.1016/j.cobeha.2017.05.001

Grossmann, I., Gerlach, T. M., \& Denissen, J. J. A. (2016). Wise Reasoning in the Face of Everyday Life Challenges. Social Psychological and Personality Science, 7(7), 611-622. https://doi.org/10.1177/1948550616652206

Grossmann, I., Huynh, A. C., \& Ellsworth, P. C. (2016). Emotional complexity: Clarifying definitions and cultural correlates. Journal of Personality and Social Psychology, 111(6), 895-916. https://doi.org/10.1037/pspp0000084

Grossmann, I., \& Kross, E. (2010). The Impact of Culture on Adaptive Versus Maladaptive SelfReflection. Psychological Science, 21(8), 1150-1157. https://doi.org/10.1177/0956797610376655

Grossmann, I., \& Kross, E. (2014). Exploring "Solomon’s paradox": Self-distancing eliminates the self-other asymmetry in wise reasoning about close relations in younger and older adults. Psychological Science, 25(8), 1571-1580. https://doi.org/10.1177/0956797614535400

Grossmann, I., Na, J., Varnum, M. E. W., Kitayama, S., \& Nisbett, R. E. (2013). A route to wellbeing: Intelligence versus wise reasoning. Journal of Experimental Psychology: General, 142(3), 944-953. https://doi.org/10.1037/a0029560

Grossmann, I., Na, J., Varnum, M. E. W., Park, D. C., Kitayama, S., \& Nisbett, R. E. (2010). 
Reasoning about social conflicts improves into old age. Proceedings of the National Academy of Sciences of the United States of America, 107(16), 7246-7250. https://doi.org/10.1073/pnas.1001715107

Gruber, J., \& Bekoff, M. (2017). A Cross-Species Comparative Approach to Positive Emotion Disturbance. Emotion Review, 9(1), 72-78. https://doi.org/10.1177/1754073915615430

Haines, S. J., Gleeson, J., Kuppens, P., Hollenstein, T., Ciarrochi, J., Labuschagne, I., ... Koval, P. (2016). The Wisdom to Know the Difference. Psychological Science, 27(12), 16511659. https://doi.org/10.1177/0956797616669086

Hauser, D. J., Ellsworth, P. C., \& Gonzalez, R. (2018). Are Manipulation Checks Necessary? Frontiers in Psychology, 9. https://doi.org/10.3389/fpsyg.2018.00998

Hölzer, M., Scheytt, N., \& Kächele, H. (1992). Das „Affektive Diktionär Ulm “als eine Methode der quantitativen Vokabularbestimmung. In C. Züll \& Mohler P.P. (Eds.), Textanalyse. ZUMA-Publikationen. (pp. 131-154). Wiesbaden: VS Verlag für Sozialwissenschaften.

Hu, C. S., Ferrari, M., Wang, Q., \& Woodruff, E. (2017). Thin-Slice Measurement of Wisdom. Frontiers in Psychology, 8. https://doi.org/10.3389/fpsyg.2017.01378

Hume, D. (1978). A Treatise of Human Nature. (L. A. Selby-Bigge, Ed.) (2nd rev). Oxford: Clarendon Press.

Im, M. (1999). Emotional Control and Virtue in the "Mencius." Philosophy East and West, 49(1), 1. https://doi.org/10.2307/1400114

Izard, C. E. (1977). Human emotions. New York: Plenum Press.

Jamieson, J. P., Mendes, W. B., \& Nock, M. K. (2013). Improving Acute Stress Responses. 
Current Directions in Psychological Science, 22(1), 51-56.

https://doi.org/10.1177/0963721412461500

Jeste, D. V., Ardelt, M., Blazer, D., Kraemer, H. C., Vaillant, G., \& Meeks, T. W. (2010). Expert Consensus on Characteristics of Wisdom: A Delphi Method Study. The Gerontologist, 50(5), 668-680. https://doi.org/10.1093/geront/gnq022

Johnson-Laird, P. N., Mancini, F., \& Gangemi, A. (2006). A hyper-emotion theory of psychological illnesses. Psychological Review, 113(4), 822-841. https://doi.org/10.1037/0033-295X.113.4.822

Johnson, E. J., \& Tversky, A. (1983). Affect, generalization, and the perception of risk. Journal of Personality and Social Psychology, 45(1), 20-31. https://doi.org/10.1037/00223514.45 .1 .20

Kahneman, D. (2000). Evaluation by moments: Past and future. In D. Kahneman \& A. Tversky (Eds.), Choices, Values and Frames (pp. 693-708). New York: Russel Sage Foundation.

Kahneman, D., Krueger, A. B., Schkade, D. A., Schwarz, N., \& Stone, A. A. (2004). A survey method for characterizing daily life experience: The day reconstruction method. Science, 306(5702), 1776-1780.

Kashdan, T. B., Barrett, L. F., \& McKnight, P. E. (2015). Unpacking emotion differentiation: Transforming unpleasant experience by perceiving distinctions in negativity. Current Directions in Psychological Science, 24(1), 10-16. https://doi.org/10.1177/0963721414550708

Kekes, J. (1983). Wisdom. American Philosophical Quarterly, 20(3), 277-286. https://doi.org/10.2307/20014008 
Keltner, D., \& Gross, J. J. (1999). Functional accounts of emotion. Cognition and Emotion, 13, $467-480$.

Kross, E., \& Ayduk, O. (2009). Boundary conditions and buffering effects: Does depressive symptomology moderate the effectiveness of distanced-analysis for facilitating adaptive self-reflection? Journal of Research in Personality, 43(5), 923-927. https://doi.org/10.1016/j.jrp.2009.04.004

Kross, E., \& Ayduk, O. (2017). Self-Distancing: Theory, Research, and Current Directions. Advances in Experimental Social Psychology, 55, 81-136. https://doi.org/10.1016/bs.aesp.2016.10.002

Kross, E., Ayduk, O., \& Mischel, W. (2005). When asking “why” does not hurt. Distinguishing rumination from reflective processing of negative emotions. Psychological Science, 16(9), 709-715. https://doi.org/10.1111/j.1467-9280.2005.01600.x

Kross, E., Bruehlman-Senecal, E., Park, J., Burson, A., Dougherty, A., Shablack, H., ... Ayduk, O. (2014). Self-talk as a regulatory mechanism: How you do it matters. Journal of Personality and Social Psychology, 106(2), 304-324. https://doi.org/10.1037/a0035173

Kross, E., Gard, D., Deldin, P., Clifton, J., \& Ayduk, Ö. (2012). “Asking why” from a distance: Its cognitive and emotional consequences for people with Major Depressive Disorder. Journal of Abnormal Psychology, 121(3), 559-569. https://doi.org/10.1037/a0028808

Kross, E., \& Grossmann, I. (2012). Boosting wisdom: Distance from the self enhances wise reasoning, attitudes, and behavior. Journal of Experimental Psychology: General, 141(1), 43-48. https://doi.org/10.1037/a0024158

Kunzmann, U., \& Baltes, P. B. (2003). Wisdom-related knowledge: Affective, motivational, and 
interpersonal correlates. Personality \& Social Psychology Bulletin, 29(9), 1104-1119. https://doi.org/10.1177/0146167203254506

Kunzmann, U., \& Glück, J. (2018). Wisdom and emotion. In R. J. Sternberg \& J. Glück (Eds.), The Cambridge Handbook of Wisdom. Cambridge, UK: Cambridge University Press.

Kuznetsova, A., Brockhoff, P. B., \& Christensen, R. H. B. (2017). lmerTest Package: Tests in Linear Mixed Effects Models. Journal of Statistical Software, 82(13). https://doi.org/10.18637/jss.v082.i13

Labouvie-Vief, G., Hakim-Larson, J., DeVoe, M., \& Schoeberlein, S. (1989). Emotions and selfregulation: A life span view. Human Development, 32(5), 279-299.

Laney, C., Campbell, H. V., Heuer, F., \& Reisberg, D. (2004). Memory for thematically arousing events. Memory \& Cognition, 32(7), 1149-1159. https://doi.org/10.3758/BF03196888

Le, T. N. (2008). Cultural Values, Life Experiences, and Wisdom. The International Journal of Aging and Human Development, 66(4), 259-281. https://doi.org/10.2190/AG.66.4.a

Levine, L. J., \& Edelstein, R. S. (2009). Emotion and memory narrowing: A review and goalrelevance approach. Cognition \& Emotion, 23(5), 833-875. https://doi.org/10.1080/02699930902738863

Liberman, N., Trope, Y., \& Stephan, E. (2007). Psychological distance. In E. T. Higgins \& A. W. Kruglanski (Eds.), Social psychology: A handbook of basic principles (pp. 353-381). New York: Guilford Press.

Lindquist, K. A., \& Barrett, L. F. (2008). Constructing emotion: the experience of fear as a conceptual act. Psychological Science, 19(9), 898-903. https://doi.org/10.1111/j.1467- 
9280.2008.02174.x

Lindquist, K. A., \& Barrett, L. F. (2010). Emotional complexity. In M. Lewis, J. M. HavilandJones, \& L. F. Barrett (Eds.), The Handbook of Emotions (pp. 513-530). New York: Guilford.

Low, K. C. P. (2014). Key Leadership Insights and Lessons from Ancient Wisdom. International Journal of Business and Social Science, 5(4), 172-180.

Lüdecke, D. (2018). sjPlot: Data Visualization for Statistics in Social Science. Retrieved from https://cran.r-project.org/package=sjPlot

Mayer, J. D., Gaschke, Y. N., Braverman, D. L., \& Evans, T. W. (1992). Mood-congruent judgment is a general effect. Journal of Personality and Social Psychology, 63(1), 119-132. https://doi.org/10.1037/0022-3514.63.1.119

McCallum, R., \& Lucas, G. (2005). Star Wars: Episode III - Revenge of the Sith [Motion picture]. United States of America: 20th Century Fox.

McEveety, V., \& Bar-David, S. (1966). Dagger of the Mind. \{Television series episode]. (Gene Roddenberry, Ed.), Star Trek: The Original Series. Unites States of America: NBC.

McKee, P., \& Barber, C. E. (1999). On defining wisdom. The International Journal of Aging and Human Development, 49(2), 149-164. https://doi.org/10.2190/8G32-BNV0-NVP9-7V6G

Mickler, C., \& Staudinger, U. M. (2008). Personal wisdom: Validation and age-related differences of a performance measure. Psychology and Aging, 23(4), 787-799.

Narvaez, D. (2010). Moral complexity: The fatal attraction of truthiness and the importance of mature moral functioning. Perspectives on Psychological Science, 5(2), 163-181. 
https://doi.org/10.1177/1745691610362351

Oakes, H., Brienza, J. P., Elnakouri, A., \& Grossmann, I. (n.d.). Wise reasoning: Converging evidence for the psychology of sound judgment. In R. J. Sternberg \& J. Glück (Eds.), Cambridge Handbook of Wisdom. New York: Cambridge University Press.

Oaksford, M., Morris, F., Grainger, B., \& Williams, J. M. G. (1996). Mood, reasoning, and central executive processes. Journal of Experimental Psychology: Learning, Memory, and Cognition, 22(2), 476-492. https://doi.org/10.1037/0278-7393.22.2.476

Ong, A. D., Benson, L., Zautra, A. J., \& Ram, N. (2018). Emodiversity and biomarkers of inflammation. Emotion, 18(1), 3-14. https://doi.org/10.1037/emo0000343

Ong, A. D., \& Bergeman, C. S. (2004). The complexity of emotions in later life. The Journals of Gerontology Series B: Psychological Sciences and Social Sciences, 59(3), 117-122. https://doi.org/10.1093/geronb/59.3.P117

Quoidbach, J., Gruber, J., Mikolajczak, M., Kogan, A., Kotsou, I., \& Norton, M. I. (2014). Emodiversity and the emotional ecosystem. Journal of Experimental Psychology: General, 143(6), 2057-2066.

Rees, L., Rothman, N. B., Lehavy, R., \& Sanchez-Burks, J. (2013). The ambivalent mind can be a wise mind: Emotional ambivalence increases judgment accuracy. Journal of Experimental Social Psychology, 49(3), 360-367. https://doi.org/10.1016/j.jesp.2012.12.017

Richard, F. D., Bond Jr., C. F., \& Stokes-Zoota, J. J. (2003). One Hundred Years of Social Psychology Quantitatively Described. Review of General Psychology, 7(4), 331-363. https://doi.org/10.1037/1089-2680.7.4.331 
Richards, A., French, C. C., Keogh, E., \& Carter, C. (2000). Test-Anxiety, inferential reasoning and working memory load. Anxiety, Stress \& Coping, 13(1), 87-109. https://doi.org/10.1080/10615800008248335

Roseman, I. J. (1991). Appraisal determinants of discrete emotions. Cognition and Emotion, 5, $161-200$.

Santos, H. C., Huynh, A. C., \& Grossmann, I. (2017). Wisdom in a complex world: A situated account of wise reasoning and its development. Social and Personality Psychology Compass, 11(10), e12341. https://doi.org/10.1111/spc3.12341

Schmid, H. (1995). Improvements in Part-of-Speech Tagging with an Application to German. In Proceedings of the ACL SIGDAT-Workshop. Dublin, Ireland.

Schwarz, N. (1990). Feelings as information: Informational and motivational functions of affective states. In E. T. Higgins \& R. M. Sorrentino (Eds.), Handbook of motivation and cognition (Vol. 2, pp. 527-561). New York: Guilford Press.

Schwarz, N., \& Clore, G. L. (1983). Mood, misattribution, and judgments of well-being: Informative and directive functions of affective states. Journal of Personality and Social Psychology, 45(Journal Article), 513-523.

Schwarz, N., Kahneman, D., \& Xu, J. (2009). Global and episodic reports of hedonic experience. In R. Belli, D. Alwin, \& F. Stafford (Eds.), Calendar and time diary: Methods in life events research (pp. 157-174). Newbury Park, CA: Sage Publications.

Staudinger, U. M., \& Baltes, P. B. (1996). Interactive minds: A facilitative setting for wisdomrelated performance? Journal of Personality and Social Psychology, 71(4), 746-762. 
Staudinger, U. M., \& Glück, J. (2011). Psychological wisdom research: Commonalities and differences in a growing field. Annual Review of Psychology, 62(1), 215-241. https://doi.org/10.1146/annurev.psych.121208.131659

Sternberg, R. J. (1998). A balance theory of wisdom. Review of General Psychology, 2(4), 347365.

Sternberg, R. J., \& Jordan, J. (2005). A handbook of wisdom: Psychological perspectives. New York, NY US: Cambridge University Press.

Thompson, E. R. (2007). Development and Validation of an Internationally Reliable Short-Form of the Positive and Negative Affect Schedule (PANAS). Journal of Cross-Cultural Psychology, 38(2), 227-242. https://doi.org/10.1177/0022022106297301

Thompson, M. M., Zanna, M. P., \& Griffin, D. W. (1995). Let's not be indifferent about (attitudinal) ambivalence. In R. E. Petty \& J. A. Krosnick (Eds.), Attitude strength: Antecedents and consequences. Ohio State University Series on Attitudes and Persuasion (pp. 361-386). Hillsdal, NJ: Lawrence Erlbaum.

Trope, Y., \& Liberman, N. (2010). Construal-level theory of psychological distance. Psychological Review, 117(2), 440-463.

Twain, M. (2003). The Adventures of Huckleberry Finn. (V. Fischer, L. Salamo, \& W. Blair, Eds.). Berkeley: University of California Press.

Venables, W. N., \& Ripley, B. D. (2002). Modern Applied Statistics with S. (Fourth). New York: Springer.

Verduyn, P., Van Mechelen, I., Kross, E., Chezzi, C., \& Van Bever, F. (2012). The relationship 
between self-distancing and the duration of negative and positive emotional experiences in daily life. Emotion, 12(6), 1248-1263. https://doi.org/10.1037/a0028289

Vervaeke, J., \& Ferraro, L. (2013). Relevance, meaning and the cognitive science of wisdom. In M. Ferrari \& N. M. Weststrate (Eds.), The Scientific Study of Personal Wisdom (pp. 325341). Dordrecht, Netherlands: Springer Netherlands. https://doi.org/10.1007/978-94-0077987-7_15

Walsh, R. (2015). What is wisdom? Cross-cultural and cross-disciplinary syntheses. Review of General Psychology, 19(3), 278-293. https://doi.org/10.1037/gpr0000045

Watson, D., \& Clark, L. A. (1999). The PANAS-X: Manual for the positive and negative affect schedule-expanded form. Department of Psychology Publications. Iowa City, IA: University of Iowa.

Watson, D., Clark, L. A., \& Tellegen, A. (1988). Development and validation of brief measures of positive and negative affect: the PANAS scales. Journal of Personality \& Social Psychology, 54(6), 1063-1070.

Webster, J. D. (2003). An exploratory analysis of a self-assessed wisdom scale. Journal of Adult Development, 10(1), 13-22.

Weststrate, N. M., Ferrari, M., \& Ardelt, M. (2016). The Many Faces of Wisdom. Personality and Social Psychology Bulletin, 42(5), 662-676. https://doi.org/10.1177/0146167216638075

Weststrate, N. M., Ferrari, M., Fournier, M. A., \& McLean, K. C. (2018). "It was the best worst day of my life": Narrative Content, Structure, and Process in Wisdom-Fostering Life Event Memories. The Journals of Gerontology, Series B: Psychological Sciences and Social 
Sciences. https://doi.org/10.1093/geronb/gby005

Weststrate, N. M., \& Glück, J. (2017). Hard-earned wisdom: Exploratory processing of difficult life experience is positively associated with wisdom. Developmental Psychology, 53(4), 800-814. https://doi.org/10.1037/dev0000286

Wilson, M., \& Daly, M. (2004). Do pretty women inspire men to discount the future? Proceedings of the Royal Society B: Biological Sciences, 271, 177-179. https://doi.org/10.1098/rsbl.2003.0134

Wilson, T. D., Wheatley, T., Meyers, J. M., Gilbert, D. T., \& Axsom, D. (2000). Focalism: A source of durability bias in affective forecasting. Journal of Personal and Social Psychology, 78(5), 821-836. https://doi.org/10.1037/0022-3514.78.5.821

Yiend, J. (2010). The effects of emotion on attention: A review of attentional processing of emotional information. Cognition \& Emotion, 24(1), 3-47. https://doi.org/10.1080/02699930903205698 


\section{Author Contributions}

I.G. provided the initial study idea. I.G. and H.O. designed Studies 3, 4a and 4b. I.G. designed Study 4c. I.G. and H.C.S. designed Study 5. H.O. conducted Studies 3, 4a, and 4b. I.G. conducted Study 4c. H.C.S. conducted Study 5. I.G. analyzed the research. All authors contributed to the interpretation of the results. I.G. wrote the first draft of the manuscript, which was revised and approved by H.O. and H.C.S. for the final submission.

Authors declare no conflict of interest. 


\title{
Supplementary Materials
}

for

Wise Reasoning Benefits from Emodiversity, Irrespective of Emotional Intensity

\author{
Igor Grossmann ${ }^{1}$ \\ Harrison Oakes ${ }^{1}$ \\ Henri C. Santos ${ }^{2}$ \\ ${ }^{1}$ University of Waterloo, Canada \\ ${ }^{2}$ Geisinger Health System
}

\begin{abstract}
Author Note
Igor Grossmann, Department of Psychology, University of Waterloo. Harrison Oakes, Department of Psychology, University of Waterloo. Henri C. Santos, Autism and Developmental Medicine Institute, Geisinger Health System.

Anonymized data, materials and code are available at Open Science Framework (osf.io/u4kx6) and pre-print is available on PsyarXiv (psyarxiv.com/jy5em).
\end{abstract}

\section{Acknowledgements}

We thank Ethan Kross and Ozlem Ayduk for comments on a previous version of the manuscript. We further thank Judith Glück for providing raw data for re-analysis in Study 1, and Jörg Lehmann for help and advice with quantifying the Study 1 corpora using Affective Dictionary Ulm. This research was supported by the Insight Grant from the Social Sciences and Humanities Research Council of Canada, the Early Researcher Award from the Ontario Ministry of Research, Innovation and Science and the Pathways to Character Templeton Initiative Grant to the first author, and the Vanier Canada Graduate Scholarship to the second author.

Correspondence concerning this article should be addressed to Igor Grossmann, 200 University Avenue West, Waterloo, Ontario, Canada N2L 3G1, Phone: +1 347 850-4467. Fax: 519-746-8631 E-mail: igrossma@uwaterloo.ca 


\section{Study 1}

After the question concerning the emotional experience, interviewers asked participants: "How did you think the other person felt?" and "What feelings do you have now as you think about this time again?" We did not pursue these questions in our main analyses, because we aimed to zero in on participants' experiences rather than their appraisal of others involved in the conflict or subsequent reappraisals. For the sake of completion and to compare responses concerning initial reflection on the past experience and reappraisal, we also analyzed responses to the latter question about their feelings now, following the procedure outlined in the main text.

Chi-square analyses indicated that the group difference was particularly pronounced for the first question concerning feelings during the experience, $\chi^{2}(11)=37.88, p<.001$, but not in response to the final question concerning present feelings, $\chi^{2}(11)=13.79, p=.245$. However, when examining responses across both questions, the groups differed substantially, $\chi^{2}(11)=$ $32.22, p<.001$. As the visual inspection of the average word counts (Figure S1) and relative dominance of distinct emotion categories (Figure S2) demonstrate, the difference in reappraisal patterns between wisdom nominees and the control group chiefly concerned the relative dominance of various emotions (i.e., the evenness component of emodiversity), with a similar count of emotions per 10 words between the two groups (i.e., the richness component of emodiversity).
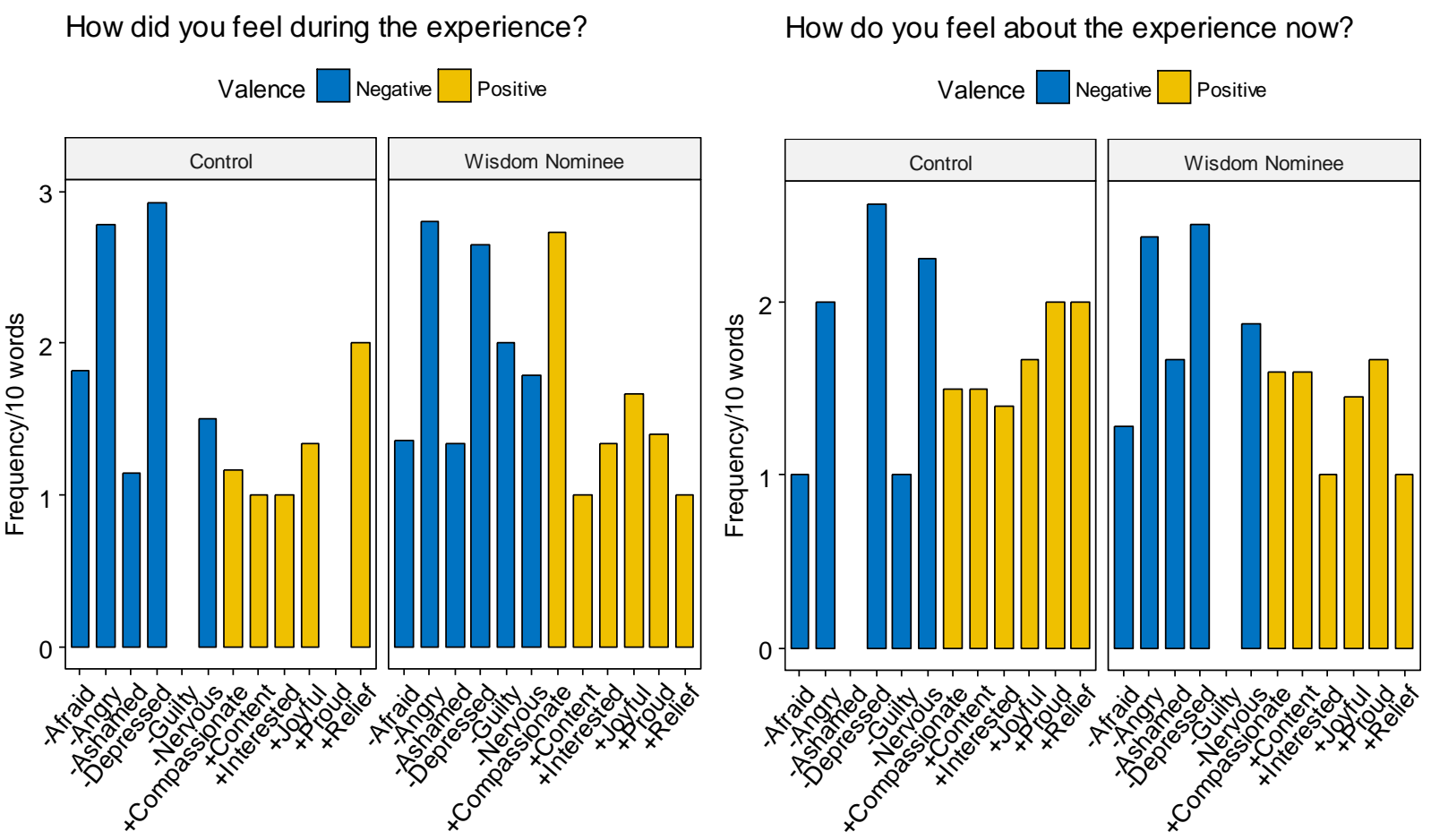

Figure S1: Frequency of each emotion theme in the transcripts of wisdom nominees and the control group. 

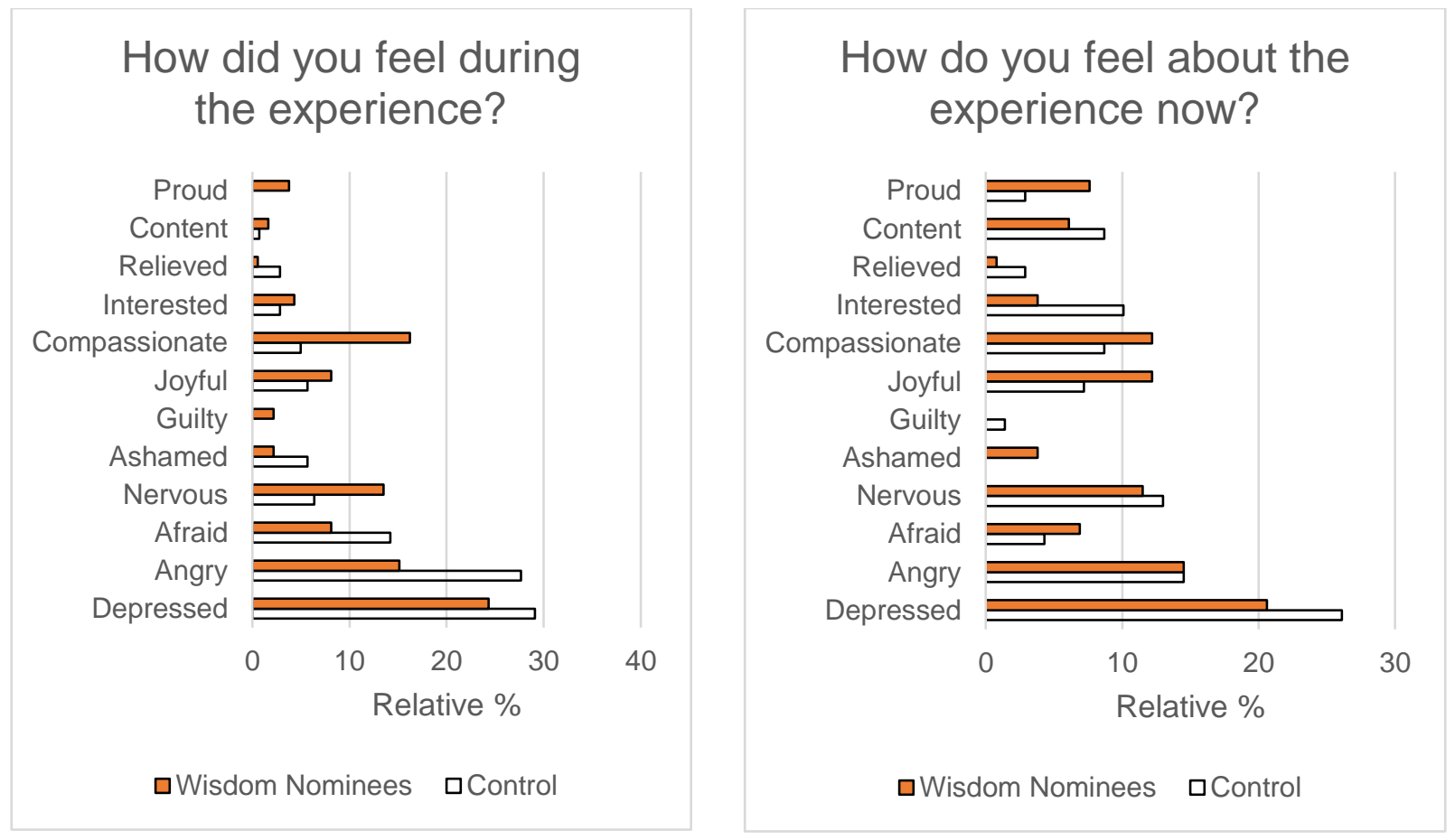

Figure S2: Relative frequency of each emotion theme in the transcripts of wisdom nominees and the control group.

\section{Examination of Emotional Content between Top and Bottom Performers on Wise Reasoning}

In the first interview session, participants reflected on a set of standardized prompts, designed to assess the presence of wisdom-related characteristics in spontaneous reasoning (Baltes \& Smith, 2008). Specifically, participants were asked: "In reflecting over their life, people sometimes realize that they have not achieved what they had once wanted to achieve. What could a person consider and do in such a situation?" Participants' spoken responses were transcribed and rated by ten trained students according to five criteria: factual knowledge, procedural knowledge, life-span contextualism, value relativism, and recognition and management of uncertainty (each student rated two criteria on a scale ranging from $1=$ Very little correspondence to an ideal response to $7=$ Very strong correspondence to an ideal response). As reported in Glück et al. (2013), wisdom nominees scored higher on an average of the five scoring criteria than the control group, $F(1,92)=7.04, p=.009, \eta^{2}=.071$. This difference held when controlling for education and the standardized measure of verbal intelligence (see Glück et al., 2013, for details). This difference also held when solely focusing on the reasoning components of the Berlin Wisdom Paradigm (average of contextualism, relativism, management of uncertainty), which most closely resemble the notion of wise reasoning explored in the present paper, $F(1,92)=4.03, p=.048, \eta^{2}=.042$.

We performed a parallel set of analyses on transcripts from the top and bottom $20 \%$ of scores on the reasoning dimensions of the Berlin Wisdom Paradigm, assessed via standardized vignettes presented on a prior interview day. Because we reduced the corpus size in each subsample, we sought to avoid low frequency counts by aggregating responses to both questions (see Figure S3). For statistical analyses, to avoid biased estimates due to low frequency counts, we compared the most frequent negative emotions (angry and depressed) to the other emotions 
mentioned. Among the top $20 \%$ of scores on wise reasoning, $44.58 \%$ of emotion-related words represented anger and depression, whereas among the bottom $20 \%$ of scores on wise reasoning, $60.98 \%$ represented anger and depression.

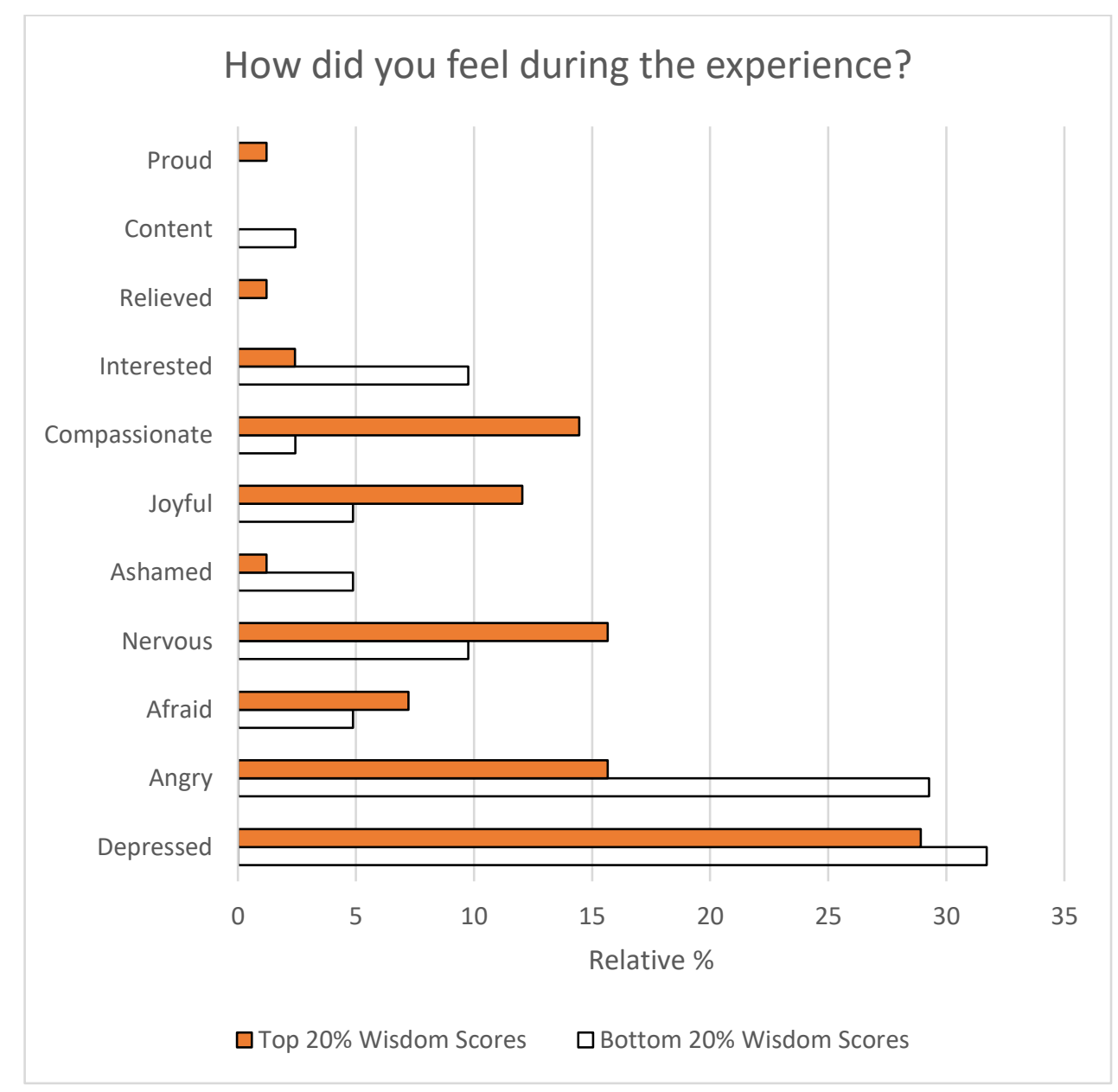

Figure S3. Distribution of emotional content in participants' narratives among the top and bottom performers on the reasoning components of the Berlin Wisdom task. 


\section{Study 2}

As Table S1 indicates, intellectual humility and the perspective-related aspects of wise reasoning were associated with search for compromise, and self-transcendence was associated with dialecticism/change. However, other components were statistically independent from each other.

Table S1

Wise reasoning: Means, standard deviations, and correlations with confidence intervals

\begin{tabular}{|c|c|c|c|c|c|c|}
\hline Variable & $M$ & $S D$ & 1 & 2 & 3 & 4 \\
\hline 1. limits & 2.72 & 2.00 & & & & \\
\hline 2. dialectic & 0.89 & 1.95 & $\begin{array}{c}.04 \\
{[-.01, .10]}\end{array}$ & & & \\
\hline 3. self-transcend & 2.95 & 1.68 & $\begin{array}{c}.01 \\
{[-.05, .06]}\end{array}$ & $\begin{array}{c}.12 * * \\
{[.07, .18]}\end{array}$ & & \\
\hline 4. divpersp & 3.66 & 1.73 & $\begin{array}{c}.08 \\
{[-.04, .21]}\end{array}$ & $\begin{array}{c}.03 \\
{[-.10, .15]}\end{array}$ & $\begin{array}{c}.08 \\
{[-.04, .21]}\end{array}$ & \\
\hline 5. compromise & 3.27 & 1.92 & $\begin{array}{c}.13 * \\
{[.01, .25]}\end{array}$ & $\begin{array}{c}.11 \\
{[-.01, .24]}\end{array}$ & $\begin{array}{c}.01 \\
{[-.11, .14]}\end{array}$ & $\begin{array}{c}.24 * * \\
{[.12, .36]}\end{array}$ \\
\hline
\end{tabular}

Note. Values in square brackets indicate the $95 \%$ confidence interval for each correlation. $* p<.05 . * * p<.01$. 
Table S2

Effects of State and Trait-Level Emodiversity and Intensity on Aspects of Wise Reasoning, Controlling for Demographics.

\begin{tabular}{|c|c|c|c|c|c|c|c|c|c|c|c|c|c|c|c|}
\hline & \multicolumn{3}{|c|}{ Int. Humil } & \multicolumn{3}{|c|}{ Change/Dialecticism } & \multicolumn{3}{|c|}{ Self-Transcendence } & \multicolumn{3}{|c|}{ Diverse Perspectives } & \multicolumn{3}{|c|}{ Compromise } \\
\hline & $B$ & $S E$ & $p$ & $B$ & $S E$ & $p$ & $B$ & $S E$ & $p$ & $B$ & $S E$ & $p$ & $B$ & $S E$ & $p$ \\
\hline $\begin{array}{l}\text { Fixed Parts } \\
\text { (Intercept) }\end{array}$ & 3.02 & 0.81 & $<.001$ & 1.17 & 0.66 & .076 & 3.60 & 0.86 & $<.001$ & 4.24 & 1.36 & .002 & 3.90 & 0.86 & $<.001$ \\
\hline $\begin{array}{l}\text { State } \\
\text { Emodiversity }\end{array}$ & 0.38 & 0.21 & .068 & 0.13 & 0.24 & .582 & 0.08 & 0.18 & .666 & 1.12 & 0.45 & .014 & 2.89 & 1.16 & .015 \\
\hline $\begin{array}{l}\text { Trait } \\
\text { Emodiversity }\end{array}$ & 1.18 & 0.34 & $<.001$ & 0.79 & 0.27 & .004 & 0.17 & 0.36 & .634 & -0.28 & 0.60 & .642 & 2.57 & 0.46 & $<.001$ \\
\hline $\begin{array}{l}\text { State Neg. } \\
\text { Intensity }\end{array}$ & 0.04 & 0.09 & .609 & -0.40 & 0.10 & $<.001$ & -0.19 & 0.07 & .010 & -0.31 & 0.20 & .130 & 0.74 & 0.52 & .162 \\
\hline $\begin{array}{l}\text { Trait Neg. } \\
\text { Intensity }\end{array}$ & -0.17 & 0.24 & .495 & -0.55 & 0.20 & .005 & -0.83 & 0.26 & .002 & -0.07 & 0.40 & .862 & -0.27 & 0.20 & .189 \\
\hline $\begin{array}{l}\text { State Pos. } \\
\text { Intensity }\end{array}$ & -0.03 & 0.07 & .633 & -0.10 & 0.08 & .223 & 0.11 & 0.06 & .062 & 0.13 & 0.15 & .391 & -0.32 & 0.34 & .343 \\
\hline $\begin{array}{l}\text { Trait Pos. } \\
\text { Intensity }\end{array}$ & 0.11 & 0.19 & .554 & -0.02 & 0.15 & .920 & 0.11 & 0.20 & .579 & 0.06 & 0.33 & .850 & 0.06 & 0.15 & .707 \\
\hline Sex & -0.11 & 0.17 & .526 & -0.00 & 0.14 & .980 & 0.27 & 0.18 & .141 & -0.28 & 0.30 & .363 & 0.35 & 0.28 & .217 \\
\hline Age & 0.01 & 0.01 & .615 & 0.01 & 0.01 & .250 & 0.04 & 0.01 & .009 & -0.05 & 0.02 & .023 & -0.63 & 0.26 & .018 \\
\hline Education & -0.04 & 0.12 & .707 & 0.16 & 0.09 & .088 & -0.01 & 0.12 & .925 & 0.24 & 0.20 & .242 & -0.02 & 0.02 & .255 \\
\hline \multicolumn{16}{|l|}{ Random Parts } \\
\hline$\sigma^{2}$ & & 2.227 & & & 2.890 & & & 1.579 & & & 1.864 & & & 2.131 & \\
\hline$\tau_{00, \text { id }}$ & & 0.601 & & & 0.205 & & & 0.812 & & & 1.055 & & & 0.396 & \\
\hline$N_{\mathrm{id}}$ & & 134 & & & 134 & & & 134 & & & 104 & & & 104 & \\
\hline $\mathrm{ICC}_{\mathrm{id}}$ & & 0.212 & & & 0.066 & & & 0.340 & & & 0.361 & & & 0.157 & \\
\hline Observations & & 1064 & & & 1064 & & & 1064 & & & 208 & & & 208 & \\
\hline$R^{2} / \Omega_{0}^{2}$ & & $.319 / .297$ & & & $168 / .147$ & & & $39 / .427$ & & & $.627 / .548$ & & & $.426 / .392$ & \\
\hline
\end{tabular}

Note. Int. Humil = intellectual humility, Neg = negative, Pos = positive. Sex: Male (1) vs. Female (0). Education: 6 levels. Sample size is smaller (134 vs. 152 in main analyses) because some participants did not indicate their full demographics. 


\section{Table S3}

Effects of State and Trait-Level Thought Suppression and Sense of Insight/Closure on Aspects of Wise Reasoning.

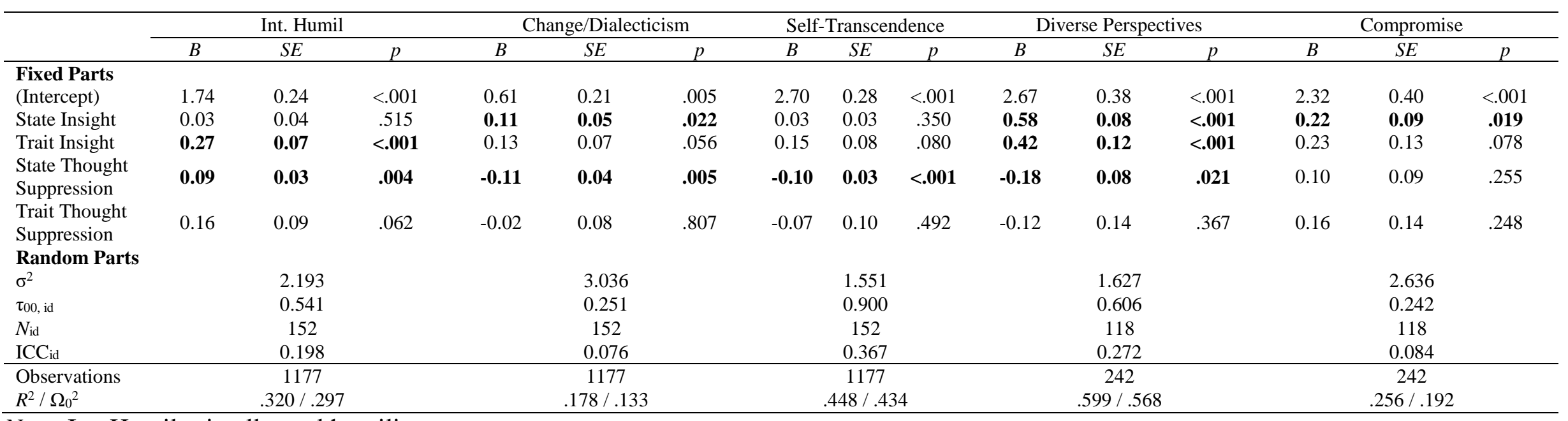

Note. Int. Humil = intellectual humility. 


\section{Table S4}

Effects of Valence-Specific Emodiversity and Emotional Intensity on Wise Reasoning.

\begin{tabular}{|c|c|c|c|c|c|c|c|c|c|c|c|c|c|c|c|}
\hline & \multicolumn{3}{|c|}{ Int. Humil } & \multicolumn{3}{|c|}{ Change/Dialecticism } & \multicolumn{3}{|c|}{ Self-Transcendence } & \multicolumn{3}{|c|}{ Diverse Perspectives } & \multicolumn{3}{|c|}{ Compromise } \\
\hline & $B$ & $S E$ & $p$ & $B$ & $S E$ & $p$ & $B$ & $S E$ & $p$ & $B$ & $S E$ & $p$ & $B$ & $S E$ & $p$ \\
\hline \multicolumn{15}{|l|}{ Fixed Parts } & .011 \\
\hline State Negative Emodiversity & 0.13 & 0.12 & .295 & 0.08 & 0.14 & .543 & -0.16 & 0.10 & .114 & -0.35 & 0.28 & .213 & 0.19 & 0.29 & .504 \\
\hline Trait Negative Emodiversity & 0.37 & 0.23 & .112 & 0.13 & 0.20 & .525 & 0.23 & 0.25 & .367 & -0.52 & 0.40 & .194 & 0.10 & 0.35 & .770 \\
\hline State Positive Emodiversity & -0.10 & 0.13 & .424 & 0.40 & 0.14 & .006 & 0.14 & 0.10 & .178 & 0.24 & 0.31 & .429 & 0.79 & 0.32 & .016 \\
\hline Trait Positive Emodiversity & 0.62 & 0.30 & .043 & 0.66 & 0.26 & .012 & -0.38 & 0.34 & .258 & 0.73 & 0.57 & .204 & 0.75 & 0.49 & .134 \\
\hline State Negative Intensity & 0.04 & 0.09 & .685 & -0.25 & 0.11 & .017 & -0.16 & 0.08 & .032 & -0.26 & 0.22 & .241 & -0.15 & 0.23 & .509 \\
\hline Trait Negative Intensity & 0.14 & 0.28 & .615 & -0.17 & 0.24 & .469 & -0.74 & 0.31 & .017 & 0.37 & 0.47 & .438 & -0.07 & 0.40 & .868 \\
\hline State Positive Intensity & -0.03 & 0.07 & .666 & -0.07 & 0.08 & .403 & 0.13 & 0.06 & .023 & 0.07 & 0.16 & .666 & 0.08 & 0.17 & .658 \\
\hline Trait Positive Intensity & 0.31 & 0.18 & .084 & 0.02 & 0.15 & .908 & 0.09 & 0.20 & .657 & -0.25 & 0.31 & .431 & 0.52 & 0.27 & .057 \\
\hline \multicolumn{16}{|l|}{ Random Parts } \\
\hline$\sigma^{2}$ & \multicolumn{3}{|c|}{2.221} & \multicolumn{3}{|c|}{2.968} & \multicolumn{3}{|c|}{1.518} & \multicolumn{3}{|c|}{2.113} & \multicolumn{3}{|c|}{2.669} \\
\hline$\tau_{00, \text { id }}$ & \multicolumn{3}{|c|}{0.571} & \multicolumn{3}{|c|}{0.219} & \multicolumn{3}{|c|}{0.892} & \multicolumn{3}{|c|}{0.960} & \multicolumn{3}{|c|}{0.206} \\
\hline$N_{\text {id }}$ & \multicolumn{3}{|c|}{152} & \multicolumn{3}{|c|}{152} & \multicolumn{3}{|c|}{152} & \multicolumn{3}{|c|}{115} & \multicolumn{3}{|c|}{115} \\
\hline $\mathrm{ICC}_{\mathrm{id}}$ & \multicolumn{3}{|c|}{0.204} & \multicolumn{3}{|c|}{0.069} & \multicolumn{3}{|c|}{0.370} & \multicolumn{3}{|c|}{0.312} & \multicolumn{3}{|c|}{0.072} \\
\hline Observations & \multicolumn{3}{|c|}{1121} & \multicolumn{3}{|c|}{1121} & \multicolumn{3}{|c|}{1121} & \multicolumn{3}{|c|}{226} & \multicolumn{3}{|c|}{226} \\
\hline$R^{2} / \Omega_{0}^{2}$ & & $321 / .295$ & & & $73 / .147$ & & & $.453 / .43$ & & & $.599 / .477$ & & & $.231 /$ & \\
\hline
\end{tabular}

Note. Int. Humil = intellectual humility. 


\section{Table S5}

Effects of Emodiversity and Emotional Intensity on Event-Related Processing Strategies.

\begin{tabular}{|c|c|c|c|c|c|c|}
\hline & \multicolumn{3}{|c|}{ Sense of Insight/Closure } & \multicolumn{3}{|c|}{ Thought Suppression } \\
\hline & $B$ & $S E$ & $p$ & $B$ & $S E$ & $p$ \\
\hline \multicolumn{7}{|l|}{ Fixed Parts } \\
\hline (Intercept) & 1.64 & 0.58 & .006 & 2.38 & 0.44 & $<.001$ \\
\hline State Emodiversity & 0.61 & 0.14 & $<.001$ & 0.89 & 0.14 & $<.001$ \\
\hline Trait Emodiversity & 1.03 & 0.31 & .001 & 1.27 & 0.23 & $<.001$ \\
\hline State Negative Intensity & -0.07 & 0.06 & .205 & 0.24 & 0.06 & $<.001$ \\
\hline Trait Negative Intensity & 0.33 & 0.22 & .142 & 0.27 & 0.16 & .104 \\
\hline State Positive Intensity & 0.03 & 0.05 & .496 & -0.13 & 0.05 & .009 \\
\hline Trait Positive Intensity & 0.16 & 0.18 & .371 & -0.46 & 0.13 & $<.001$ \\
\hline \multicolumn{7}{|l|}{ Random Parts } \\
\hline$\sigma^{2}$ & \multicolumn{3}{|c|}{1.119} & \multicolumn{3}{|c|}{1.149} \\
\hline$\tau_{00, \text { id }}$ & \multicolumn{3}{|c|}{0.731} & \multicolumn{3}{|c|}{0.332} \\
\hline$N_{\text {id }}$ & \multicolumn{3}{|c|}{152} & \multicolumn{3}{|c|}{152} \\
\hline $\mathrm{ICC}_{\mathrm{id}}$ & \multicolumn{3}{|c|}{0.395} & \multicolumn{3}{|c|}{0.224} \\
\hline Observations & \multicolumn{3}{|c|}{1177} & \multicolumn{3}{|c|}{1177} \\
\hline $\mathrm{R}^{2} / \Omega_{0}^{2}$ & \multicolumn{3}{|c|}{$.486 / .475$} & \multicolumn{3}{|c|}{$.384 / .370$} \\
\hline
\end{tabular}




\section{Study 3}

\section{Calculating Emotional Richness and Evenness Scores for Negative and Positive Emodiversity}

We calculated emotional richness by counting the number of emotions experienced above $0=n o t$ at all. We calculated emotional evenness by dividing emodiversity scores by the log of emotional richness.

\section{Did Participants Focus on Unpleasant Events?}

In our preliminary analyses we explored whether participants followed the instructions and selected subjectively unpleasant events. Because scores of positive emotional intensity were not normally distributed, we applied the Related-Samples Wilcoxon Signed-Ranks Test to compare negative and positive emotional intensity scores. This test demonstrated that participants reported greater negative than positive emotional intensity in their conflicts: $M d n$ difference $=1.54[1.46,1.63], V=1036400$. For positive emotional intensity, the median was significantly lower than the scale midpoint: $M d n=2.31$ [2.25, 2.38], $V=58946, p<.001$, whereas the median of negative emotional intensity was significantly higher than the scale midpoint: $M d n=3.92$ [3.85, 3.97], $V=485820, p=.002$.

\section{Sub-Score Specific Analyses of Condition, Separately by Exploratory (Studies 3a \& b) and Confirmatory (Studies 3c \& d) Samples}

Below, we report results of analyses of condition and order, separately for exploratory (Studies 3a $\&$ b) and confirmatory (Studies $3 c \& d$ ) samples. Overall, in the exploratory samples we observed a main effect of ego-decentered (vs. egocentric) condition resulting in greater self-transcendence and change facets of SWIS, and a consistent trend in search for a compromise in the same direction. Further, in the confirmatory samples, we observed consistent Condition X Order interactions, with predicted effects of egodecentered (vs. egocentric) condition on three out of five facets of SWIS - self-transcendence, intellectual humility, and consideration of others' perspectives - when the reasoning task preceded the emotion task, but not vice versa.

\section{Self-Transcendence/Observer Viewpoint - Manipulation Check}

The observer viewpoint items of the SWIS most closely relate to our manipulation to use $3^{\text {rd }}$ - vs. $1^{\text {st }}$-person language in participants' reflection on the social conflict. Therefore, we treated the averaged index of observer as a manipulation check. In the exploratory samples, we observed the predicted main effect of condition on observer viewpoint, $F(1,626)=10.44, p=.001, \eta_{\mathrm{p}}{ }^{2}=.01890 \% C I[.00, .03]$. Participants in the ego-decentering condition $(M=2.21, S D=1.10)$ took an observer's viewpoint to a greater extent than those in the egocentric condition $(M=1.91, S D=1.14)$. Task order did not significantly predict observer viewpoint, $F(1,626)=1.25, p=.264, \eta_{\mathrm{p}}{ }^{2}=.002$, nor did it interact with condition, $F(1,626)<1$, ns.

In contrast, in the confirmatory samples we did not observe a significant main effect of condition, $F(1,931)<1$, but we found a marginal effect of task order, $F(1,931)=2.85, p=.091$. When the emotion task came first $(M=2.09, S D=1.13)$, participants took an observer viewpoint less than when the reasoning task came first $(M=2.02, S D=1.19)$. Additionally, the Condition X Task Order interaction was marginally significant, $F(1,931)=2.96, p=.086, \eta_{\mathrm{p}}{ }^{2}=.003$. Simple effects analyses revealed that when the reasoning task came first, participants in the ego-decentered condition reported viewing events from an observer viewpoint more $(M=2.21, S D=1.13)$ than participants in the egocentric condition $(M=$ $1.86, S D=1.22), F(1,476)=10.72, p=.001, \eta_{\mathrm{p}}{ }^{2}=.02$. However, when the emotion task preceded the reasoning task, participants in the ego-decentered condition did not significantly differ in their viewing events from an observer viewpoint $(M=2.13, S D=1.10)$ from participants in the egocentric condition $(M$ $=2.04, S D=1.16), F(1,454)=0.56, p=.456$.

\section{Intellectual Humility}

In the exploratory samples, we observed a significant effect of order, $F(1,626)=6.20, p=.013$, $\eta_{\mathrm{p}}{ }^{2}=.010$. Participants completing the emotion task first $(M=1.74, S D=0.94)$ reported recognizing the 
limits of their knowledge significantly less than participants who completed the reasoning task first $(M=$ $1.94, S D=0.99)$. Condition did not significantly predict intellectual humility, $F(1,626)=1.84, p=.175$, $\eta_{\mathrm{p}}{ }^{2}=.003$, nor did it significantly interact with condition, $F(1,626)<1, n s$.

In contrast, in the confirmatory samples we observed a significant Condition X Task Order interaction, $F(1,931)=6.93, p=.009$. Simple effects analyses revealed that when the reasoning task came first, participants in the ego-decentered condition reported greater intellectual humility $(M=1.95$, $S D=0.99)$ than participants in the egocentric condition $(M=1.72, S D=1.04), F(1,476)=6.95, p=.009$,

$\eta_{\mathrm{p}}{ }^{2}=.01$. However, when the emotion task preceded the reasoning task, participants in the ego-decentered condition did not significantly differ in their intellectual humility $(M=1.69, S D=1.01)$ compared to participants in the egocentric condition $(M=1.80, S D=1.01), F(1,454)=1.24, p=.265$.

\section{Change}

In the exploratory samples, we observed a main effect of condition, such that participants reported greater recognition of change in the ego-decentered condition $(M=2.02, S D=1.10)$ as compared to the egocentric condition $(M=1.93, S D=1.09), F(1,626)=4.87, p=.028, \eta_{\mathrm{p}}{ }^{2}=.009$. Neither in the exploratory nor confirmatory samples did we observe any further significant effects of condition, order, or their interaction, all $F s<2.26, n s$. Notably, the patterns of the task order factor suggest a consistent pattern of greater recognition of change and multiple ways a situation may unfold if the reasoning task preceded (exploratory: $M=2.28, S D=1.05$; confirmatory: $M=2.26, S D=1.01$ ) rather than followed the emotion task (exploratory: $M=2.15, S D=1.01$; confirmatory: $M=2.17, S D=$ 1.02), exploratory: $F(1,626)=2.26, p=.133$, confirmatory: $F(1,931)=1.72, p=.189$.

\section{Others' Perspectives}

In the exploratory samples, we did not observe any significant effects, all $F$ s $<1.48, n s$. In contrast, in the confirmatory samples we observed a marginal Condition X Task Order interaction, $F(1$, $931)=2.77, p=.097$. Simple effects analyses revealed that when the reasoning task came first, participants in the ego-decentered condition reported greater consideration of others' perspectives $(M=$ $2.00, S D=1.02)$ than participants in the egocentric condition $(M=1.78, S D=1.04), F(1,476)=5.69, p=$ $.017, \eta_{\mathrm{p}}^{2}=.01$. However, when the emotion task preceded the reasoning task, participants in the egodecentered condition did not significantly differ in their likelihood of considering others' perspectives $(M$ $=1.84, S D=1.02)$ compared to participants in the egocentric condition $(M=1.84, S D=0.97), F(1,454)$ $<1, n s$.

\section{Search for Compromise/Conflict Resolution}

Neither in the exploratory nor confirmatory samples did we observe any significant effects of condition, order, or their interaction, all $F s<2.39, n s$. Notably, the patterns of the condition factor in the exploratory analyses suggest a consistent pattern of greater search for compromise/conflict resolution in the ego-decentered condition $(M=2.27, S D=0.97)$ than in the egocentric condition $(M=2.15, S D=$ $0.97), F(1,626)=2.39, p=.122$.

\section{Emotional Intensity}

In the exploratory samples, participants reported somewhat greater negative intensity when the emotion task appeared before $(M=4.00, S D=1.04)$ rather than after the reasoning task $(M=3.86, S D=$ $1.01), F(1,626)=3.70, p=.055, \eta_{\mathrm{p}}{ }^{2}=.01$. Neither the main effect of condition, $F(1,626)=1.63, p=$ .202 , nor the Condition X Task Order interaction were significant, $F(1,626)<1$. In the confirmatory samples, none of the effects were significant, all $F \mathrm{~s}(1,626)<1.10$, all $p \mathrm{~s}>.294$.

In the exploratory samples, positive emotional intensity did not differ as a function of condition, task order, or their interaction, all $F \mathrm{~s}(1,931)<0.12$. In the confirmatory samples, however, participants reported marginally lower positive intensity when the emotion measures appeared before $(M=3.95, S D=$ 1.06) rather than after the reasoning tasks $(M=3.86, S D=1.05), F(1,931)=3.73, p=.054, \eta_{\mathrm{p}}{ }^{2}=.00$. Neither the main effect of condition nor its interaction with task order were significant, all $F \mathrm{~s}(1,931)<$ 0.50 . 


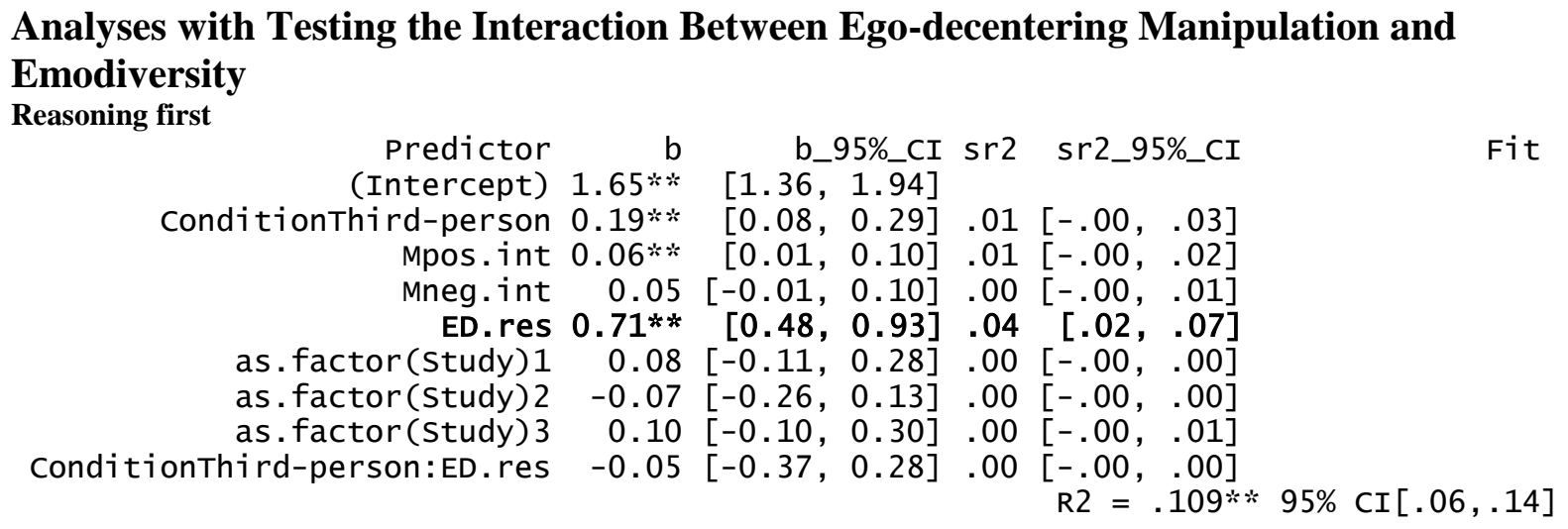

Emotion first

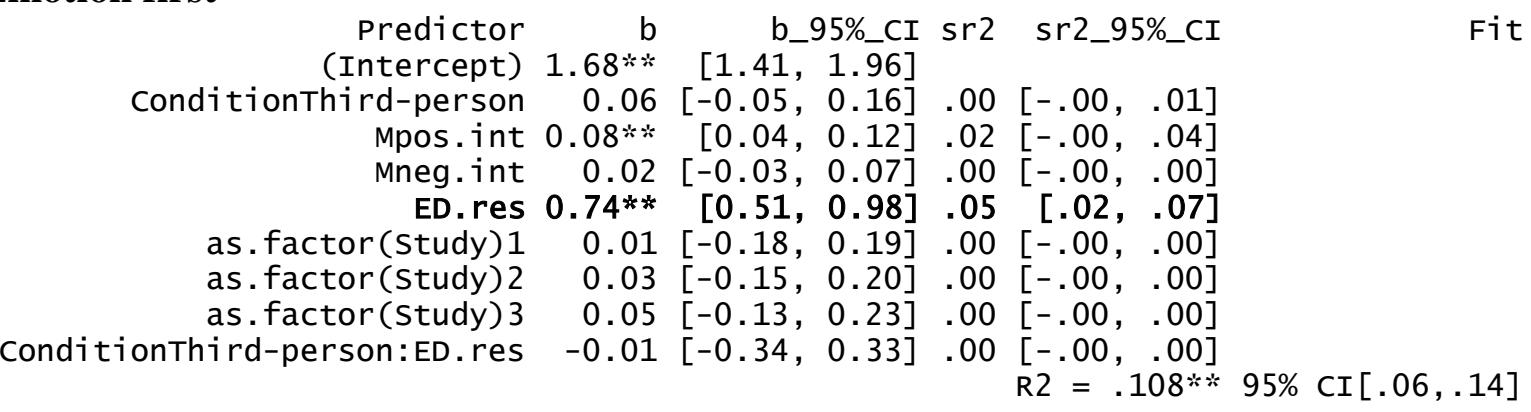




\section{Analyses with Negative and Positive (Instead of Global) Emodiversity}

Results indicated that both positive and negative emodiversity, and positive emotional intensity consistently predicted wise reasoning. The effect was larger for negative emodiversity.

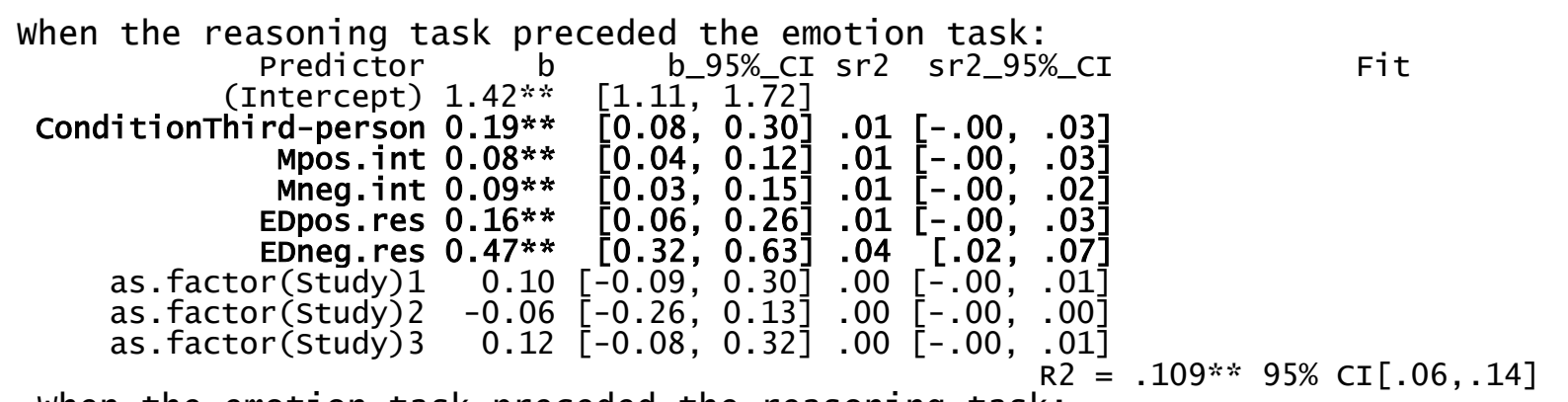

$$
\text { R2 }=.0109 * 95 \% \mathrm{CI}[.06, .14]
$$

When the emotion task preceded the reasoning task:

$$
\begin{aligned}
& \text { Predictor b } \text { b_95\%_CI sr2 sr2_95\%_CI } \quad \text { Fit } \\
& \text { ConditionThird-person } 0.05[-0.05,0.16] .00[-.00, .01] \\
& \text { Mpos.int } 0.10^{* *}[0.06,0.15] .03[.01, .05] \\
& \text { Mneg.int } 0.05[-0.00,0.11] .00[-.00, .01] \\
& \text { EDpos.res } 0.15 * * \quad[0.06,0.25] .01[-.00, .03] \\
& \text { EDneg.res } 0.49 * * \quad[0.34,0.64] .05 \quad[.02, .08] \\
& \text { as.factor(study) } 1 \quad 0.02[-0.16,0.20] .00[-.00, .00] \\
& \begin{array}{lllll}
\text { as.factor (study) } 2 & 0.03[-0.14,0.21] .00[-.00, & .00] \\
\text { as.factor(study) } 3 & 0.07[-0.11,0.26] & .00[-.00, .00]
\end{array}
\end{aligned}
$$

Note. A significant $b$-weight indicates the semi-partial correlation is also ignificant. b represents unstandardized regression weights. sr2 represents th e semi-partial correlation squared. Square brackets are used to enclose the 1 ower and upper limits of a confidence interval.

* indicates $p<.05 . * *$ indicates $p<.01$. 


\section{Effects of Richness and Evenness on Wise Reasoning}

When the reasoning task came first, both evenness and richness of negative emotions simultaneously predicted wiser reasoning.

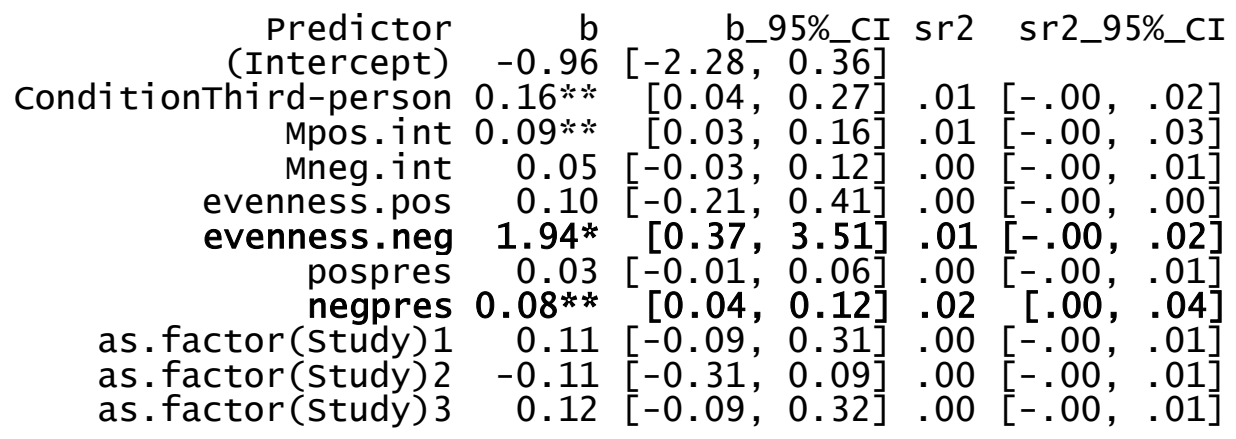

Fit

$95 \%$ CI $[.06, .116 * * *$

When the emotion task came first, the richness of positive and negative emotions simultaneously predicted wiser reasoning.

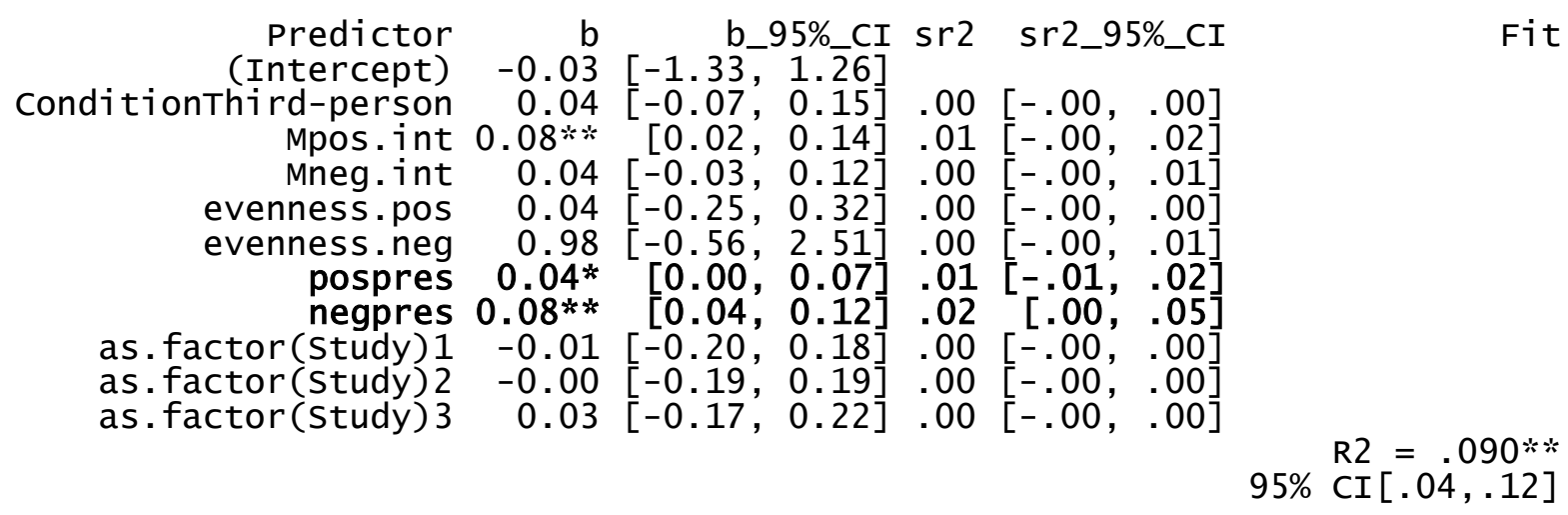

\section{Effects of Manipulation on Intensity of Distinct Emotions}

We explored whether our manipulation impacted the intensity of distinct positive and negative emotions when the emotions task preceded the reasoning task. These post-hoc analyses indicated that participants in the ego-decentered condition reported being marginally less anxious $(M=3.41, S D=0.09)$ compared to participants in the egocentric condition $(M=3.67, S E=0.09), b=-0.24, S E=0.13, t(536)=$ $1.93, p=.054$. The ego-decentering manipulation had no significant impact on the intensity of the other emotions, all $t \mathrm{~s}<1.48, n s$.

\section{Effect of Emodiversity When Controlling for Demographics}

Controlling for age, participant sex, and education level did not significantly attenuate the effects reported in our manuscript. When the reasoning task came first, we replicated the effects of condition, positive emotional intensity and global emodiversity, and also observed a negative effect of age. Given the distribution of the interquartile range, the effect of age seems to be driven by the difference between younger and middle-aged adults, replicating previous work (Brienza et al., 2017). When the emotion task came first, we replicated the effects of global emodiversity and positive emotional intensity from our main analyses. We also observed a small effect suggesting that, compared to participants who identified their sex as "Female", those who did not identify their sex as either "Male" or "Female" reported wiser reasoning. Because this effect was small in magnitude and not hypothesized, we did not follow-up on it further. 


\section{Reasoning Task First}

Predictor

(Intercept) $1.83 \% *$

ConditionThird-person $0.19 \% *$ Mpos.int $0.06 \% *$

Mneg.int 0.05

ED. res $0.68 * *$ Age $-0.01 *$

sex.codemale -0.01

sex.codeother 0.03

edu. $4 \quad-0.00$

as.factor(study) $1 \quad 0.10$

as.factor (study) $2 \quad-0.04$

as.factor (study) $3 \quad 0.11$ b

$[1.46,2 . \overline{2} 0]$

$[0.08,0.30]$

$[0.02,0.10]$

$\left[\begin{array}{ll}-0.01, & 0.10\end{array}\right]$

$[-0.01,-0.00]$

$[-0.13,0.11] .00$

$[-0.66,0.72]$

$[-0.07,0.06]$

$[-0.09,0.30]$

$[-0.24,0.16] .00$

$[-0.09,0.32]$

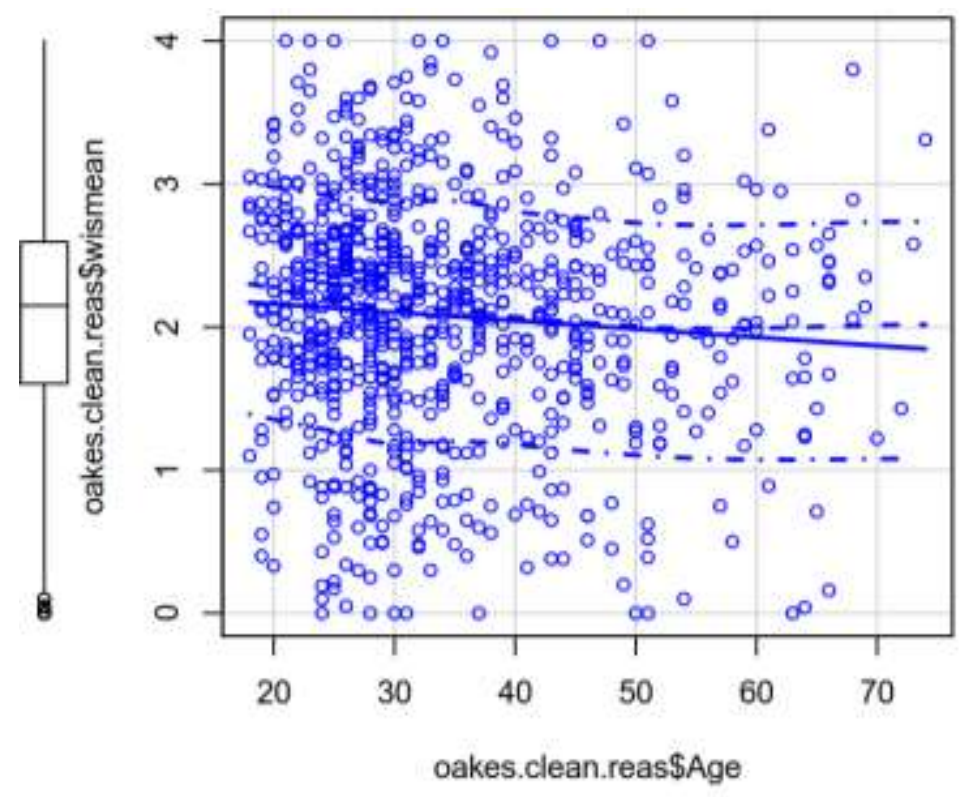

$R 2=.115 \% *$

95\% CI $[.07, .15]$

$.00[-.00, .01]$

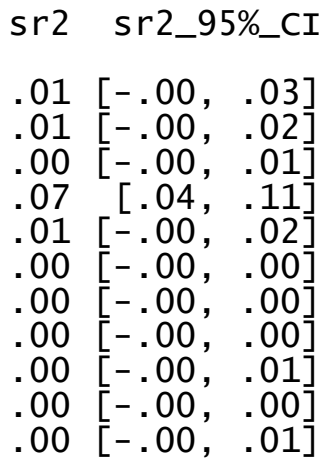

Fit

Figure S4. Participant age is negatively related to wise reasoning. 


\section{Emotion Task First}

\begin{tabular}{|c|c|c|c|c|}
\hline Predictor & $\frac{b}{79 * *}$ & b_95\% $C I$ & $\mathrm{sr} 2$ & Sr2_95\%_CI \\
\hline ditionthird-persor & $\begin{array}{r}1.06 \\
0.06\end{array}$ & {$[-0.05,0.16]$} & .00 & .01] \\
\hline Mpos.int & $0.08 * *$ & {$[0.04$,} & .02 & \\
\hline Mneg.int & 0.02 & {$[-0.03$,} & .00 & {$[-.00$,} \\
\hline ED.res & $0.74 * *$ & $0.91]$ & .09 & {$[.05$,} \\
\hline $\mathrm{Age}$ & -0.00 & $0.00]$ & .0 & 00 \\
\hline sex. codema1e & 0.02 & $0.14]$ & .0 & {$[-.00$} \\
\hline sex.codeother & $0.90 *$ & $1.74]$ & .0 & .01 \\
\hline $\begin{array}{r}\text { edu. } 4 \\
\text { s. factor(studv) } 1\end{array}$ & $\begin{array}{r}-0.03 \\
0.00\end{array}$ & $.09,0.03]$ & $\begin{array}{r}.00 \\
00\end{array}$ & {$[-.00$} \\
\hline ctor (study) 2 & 0.03 & 4 & .0 & \\
\hline as.factor (study) 3 & 0.05 & 0.2 & .00 & \\
\hline
\end{tabular}

Fit

$\mathrm{R} 2=.115 * *$

$95 \%$ CI $[.06, .15]$

Note. A significant b-weight indicates the semi-partial correlation is also $s$ ignificant. b represents unstandardized regression weights. sr2 represents th e semi-partial correlation squared. Square brackets are used to enclose the 1 ower and upper limits of a confidence interva1.* indicates $p<.05$. ** indic ates $\mathrm{p}<.01$.

Table S6

Demographic Information for Samples Used in Study 3.

\begin{tabular}{|c|c|c|c|c|}
\hline & \multicolumn{2}{|c|}{$\begin{array}{c}\text { Exploratory Samples } \\
\text { (before pre-registration) }\end{array}$} & \multicolumn{2}{|c|}{$\begin{array}{l}\text { Confirmatory Samples } \\
\text { (post pre-registration) }\end{array}$} \\
\hline & Sample a & Sample b & Sample c & Sample d \\
\hline $\boldsymbol{N}_{\text {Recruited }}$ & 207 & 532 & 570 & 446 \\
\hline$N_{\text {Valid }}$ & 177 & 458 & 518 & 420 \\
\hline $\operatorname{Age}_{\text {mean }}(S D)$ & $32.7(10.5)$ & $34.1(11.8)$ & $35.7(12.0)$ & $33.6(10.8)$ \\
\hline Gender (\%f/m/other) & $75.1 / 23.7 / 1.1$ & $69.2 / 30.1 / 0.7$ & $56.8 / 43.1 / 0.2$ & $72.9 / 26.7 / 0.5$ \\
\hline \multicolumn{5}{|l|}{ Ethnicity $(\%)$} \\
\hline Asian-Am. & 3.4 & 4.1 & 7.5 & 3.8 \\
\hline African-Am. & 9.0 & 6.6 & 6.0 & 8.8 \\
\hline White & 79.1 & 81.7 & 77.0 & 76.2 \\
\hline Latino & 4.5 & 4.1 & 6.6 & 5.7 \\
\hline "Other" & 3.9 & 3.5 & 2.9 & 5.4 \\
\hline Income $_{\text {median }}$ & $35,001-75,000$ & $35,001-75,000$ & $35,001-75,000$ & $35,001-75,000$ \\
\hline \multicolumn{5}{|l|}{ Education (\%) } \\
\hline High school & 7.9 & 9.0 & 10.8 & 9.0 \\
\hline Some college & 34.5 & 33.6 & 31.9 & 32.9 \\
\hline College & 37.3 & 43.2 & 43.2 & 41.9 \\
\hline Post-grad & 20.3 & 14.2 & 14.1 & 16.2 \\
\hline
\end{tabular}

Note. $N_{\text {Valid }}=$ sample size after screening procedures. 


\section{Study 4}

\section{Study 4a Manipulation Instructions \\ Diminished emodiversity.}

We are going to ask you to reflect on the event you just thought about. While you are reflecting, we would like you to focus on how good or bad you are feeling.

Just as there are dimensions defining colors, the dimension of valence defines how we feel. For instance, a fight with your friend, or a feeling of regret at losing your temper might make you feel very bad. While you are reflecting on the event you just described, pay attention to whether it makes you feel good or bad.

Please, spend 10s reflecting on this event. Afterward, you will be asked to report the extent to which your reflection made you feel good or bad.

\section{Enhanced emodiversity.}

We are going to ask you to reflect on the event you just thought about. While you are reflecting, we would like you to focus on the nuances and subtleties of what you are feeling.

Just as there are many nuances and shades of colors, there are many variations and shades of emotions. For instance, a fight with your friend might make you feel some anger at your friend, yourself, or both, some sadness that you and your friend are fighting, and some regret at losing your temper. While you are reflecting on the event, pay attention to the subtle differences between the feelings you are having toward the event.

Please, spend 10s reflecting on this event. Afterward, you will be asked to report the extent to which your reflection made you feel a variety of different emotions.

\section{Study 4b Manipulation Instructions}

Diminished emodiversity.

Over the next 30 seconds, we would like you to reflect on the feeling you experienced most strongly during this negative event. How did the negative event trigger this feeling? Try to relive this experience as vividly as possible in your mind.

When the 30 seconds are up, you will be able to continue to the next page.

\section{Enhanced emodiversity.}

Over the next 30 seconds, we would like you to reflect on the different feelings you experienced during this recent negative event. How did the negative event trigger these different feelings? Try to relive them by focusing on each feeling to an equal degree.

When the 30 seconds are up, you will be able to continue to the next page. 


\section{Study 4c Manipulation Instructions}

We would like you to reflect on the emotions you experienced during your most recent serious negative experience you had with another person, which you have not fully resolved yet. Please, carefully consider each emotion below and choose as many emotions from the following list as you experienced.

When the 30 seconds are up, you will be able to continue to the next page.

Diminished emodiversity. upset, hostile, ashamed, nervous, afraid

Enhanced emodiversity. afraid, scared, frightened, nervous, jittery, shaky, angry, hostile, irritable, scornful, disgusted, loathing, guilty, ashamed, blameworthy, angry at self, disgusted with self, dissatisfied with self, sad, blue, downhearted, alone, lonely

\section{Wording of Quality Check}

Participants reported if they could think of any reason why we should not use their responses (e.g., they were tired or distracted when they were answering the questions, or they didn't read the instructions carefully, so their answers may not be accurate; yes vs. no). We specified that participants would receive compensation irrespective of their answer.

\section{Reliabilities of SWiS}

Across Studies $4 \mathrm{a}-\mathrm{c}$, each aspect of wise reasoning showed acceptable reliability. Study 4a as: Limits $=.88 ;$ Change $=.82$; Self-Transcendence $=.91$, Perspectives $=.89$, Compromise/Resolution $=.88$ Study $4 \mathrm{~b} \alpha \mathrm{s}$ : Limits $=.86 ;$ Change $=.83$; Self-Transcendence $=.90$, Perspectives $=.88$, Compromise/Resolution $=.88$

Study $4 \mathrm{c}$ as: Limits $=.81 ;$ Change $=82$; Self-Transcendence $=.82$, Perspectives $=.88$

\section{Analyses controlling for age, sex and education}

Emodiversity (and positive emotional intensity) predicted wise reasoning when simultaneously including three demographic covariates: Age, sex, and level of education. Education was not significantly related to wise reasoning. In Study 4a, women scored higher than men. In Study 4c, but not in Studies 4a-b, age was significantly negatively related to wise reasoning. Notably, the median age of the Study $4 \mathrm{c}$ sample was 31 and $75 \%$ of the sample was under the age of 41 , suggesting that the effect was driven by differences between younger and middle-aged adults (see scatterplot at right). The latter observation is consistent with recent work using the situated wise reasoning scale (Brienza et al., 2017), observing that middle aged adults

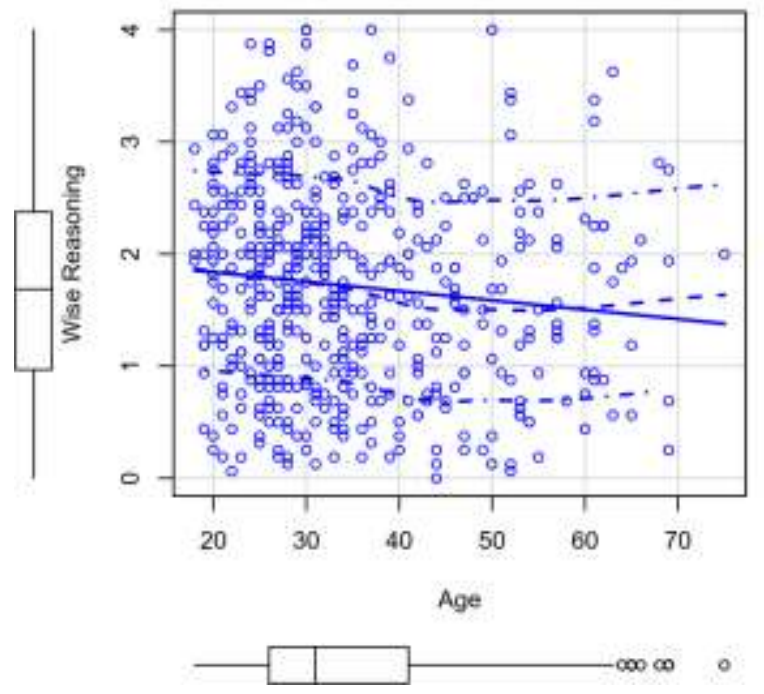


score lower on wise reasoning than their younger counterparts.

\section{Study 4a}

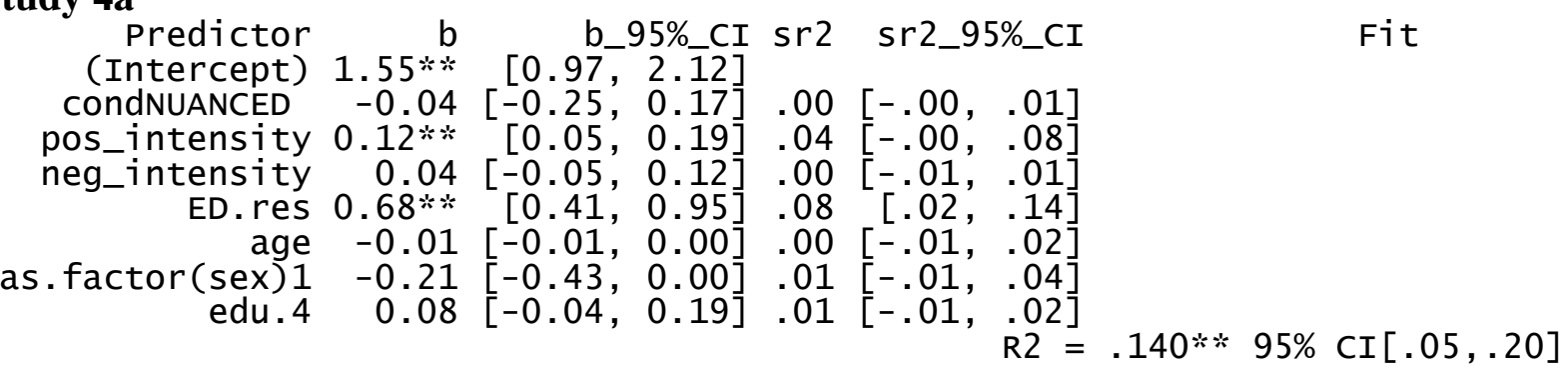

\section{Study 4b}

(Intercept) $1.28 * *$

condoneemo -0.03

pos_intensity $0.14 * *$

neg_intensity $0.11 * *$

ED. res $0.41 * *$

age -0.01

$\begin{array}{ll}\text { edu.4 } & 0.02 \\ \text { sex: m vs. f } & 0.07 \\ \text { sex: oth vs. f } & 0.52\end{array}$

b b_95\%_CI sr2 sr2_95\%_CI

Fit

$[0.94,1.6 \overline{2}]$

$[-0.15,0.09] .00[-.00, .00]$

$[0.10,0.17] .06[.03, .09]$

$[0.06,0.16] .02 \quad[.00, .04]$

$[0.31,0.51] .07 \quad[.04, .10]$

$[-0.01,0.00] .00[-.00, .01]$

$[-0.04,0.09] .00[-.00, \quad .00]$

$0.52[-1.09,2.13] .00[-.00, .00]$

$\mathrm{R} 2=.170 * * 95 \% \mathrm{CI}[.12, .21]$

Study 4c

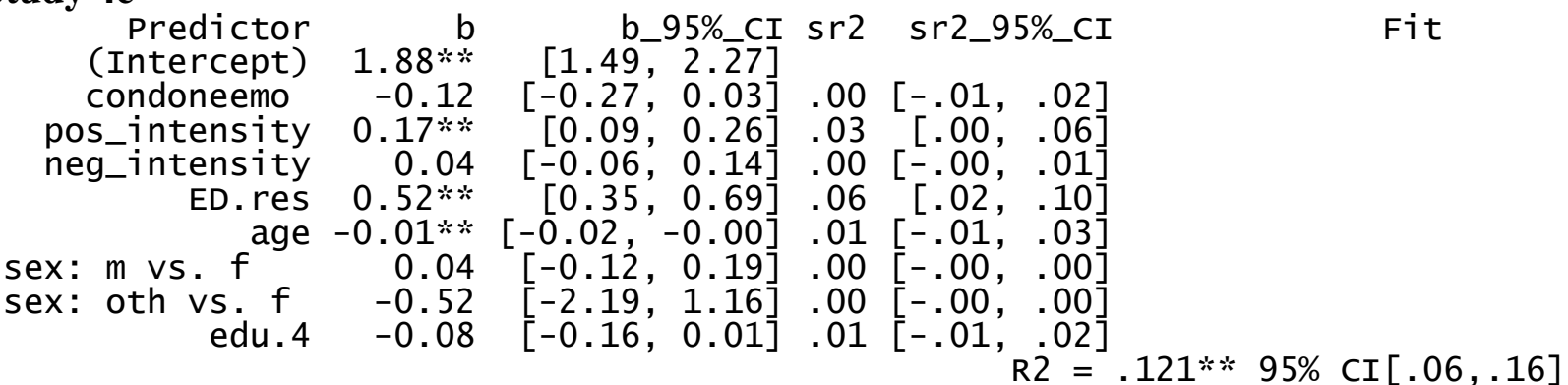

\section{Analyses Separately for Positive and Negative Emodiversity}

Both positive and negative emodiversity predicted wise reasoning. Whereas in Studies $4 a-b$ effects were largely equivalent, in Study $4 c$ negative emodiversity was a stronger predictor.

Study 4a

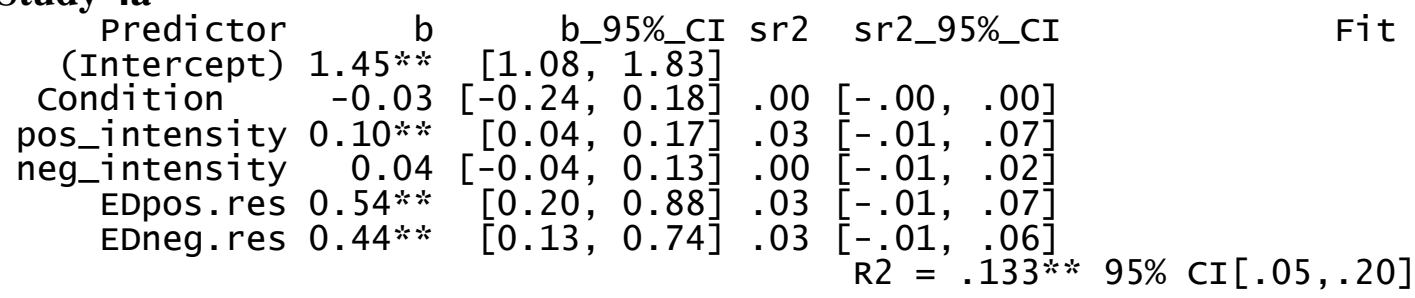

\section{Study $4 b$}

\begin{tabular}{|c|c|c|c|c|}
\hline $\begin{array}{r}\text { Predictor } \\
\text { (Intercept) }\end{array}$ & $\begin{array}{r}b \\
1.13 * *\end{array}$ & b_95\%_cI & $\mathrm{sr} 2$ & sr2_95\%_CI \\
\hline condoneemo & -0.03 & {$[-0.14,0.09]$} & & \\
\hline os_intensity & $13 * *$ & {$[0.10$,} & & \\
\hline g_intensity & $4 * *$ & & & \\
\hline EDpos.res & $0.31 * *$ & 43 & & {$[.00$} \\
\hline EDneg.res & $0.26 * *$ & & & {$[-.00$,} \\
\hline
\end{tabular}




$$
\mathrm{R} 2=.156 * 95 \% \mathrm{CI}[.11, .20]
$$

\section{Study 4c}

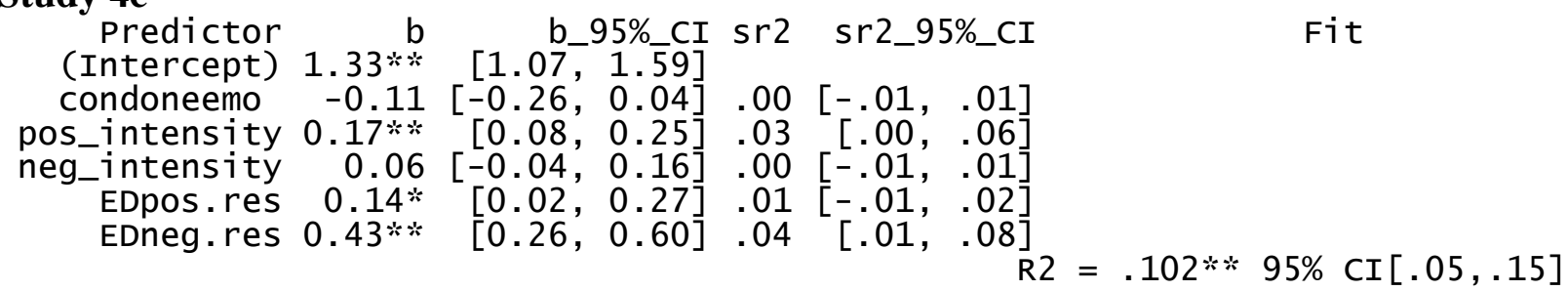

\section{Analyses Separately for each Aspect of Wise Reasoning}

\section{Intellectual Humility}

\section{Study 4a}

Predictor

(Intercept) $1.43 * * \quad[1.02,1.85]$

pos_intensity $0.13 * \quad[0.05,0.20] 0.19 \quad[0.08,0.31] .04[-.01, .08] .19 * *$

neg_intensity $0.01[-0.09,0.11] 0.01[-0.11,0.13] .00[-.00, .00]-.02$

\section{Study $4 b$}

ED.res $0.58 * *[0.26,0.90] 0.21 \quad[0.09,0.32] .04[-.00, .09] .21 * *$

$\mathrm{R} 2=.080$

Predictor (Intercept) $1.11 * *[0 . \overline{8} 6, \overline{1} .36]$

pos_intensity $0.13 * *[0.09,0.17] 0.20[0.14,0.27] .04[.01, .07] .21 * *$

neg_intensity $0.11 *[0.05,0.17] 0.12[0.05,0.19] .01[-.00, .03] .13 * *$

ED.res $0.44 * *[0.32,0.56] 0.25[0.18,0.31] .06[.03, .09] .25 * *$

$\mathrm{R} 2=.118$

\section{Study 4c}

\section{Predic}

b $\quad$ b_95\%_CI beta beta_95\%_CI sr2 sr2_95\%_CI r

$\begin{array}{lllll}{[1.08,1.63]} & 1.13 & {[0.04,0.22] .02} & {[-.01, .04] .12 * *}\end{array}$

neg_intensity $-0.04[-0.15,0.07]-0.03[-0.12,0.06] .00[-.00, .01] .00$

ED.res $0.55 *[0.35,0.74] \quad 0.24[0.16,0.33] .06[.02, .10] .24 * * \quad R 2=.073$

\section{Change}

\section{Study 4a}

Predictor

(Intercept) $1.45 * *$

pos_intensity $0.09 *[0.02,0.17] 0.15[0.03,0.27] .02[-.01, .06] .13 *$

neg_intensity $0.09 *[0.00,0.19] 0.12[0.00,0.23] .01[-.01, .04] \quad .09$

\section{Study 4b}

$$
\text { ED.res } 0.67 * *[0.37,0.98] 0.25[0.14,0.37] .06[.01, .12] .25 * *
$$

\begin{tabular}{|c|c|c|c|c|c|c|c|c|c|}
\hline $\begin{array}{r}\text { Predictor } \\
\text { (Intercept) }\end{array}$ & $1.38 * *$ & $\begin{array}{r}\mathrm{b} \\
{[1.14,}\end{array}$ & $\begin{array}{r}95 \% \_C I \\
1.62]\end{array}$ & beta & beta_95\%_cI & sr2 & sr2_9 & \%_CI & \\
\hline s intensity & $0.14 * *$ & [0.10, & $\begin{array}{l}1.02 \\
0.18]\end{array}$ & $0.2-2$ & & .06 & & & \\
\hline eg_intens & 0 . & & 0 & 0 . & & .02 & & .0 & \\
\hline & $* *$ & & & 0 & 10 & .03 & 01 & $.05]$ & .17 \\
\hline
\end{tabular}

$\mathrm{R} 2=.095$

\section{Study 4c}

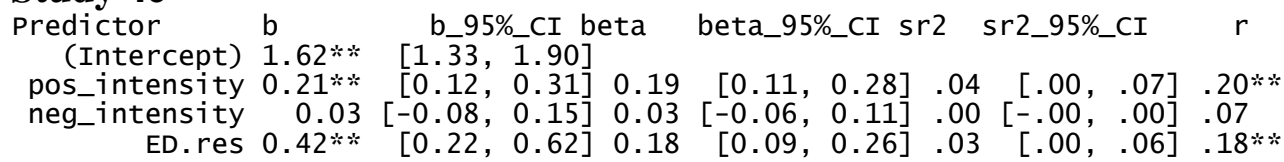

$\mathrm{R} 2=.111$

\section{Self-transcendence}

\section{Study 4a}

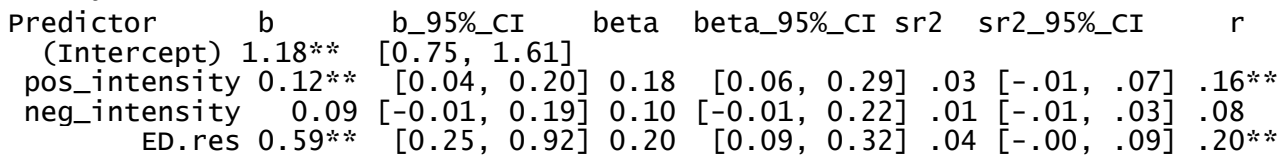

$\mathrm{R} 2=.073$

$\mathrm{R} 2=.078$ 


\section{Study $4 b$}

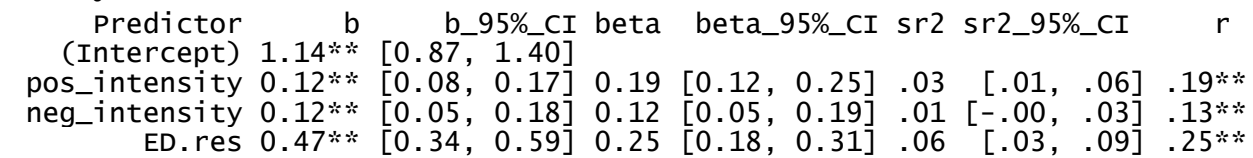

\section{Study 4c} ED.res $0.47 *[0.34,0.59] 0.25[0.18,0.31] .06[.03, .09] .25 * *$

\section{Predictor}

(Intercept) $1.18 * * \frac{\mathrm{b}}{[0.89,1.47]}$

pos_intensity $0.09[-0.01,0.18] 0.08[-0.01,0.17] .01[-.01, .02] .11 *$

neg_intensity $0.15 * \quad[0.04,0.27] 0.11 \quad[0.03,0.20] .01[-.01, .03] .13 * *$ ED.res $0.58 * * \quad[0.38,0.78] 0.24 \quad[0.16,0.33] .06[.02, .10] .24 \% *$

$\mathrm{R} 2=.084$

\section{Perspectives \\ Study 4a}

\begin{tabular}{|c|c|c|c|c|c|c|c|c|c|}
\hline redictor & & b_95\%_CI beta & & ta_95\%_CI & [ sr2 & sr2 & 95\%_CI & & $c$ \\
\hline $\begin{array}{l}\text { (Intercept) } \\
\text { pos_intensity }\end{array}$ & $\begin{array}{l}1.36 * * \\
0.13 * *\end{array}$ & $\begin{array}{l}{[0.96,1.77]} \\
{[0.05,0.20]}\end{array}$ & 0.19 & & & .04 & & & $.19^{\prime}$ \\
\hline & & 0.12 & & & & .0 & & & \\
\hline & & & & & & & & & \\
\hline to & & & & & & & & & \\
\hline $\begin{array}{l}\text { ictor } \\
\text { cept) }\end{array}$ & $1.28 * *$ & $\begin{array}{r}\text { b_95\%_cI } \\
{[1.04,1.53]}\end{array}$ & be & beta_9 & 95\%_CI & $\mathrm{sr} 2$ & sr2_95 & 5\%_CI & \\
\hline os & $0.17 * *$ & & 0 . & & & .07 & & & $.27 * *$ \\
\hline & & & & & & .0 & & & \\
\hline
\end{tabular}

\section{Study 4c} ED.res $0.46 * *[0.34,0.58] 0.26[0.19,0.32] .07[.03, .10] .26 * *$

$\mathrm{R} 2=.102$

$\begin{array}{rrrrrrrr}\text { Predictor } & \mathrm{b} & \mathrm{b} \_95 \% \_C I & \text { beta } & \text { beta_95\%_CI } & \text { sr2 } & \text { sr2_95\%_CI } & r \\ \text { (Intercept) } & 1.33 * * & {[1.02,1.65]} & & & & & \\ \text { pos_intensity } & 0.16 * * & {[0.06,0.27]} & 0.14 & {[0.05,0.23]} & .02 & {[-.00, .04]} & .14 * * \\ \text { neg_intensity } & -0.01 & {[-0.14,0.11]} & -0.01 & {[-0.10,0.08]} & .00 & {[-.00, .00]} & .02\end{array}$
ED.res $0.53 * *[0.32,0.75] 0.21[0.13,0.30] .04[.01, .08] .21 \% *$

$\mathrm{R} 2=.063$

\section{Compromise/Resolution}

\section{Study 4a}

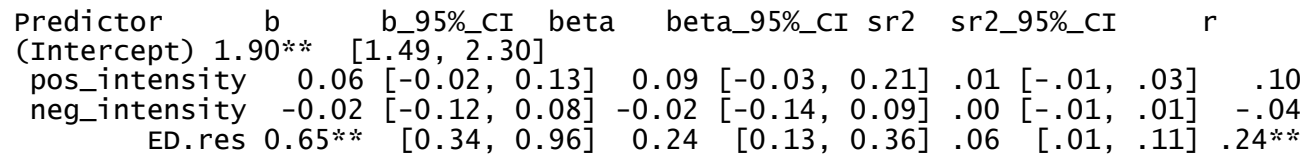

\section{Study $4 b$}

$\mathrm{R} 2=.069$

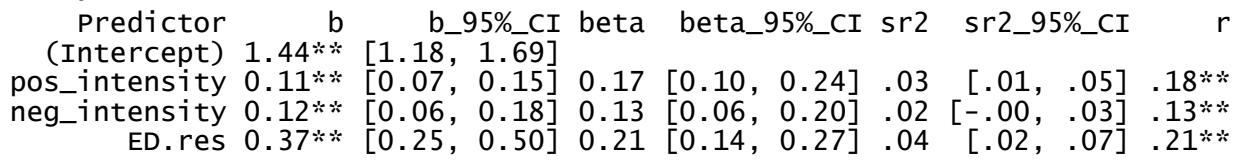

$\mathrm{R} 2=.090$ 


\section{Study 5}

\section{Study 5: Statement on the Conflict in Ukraine}

Ukraine shares history and cultural heritage with many of its different neighbors. People in Eastern Ukraine identify with Russia, and many Russians see Ukraine as part of their motherland. In contrast, people in Western Ukraine identify with Western Europe. In the last few years Ukraine became a battleground for political and economic influence from Russia and the West. The country is in an economic recession and suffers a huge deficit: it requires more goods from abroad than it produces and sells. Many Ukrainians wish to join with Russia to avoid significant economic hardship. Many others wish to cut ties with Russia and seek deals with the European Union, where they see opportunities for more jobs.

Last year, pro-Western Ukrainians hoped that a trade agreement with European Union would help the economy. However, at the last moment, Ukraine's President Yanukovych turned away a European deal in favor of a $\$ 15$ billion bailout from Russia. Some say it was a corrupt decision made under pressure from the Kremlin. Following this, hundreds of thousands of people took the protest to the streets. In the weeks and months that followed, the protests turned into a general outcry against governmental corruption and police violence. Eventually, after much destruction and violence protesters took control of Kiev's city center, and parliament voted to remove Mr. Yanukovych from office, who in turn fled the country. Some say the protesters have been financially backed up by the Western powers, interested in the natural resources of the country.

Recently in Crimea, a southern peninsula of Ukraine with a predominantly Russian ethnic majority $(58 \%)$ and a large Russian military presence, an internationally-disputed election took place in which the majority voted in favor of independence from Ukraine and to join Russia. Some fear that that the events in Crimea are a sign of things to come and that Ukraine will be split as a result of the current crisis. 
Table S7

Spearman's Rho Correlations Between Aspects of Wise Reasoning

\begin{tabular}{|c|c|c|c|c|c|}
\hline & & 2. & 3. & 4. & 5. \\
\hline \multirow[t]{3}{*}{ 1. Limits } & Correlation Coefficient & .296 & .124 & .171 & -.039 \\
\hline & Sig. (2-tailed) & .000 & .025 & .002 & .480 \\
\hline & $\mathrm{N}$ & 329 & 329 & 329 & 329 \\
\hline \multirow[t]{3}{*}{ 2. Change } & Correlation Coefficient & -- & .030 & -.011 & .021 \\
\hline & Sig. (2-tailed) & & .586 & .849 & .699 \\
\hline & $\mathrm{N}$ & & 329 & 329 & 329 \\
\hline \multirow[t]{3}{*}{ 3. Perspectives } & Correlation Coefficient & & -- & .132 & .076 \\
\hline & Sig. (2-tailed) & & & .017 & .171 \\
\hline & $\mathrm{N}$ & & & 329 & 329 \\
\hline \multirow[t]{3}{*}{ 4. Compromise } & Correlation Coefficient & & & -- & .219 \\
\hline & Sig. (2-tailed) & & & & .000 \\
\hline & $\mathrm{N}$ & & & & 329 \\
\hline \multirow[t]{3}{*}{ 5. Resolution } & Correlation Coefficient & & & & - \\
\hline & Sig. (2-tailed) & & & & \\
\hline & $\mathrm{N}$ & & & & \\
\hline
\end{tabular}

Note. Wise reasoning themes were scored $0=$ No presence, $1=$ Partial or full presence.

\section{Effects of Emodiversity and Intensity When Controlling for Response Length}

$\begin{array}{lrrrr} & \text { value } & \text { Std. Error } & \text { t value } & \text { v value } \\ \text { ED.res } & 0.563847699 & 0.2230449936 & 2.5279550 & 0.0114729067036713813094 \\ \text { pos_intensity } & -0.088875916 & 0.0891031127 & -0.9974502 & 0.3185460436633683611873 \\ \text { neg_intensity } & -0.022632993 & 0.0921943179 & -0.2454923 & 0.8060752853236525794500 \\ \text { WC } & 0.002232572 & 0.0006152645 & 3.6286380 & 0.0002849203826367818272 \\ 0 \mid 1 & -0.983540921 & 0.3474369953 & -2.8308468 & 0.0046424945635085857615 \\ 0 & 0.599774035 & 0.3437349926 & 1.7448734 & 0.0810069139942479338190 \\ 1 \mid 2 & 1.819449174 & 0.3574842057 & 5.0895932 & 0.0000003588325079883965 \\ 2 \mid 3 & 3.271660167 & 0.4073029004 & 8.0324991 & 0.0000000000000009550697 \\ 3 \mid 4 & 5.174424626 & 0.6688971089 & 7.7357557 & 0.0000000000000102790676\end{array}$

\section{Effects of Emodiversity and Intensity When Controlling for Demographics}

$\begin{array}{lrrrr} & \text { Value } & \text { Std. Error } & t \text { value } & p \text { value } \\ \text { ED.res } & 0.4587007972 & 0.22618236 & 2.028013144 & 0.042558906539 \\ \text { pos_intensity } & -0.0901929254 & 0.09095542 & -0.991616812 & 0.321384484909 \\ \text { neg_intensity } & 0.0005825878 & 0.09435648 & 0.006174327 & 0.995073630982 \\ \text { Age } & -0.0108929998 & 0.01600413 & -0.680636933 & 0.496101251379 \\ \text { as.factor(Sex) } & -0.0120911883 & 0.20616956 & -0.058646817 & 0.953233420544 \\ \text { as.factor(Sex)3 } & -0.4505314528 & 1.11063116 & -0.405653531 & 0.684997190259 \\ \text { edu.4 } & -0.0438314353 & 0.11240872 & -0.389929139 & 0.696588946425 \\ \text { residence } & -0.0463648476 & 0.05316761 & -0.872050549 & 0.383180801501 \\ 0 \mid 1 & -2.2337732135 & 0.63904745 & -3.495473185 & 0.000473221999 \\ \text { 1 } 12 & -0.6813501281 & 0.62610759 & -1.088231694 & 0.276492836333 \\ 2 \mid 3 & 0.5034775502 & 0.62743863 & 0.802433142 & 0.422302448170\end{array}$




$\begin{array}{lllll}3 \mid 4 & 1.9435469913 & 0.65442720 & 2.969844467 & 0.002979505585 \\ 4 \mid 5 & 3.8382060543 & 0.84161802 & 4.560508394 & 0.000005102992\end{array}$

\section{Effects of Emodiversity and Intensity when Controlling for Political Orientation}

$\begin{array}{lrrrr} & \text { Value } & \text { Std. Error } & t \text { value } & p \text { value } \\ \text { ED.res } & 0.469535833 & 0.22397815 & 2.09634664 & 0.036051452463116196 \\ \text { pos_intensity } & -0.094540123 & 0.09010084 & -1.04927022 & 0.294053767109655528 \\ \text { neg_intensity } & -0.006270842 & 0.09193247 & -0.06821140 & 0.945617355076453059 \\ \text { Polit } & 0.005543123 & 0.04137139 & 0.13398446 & 0.893414863148926819 \\ 0 \mid 1 & -1.540817205 & 0.33514503 & -4.59746402 & 0.000004276644431604 \\ 1 \mid 2 & 0.004902576 & 0.32400054 & 0.01513138 & 0.987927363414557669 \\ 1 \mid 2 & 1.201044564 & 0.33387211 & 3.59731922 & 0.000321513802785905 \\ 2 \mid 3 & 2.676560896 & 0.38771449 & 6.90343271 & 0.000000000005076071 \\ 3 \mid 4 & 4.513037850 & 0.65389052 & 6.90182484 & 0.000000000005133872\end{array}$

\section{Valence-Specific Effects of Emodiversity and Emotional Intensity}

$\begin{array}{lrrrr} & \text { Value Std. Error } & t \text { value } & p \text { value } \\ \text { EDpos.res } & 0.24358150 & 0.18663703 & 1.30510813 & 0.1918560324202798206 \\ \text { EDneg.res } & 0.29625397 & 0.24273658 & 1.22047518 & 0.2222847935997241953 \\ \text { pos_intensity } & -0.08385516 & 0.08945639 & -0.93738592 & 0.3485600784651780581 \\ \text { neg_intensity } & 0.00232775 & 0.09148872 & 0.02544303 & 0.9797015913130138198 \\ 0 \mid 1 & -1.51436130 & 0.31009055 & -4.88360992 & 0.0000010416103775247 \\ 1 \mid 2 & 0.01734348 & 0.29746595 & 0.05830407 & 0.9535064249700383465 \\ 2 \mid 3 & 1.20113674 & 0.30669317 & 3.91641172 & 0.0000898767067224340 \\ 3 \mid 4 & 2.63576861 & 0.36118403 & 7.29757797 & 0.0000000000002929939 \\ 4 \mid 5 & 4.52989299 & 0.64102634 & 7.06662531 & 0.0000000000015874682\end{array}$

$\begin{array}{lrrr} & \text { OR } & 2.5 \% & 97.5 \% \\ \text { EDpos.res } & 1.2758103 & 0.8855421 & 1.842107 \\ \text { EDneg.res } & 1.3448117 & 0.8354363 & 2.166686 \\ \text { pos_intensity } & 0.9195644 & 0.7713404 & 1.095844 \\ \text { neg_intensity } & 1.0023305 & 0.8374528 & 1.199345\end{array}$

It appears the effect of emodiversity is driven by both positive and negative emodiversity (similar effect size OR), though neither reaches significance. It is also possible that it is the balance between positive and negative emotions that chiefly contributes to the association between global emodiversity and wise reasoning in Study 5 . 


\section{Relationship Between Emodiversity, Emotional Dialecticism and Wise Reasoning}

Emodiversity can be viewed as one of the ways to conceptualize emotional complexity. Other conceptualizations include emotional dialecticism - i.e., co-occurrence of positive and negative emotions. Notably, whereas emodiversity focuses on differentiated (rich) and balanced (even) representation of emotions, emotional dialecticism chiefly concerns the relationship of emotions when collapsing individual emotions into positive and negative affect. On the level of a situation, such co-occurrence can be conceptualized through a percentage of joint experience of positive and negative emotions from a list (i.e., above "not at all" level), relative to the overall frequency of mentioning experiencing any emotions from the same list (Grossmann, Huynh, \& Ellsworth, 2016), or through metrics of ambivalence borrowed from attitude research (Thompson, Zanna, \& Griffin, 1995) to assess mixed affect (Ersner-Hershfield, Mikels, Sullivan, \& Carstensen, 2008; Larsen, Hershfield, Stastny, \& Hester, 2016; Schimmack, Oishi, \& Diener, 2002). The latter metric uses ambivalence-specific formula, examining either average scores of reported positive and negative emotions or specifically focuses on terms concerning feeling happy vs. feeling unhappy/sad.

Are the metrics of emotional dialecticism related to emodiversity and wise reasoning, and if so, how? Prior research demonstrated a positive relationship between emodiversity and the percentage of joint experience of positive and negative emotions metric of emotional dialecticism (Grossmann et al., 2016). To our knowledge, little published work has examined how emodiversity related to emotional ambivalence. Therefore, we sought to perform exploratory analyses investigating these questions across Studies 2-5. We used the Thompson et al. (1995) formula to calculate ambivalence, based on recommendations in prior work. Whenever possible, we included both ambivalence metrics based on average positive/negative affect scores or scores specific to feeling happy and feeling unhappy/sad.

Results are reported in Tables S8-S12, showing that in each study emodiversity was consistency associated with the percentage of joint experience of positive and negative emotions, replicating prior research (Grossmann et al., 2016). Additionally, we find a significant positive relationship between emodiversity and metrics of emotional ambivalence, albeit of somewhat smaller magnitude. Moreover, Tables S8-12 indicate that across studies, emodiversity was a stronger predictor of wise reasoning relative to the other metrics of emotional complexity. Notably, in five out of six samples, percentage of joint experience of positive and negative emotions was significantly associated with wise reasoning, with an effect size comparable to or somewhat smaller than the effect size of emodiversity on wise reasoning. The relationship between emotional ambivalence and wise reasoning was more mixed, with only three samples demonstrating a non-negligible positive association. Overall, it appears that emotional dialecticism may also show a positive relationship to wise reasoning, even though less reliably compared to emodiversity relationship to wise reasoning. 
Table S8

Study 2: Wise Reasoning, Emodiversity, and Emotional Dialecticism (descriptives, and correlations with confidence intervals)

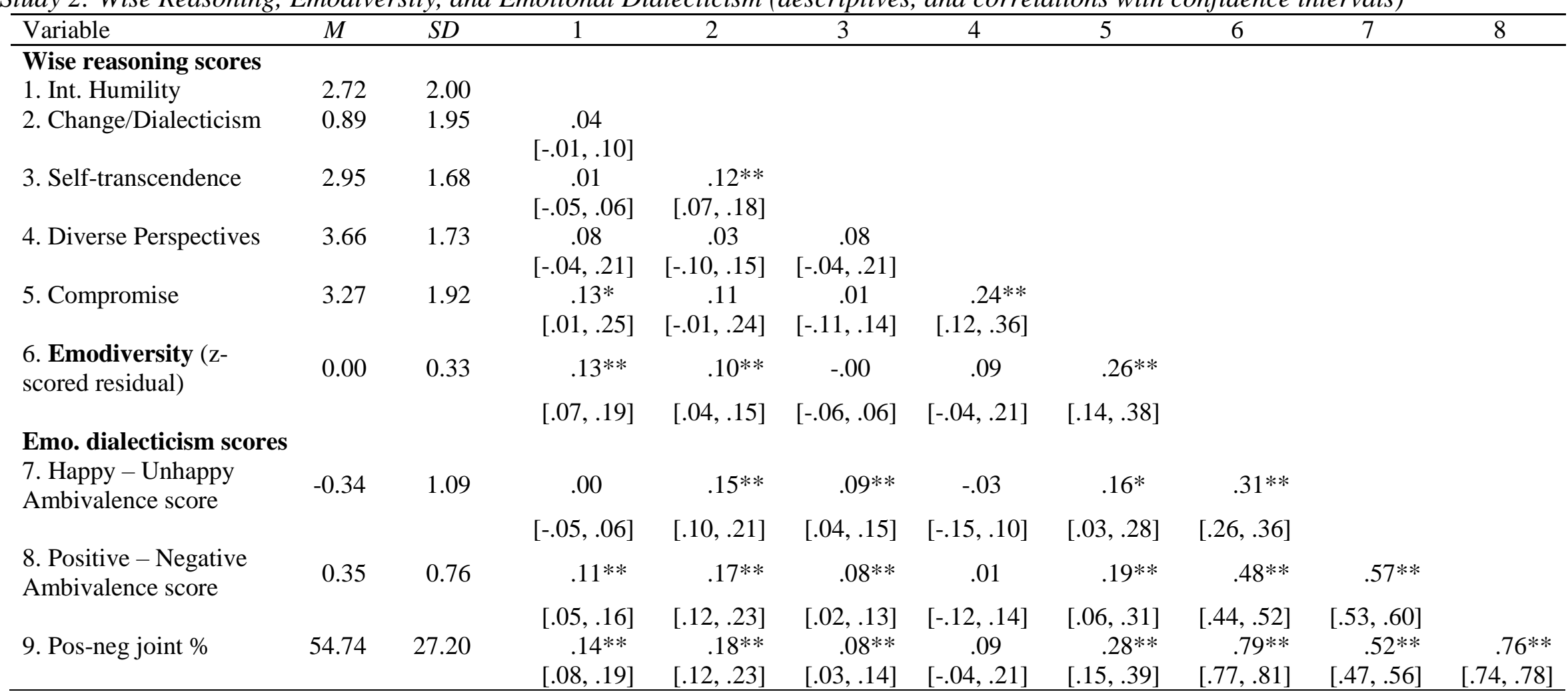

Note. $M$ and $S D$ are used to represent mean and standard deviation, respectively. Pos-neg joint $\%=\%$ cross-valence emotions to total count. Values in square brackets indicate the $95 \%$ confidence interval for each correlation. The confidence interval is a plausible range of population correlations that could have caused the sample correlation (Cumming, 2014). * indicates $p<.05$. ** indicates $p<.01$. 
Table S9

Study 3: Wise Reasoning, Emodiversity, and Emotional Dialecticism (descriptives, and correlations with confidence intervals)

\begin{tabular}{|c|c|c|c|c|c|}
\hline Variable & $M$ & $S D$ & 1 & 2 & 3 \\
\hline 1. Wise reasoning (averaged score) & 2.04 & 0.80 & & & \\
\hline 2. Emodiversity (z-scored residual) & 0.00 & 0.33 & $\begin{array}{c}.28 * * \\
{[.24, .33]}\end{array}$ & & \\
\hline 3. Positive - Negative Ambivalence score & 0.17 & 1.41 & $\begin{array}{c}.08 * * \\
{[.03, .13]}\end{array}$ & $\begin{array}{c}.40^{* *} \\
{[.36, .44]}\end{array}$ & \\
\hline 4. Pos-neg joint $\%$ & 56.13 & 30.02 & $\begin{array}{c}.19 * * \\
{[.14, .24]}\end{array}$ & $\begin{array}{c}.78 * * \\
{[.76, .80]}\end{array}$ & $\begin{array}{c}.72 * * \\
{[.70, .75]}\end{array}$ \\
\hline
\end{tabular}

Note. $M$ and $S D$ are used to represent mean and standard deviation, respectively. Pos-neg joint $\%=\%$ cross-valence emotions to total count. Values in square brackets indicate the $95 \%$ confidence interval for each correlation. The confidence interval is a plausible range of population correlations that could have caused the sample correlation (Cumming, 2014). * indicates $p<.05$. ** indicates $p<.01$.

\section{Table S10}

Study 4a: Wise Reasoning, Emodiversity, and Emotional Dialecticism (descriptives, and correlations with confidence intervals)

\begin{tabular}{|c|c|c|c|c|c|c|}
\hline Variable & $M$ & $S D$ & 1 & 2 & 3 & 4 \\
\hline 1. Wise reasoning (average score) & 1.75 & 0.93 & & & & \\
\hline 2. Emodiversity (z-scored residual) & 0.00 & 0.38 & $\begin{array}{c}.29 * * \\
{[.17, .39]}\end{array}$ & & & \\
\hline 3. Happy - Sad Ambivalence score & -0.68 & 1.52 & $\begin{array}{c}.12 \\
{[-.00, .23]}\end{array}$ & $\begin{array}{c}.04 \\
{[-.08, .16]}\end{array}$ & & \\
\hline 4. Positive - Negative Ambivalence score & -0.33 & 1.54 & $\begin{array}{c}.19 * * \\
{[.07, .30]}\end{array}$ & $\begin{array}{c}.17 * * \\
{[.05, .28]}\end{array}$ & $\begin{array}{c}.75 * * \\
{[.69, .79]}\end{array}$ & \\
\hline 5. Pos-neg joint $\%$ & 34.24 & 34.74 & $\begin{array}{c}.25^{* *} \\
{[.14, .36]}\end{array}$ & $\begin{array}{c}.52 * * \\
{[.42, .60]}\end{array}$ & $\begin{array}{c}.47 * * \\
{[.37, .56]}\end{array}$ & $\begin{array}{c}.75 * * \\
{[.69, .80]}\end{array}$ \\
\hline
\end{tabular}

Note. $M$ and $S D$ are used to represent mean and standard deviation, respectively. Pos-neg joint $\%=\%$ cross-valence emotions to total count. Values in square brackets indicate the $95 \%$ confidence interval for each correlation. The confidence interval is a plausible range of population correlations that could have caused the sample correlation (Cumming, 2014).* indicates $p<.05$. ** indicates $p<.01$. 


\section{Table S10}

Study 4b: Wise Reasoning, Emodiversity, and Emotional Dialecticism (descriptives, and correlations with confidence intervals)

\section{Variable}

1. Wise reasoning (average score)

2. Emodiversity (z-scored residual)

3. Positive - Negative Ambivalence score

4. Pos-neg joint $\%$

$M$

1.90

0.00

1.60

38.46 $M$

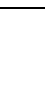

0.89

0.58

$S D$
1 2 3

1.58

35.01

$\begin{array}{cc}.28 * * & \\ {[.21, .34]} & \\ .12 * * & -.10^{*} \\ {[.04, .20]} & {[-.18,-.01]} \\ .30^{* *} & .65^{* *} \\ {[.23, .36]} & {[.61, .69]}\end{array}$

1]

rastervals)

Note. $M$ and $S D$ are used to represent mean and standard deviation, respectively. Pos-neg joint $\%=\%$ cross-valence emotions to total count. Values in square brackets indicate the $95 \%$ confidence interval for each correlation. The confidence interval is a plausible range of population correlations that could have caused the sample correlation (Cumming, 2014). * indicates $p<.05 . * *$ indicates $p<.01$.

\section{Table S11}

Study 4c: Wise Reasoning, Emodiversity, and Emotional Dialecticism (descriptives, and correlations with confidence intervals)

\begin{tabular}{|c|c|c|c|c|c|}
\hline Variable & $M$ & $S D$ & 1 & 2 & 3 \\
\hline 1. Wise reasoning (average score) & 1.72 & 0.90 & & & \\
\hline 2. Emodiversity (z-scored residual) & 0.00 & 0.43 & $\begin{array}{c}.25^{* *} \\
{[.17, .33]}\end{array}$ & & \\
\hline 3. Positive - Negative Ambivalence score & 0.34 & 0.82 & $\begin{array}{c}.07 \\
{[-.02, .16]}\end{array}$ & $\begin{array}{c}.46^{* *} \\
{[.39, .53]}\end{array}$ & \\
\hline 4. Pos-neg joint $\%$ & 48.89 & 26.78 & $\begin{array}{l}.23^{* *} \\
{[.15, .31]}\end{array}$ & $\begin{array}{c}.85 * * \\
{[.82, .87]}\end{array}$ & $\begin{array}{c}.73^{* *} \\
{[.69, .77]}\end{array}$ \\
\hline
\end{tabular}

Note. $M$ and $S D$ are used to represent mean and standard deviation, respectively. Pos-neg joint $\%=\%$ cross-valence emotions to total count. Values in square brackets indicate the $95 \%$ confidence interval for each correlation. The confidence interval is a plausible range of population correlations that could have caused the sample correlation (Cumming, 2014). * indicates $p<.05 . * *$ indicates $p<.01$. 


\section{Table S12}

Study 5: Wise Reasoning, Emodiversity, and Mixed Emotions (Means, standard deviations, and correlations with confidence intervals

\begin{tabular}{|c|c|c|c|c|c|c|}
\hline Variable & $M$ & $S D$ & 1 & 2 & 3 & 4 \\
\hline 1. Wise reasoning (count score) & 1.51 & 1.17 & & & & \\
\hline 2. Emodiversity (z-scored residual) & 0.00 & 0.45 & $\begin{array}{c}.11^{*} \\
{[.00, .22]}\end{array}$ & & & \\
\hline 3. Happy - Sad Ambivalence score & -0.49 & 1.17 & $\begin{array}{c}.04 \\
{[-.06, .15]}\end{array}$ & $\begin{array}{c}.32 * * \\
{[.22, .41]}\end{array}$ & & \\
\hline 4. Positive - Negative Ambivalence score & -0.03 & 1.03 & $\begin{array}{c}.05 \\
{[-.06, .15]}\end{array}$ & $\begin{array}{c}.35 * * \\
{[.25, .44]}\end{array}$ & $\begin{array}{c}.68^{* *} \\
{[.62, .73]}\end{array}$ & \\
\hline 5. Pos-neg joint $\%$ & 40.50 & 31.54 & $\begin{array}{c}.06 \\
{[-.04, .17]}\end{array}$ & $\begin{array}{c}.71 * * \\
{[.65, .76]}\end{array}$ & $\begin{array}{c}.53 * * \\
{[.45, .61]}\end{array}$ & $\begin{array}{c}.75^{* *} \\
{[.70, .79]}\end{array}$ \\
\hline
\end{tabular}

Note. $M$ and $S D$ are used to represent mean and standard deviation, respectively. Pos-neg joint $\%=\%$ cross-valence emotions to total count. Values in square brackets indicate the $95 \%$ confidence interval for each correlation. The confidence interval is a plausible range of population correlations that could have caused the sample correlation (Cumming, 2014). * indicates $p<.05$. ** indicates $p<.01$ 
